\title{
मबन
}

Autarquia associada à Universidade de São Paulo

\section{ESTUDO COMPARATIVO DAS RESPOSTAS DE DIODOS DE SI PARA DOSIMETRIA DE RADIAÇÃO GAMA}

\section{KELLY CRISTINA DA SILVA PASCOALINO}

Dissertação apresentada como parte dos requisitos para obtenção do Grau de Mestre em Ciências na Área de Tecnologia Nuclear - Aplicações

Orientadora:

Profa. Dra. Carmen Cecília Bueno Tobias

São Paulo 


\title{
INSTITUTO DE PESQUISAS ENERGÉTICAS E NUCLEARES
}

Autarquia associada à Universidade de São Paulo

ESTUDO COMPARATIVO DAS RESPOSTAS DE DIODOS DE SI PARA DOSINETRIA DE RADIAÇÃO GAMA

\author{
KELLY CRISTINA DA SILVA PASCOALINO
}

Dissertação apresentada como parte dos requisitos para obtenção do Grau de Mestre em Ciências na Área de Tecnologia Nuclear - Aplicações

Orientadora:

Profa. Dra. Carmen Cecília Bueno Tobias

São Paulo 
Dedico este trabalho a todos aqueles que direta ou indiretamente me ajudaram a conquistar mais uma grande etapa em minha vida. Sobretudo, dedico este trabalho a minha mãe, minha madrinha e meu namorado, pois sem eles meus sonhos não poderiam tornar-se realidade.

Dedico também este trabalho ao meu pai, pois sei que esteve ao meu lado em cada momento da minha vida. 


\section{AGRADECIMENTOS}

À Deus, pois sem a ajuda dele eu não teria forças para lutar pelos meus sonhos e superar os momentos difíceis em minha vida.

À Profa. Dra. Carmen Cecília Bueno Tobias, pelos valiosos ensinamentos transmitidos a mim no tocante a pesquisa e relações pessoais além da dedicação e zelo a cada integrante do grupo de pesquisa.

À Profa. Dra. Josemary Angélica Corrêa Gonçalves, por sua colaboração e dedicação ao desenvolvimento deste projeto além do incentivo e compreensão nos momentos de grandes dificuldades.

Ao Instituto de Pesquisas Energéticas e Nucleares, pela contribuição à minha formação acadêmica, disponibilizando tecnologia suficiente para o desenvolvimento deste projeto.

Ao Conselho Nacional de Desenvolvimento Científico e Tecnológico (CNPq), pela concessão da bolsa de mestrado, fundamental para o meu desenvolvimento profissional e pessoal.

Aos engenheiros Carlos Gaia e Elizabeth Somessari, amigos, pela dedicação e flexibilidade no agendamento das longas irradiações necessárias para a conclusão deste projeto.

Aos amigos do grupo de pesquisa, pela paciência e sorrisos em momentos difíceis fortalecendo a união em nosso grupo. 


\title{
ESTUDO COMPARATIVO DAS RESPOSTAS DE DIODOS DE SI PARA DOSIMETRIA DE RADIAÇÃO GAMA
}

\author{
Kelly Cristina da Silva Pascoalino
}

\begin{abstract}
RESUMO
Neste trabalho é apresentado um estudo comparativo da resposta de diodos de Si para dosimetria de radiação gama. Os diodos investigados, crescidos pelas técnicas de fusão zonal $(\mathrm{Fz})$ e Czchocralski magnético $(\mathrm{MCz})$, foram processados no Instituto de Física da Universidade de Helsinki no âmbito das pesquisas e desenvolvimento de dispositivos de Si resistentes a danos de radiação segundo a colaboração RD50 do CERN (European Organization for Nuclear Research). Para estudar a resposta dosimétrica dos diodos, eles foram acoplados diretamente no modo fotovoltaico na entrada de um eletrômetro digital para medir o sinal de fotocorrente devido a incidência de raios gama provenientes de uma fonte de ${ }^{60} \mathrm{Co}$ (Gammacell 220). O parâmetro dosimétrico usado para estudar a resposta destes dispositivos foi a carga, obtida pela integração do sinal de corrente pelo tempo de exposição, em função da dose absorvida. Estudos da influência dos procedimentos de pré-irradiação na sensibilidade e estabilidade destes diodos mostraram que a sensibilidade decresce com a dose total absorvida mas depois de uma pré-irradiação de cerca de $873 \mathrm{kGy}$, eles se tornaram mais estáveis. Efeitos dos danos de radiação eventualmente produzidos nos diodos foram monitorados mediante medidas dinâmicas de corrente e de capacitância depois de cada etapa de irradiação. Ambas as amostras exibiram boa reprodutibilidade de resposta, 2,21\% (Fz) e 2,94\% (MCz), obtida com 13 medidas consecutivas de $15 \mathrm{kGy}$ comparadas com a equivalente dose de $195 \mathrm{kGy}$ absorvida em uma única etapa de irradiação. É importante notar que estes resultados são melhores do que aqueles obtidos com dosímetros de rotina de polimetilmetacrilato (PMMA) usados em processamento por radiação.
\end{abstract}




\title{
COMPARATIVE STUDY OF Si DIODES RESPONSE FOR GAMMA RADIATION DOSIMETRY
}

\author{
Kelly Cristina da Silva Pascoalino
}

\begin{abstract}
In this work it is presented the comparative study of $\mathrm{Si}$ diodes response for gamma radiation dosimetry. The diodes investigated, grown by float zone (Fz) and magnetic Czchcralski $(\mathrm{MCz})$ techniques, were processed at the Physics Institute of Helsinki University in the framework of the research and development of rad-hard silicon devices. To study the dosimetric response of these diodes they were connected in the photovoltaic mode to the input of a digital electrometer to measure the photocurrent signal due to the incidence of gamma-rays from a ${ }^{60} \mathrm{Co}$ source (Gammacell 220). The dosimetric parameter utilized to study the response of these devices was the charge, obtained trough the integration of the current signals, as a function of the absorbed dose. Studies of the influence of the pre-irradiation procedures on both sensivity and stability of these diodes showed that the sensitivity decreased with the total absorbed dose but after a preirradiation of about $873 \mathrm{kGy}$ they became more stable. Radiation damage effects eventually produced in the devices were monitored trough dynamic current and capacitance measurements after each irradiation step. Both samples also exhibited good response reproducibility, 2,21\% $(\mathrm{Fz})$ and 2,94\% $(\mathrm{MCz})$, obtained with 13 consecutive measurements of $15 \mathrm{kGy}$ compared with the equivalent $195 \mathrm{kGy}$ absorbed dose in one step of irradiation. It is important to note that these results are better than those obtained with routine polimetylmetacrilate (PMMA) dosimeters used in radiation processing dosimetry .
\end{abstract}




\section{SUMÁRIO}

Página

1. INTRODUÇÃ

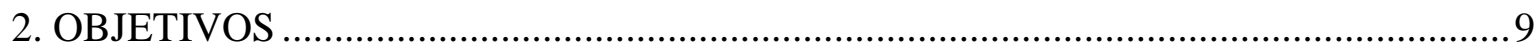

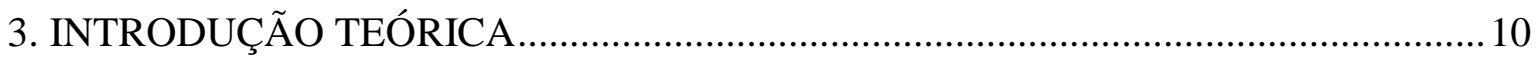

3.1 Principais Métodos de Crescimento de Cristais Semicondutores.................................. 10

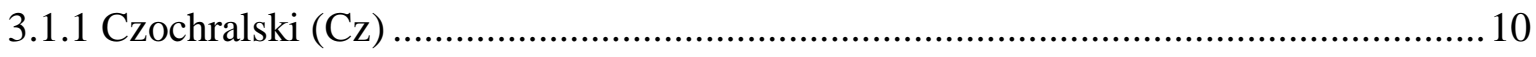

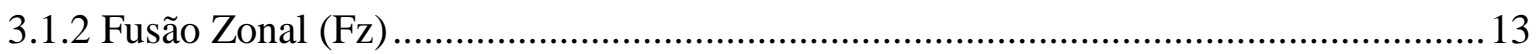

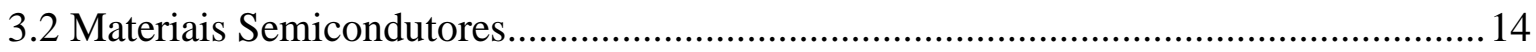

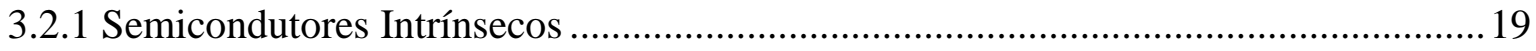

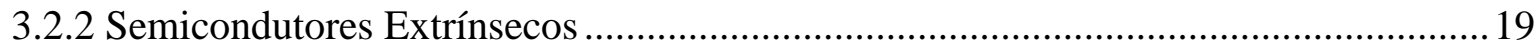

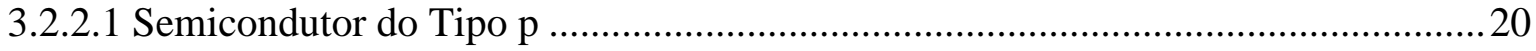

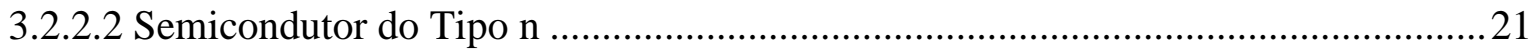

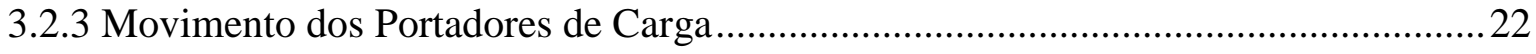

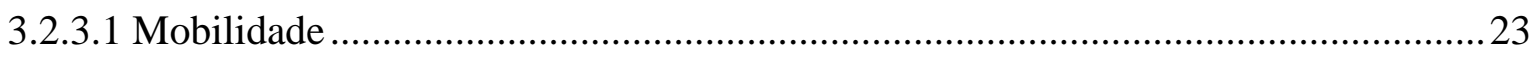

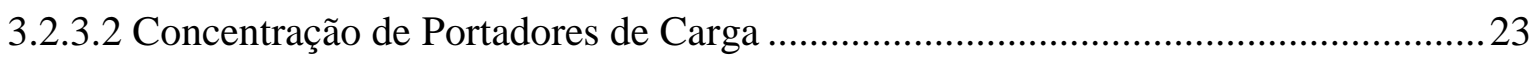

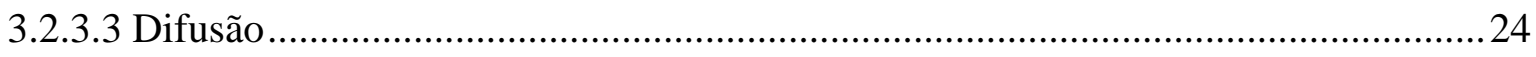

3.2.4 Principais Processos de Geração e Recombinação de Portadores de Cargas ..............25

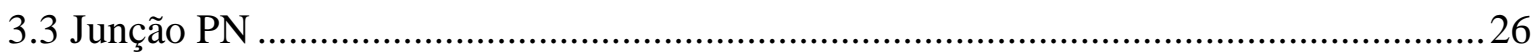

3.4 Princípio de Funcionamento de Diodos de Si como Dosímetros de Radiação................36

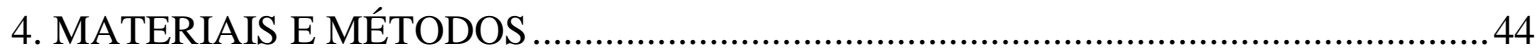

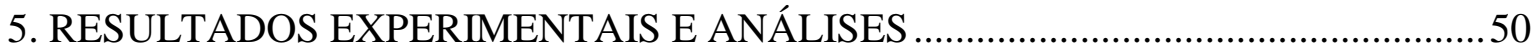

5.1 Estudo dos Danos Induzidos pela Radiação - Caracterização Elétrica ..........................50

5.2 Resposta dos Diodos como Dosímetros de Radiação .....................................................56

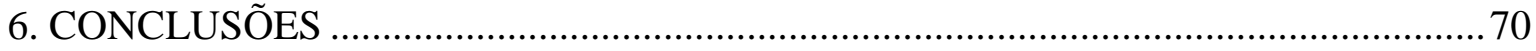

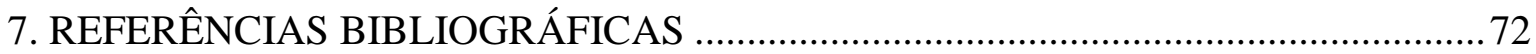




\section{INTRODUÇÃO}

Os detectores semicondutores, sobretudo os de Silício ( $\mathrm{Si}$ ) vêm sendo cada vez mais utilizados na área de Física de Altas Energias (FAE) devido principalmente a sua rapidez de resposta, excelente resolução espacial e elevada relação sinal-ruído. Entretanto, nestas aplicações, os detectores devem apresentar uma boa tolerância aos danos de radiação, pois estão sujeitos a doses elevadas.

Os danos causados pela radiação estão relacionados basicamente com alterações na estrutura cristalina do Si e, em termos das propriedades macroscópicas dos detectores, traduzem-se em: aumento da corrente reversa do dispositivo, alteração da densidade de carga espacial efetiva e, portanto, da tensão de depleção do diodo, e o armadilhamento de elétrons e lacunas que conduz à redução da eficiência de coleta de cargas [1-3].

Estudos iniciais mostraram que os danos induzidos pela radiação em detectores de Si são menos intensos em dispositivos com resistividades menores [4-5]. Investigações complementares têm sido conduzidas pela colaboração RD48 do CERN com relação aos danos induzidos por hádrons na estrutura do Si e o respectivo impacto nas propriedades do detector. Estes estudos têm mostrado que a inserção proposital de oxigênio, em concentrações superiores a $10^{17} \mathrm{~cm}^{-3}$, na estrutura do Si aumenta a tolerância do dispositivo aos danos induzidos por radiação [6-9].

Devido ao empenho da comunidade científica para o aperfeiçoamento de detectores de Si com a finalidade de sua aplicação em elevados campos de radiação, novas tecnologias têm surgido. Dentre estas tecnologias deve-se ressaltar a produção de diodos com estruturas complexas constituídas por múltiplos anéis de guarda que permitem a utilização dos dispositivos após a manifestação dos danos em sua estrutura [10]. De fato, com os anéis de guarda o potencial elétrico entre o eletrodo coletor de cargas e a borda do dispositivo varia gradualmente, evitando que ocorra a ruptura do semicondutor, mesmo para tensões de polarização maiores do que a de depleção total.

Os excelentes resultados obtidos na produção de diodos de Si resistentes a danos de radiação aliados a necessidade de dotar o LDPI (Laboratório de Dosimetria em Processos de Irradiação - IPEN-CNEN/SP) de dosímetros semicondutores para a dosimetria gama de altas doses motivaram a proposição deste trabalho de mestrado. 
Uma análise dos resultados anteriormente obtidos em nosso grupo, quanto à alteração das propriedades elétricas dos detectores devido à influência dos danos induzidos pela radiação gama, conduziu a escolha deste plano de trabalho, baseando-se no estudo comparativo da resposta de diodos crescidos pelos métodos de Fusão Zonal Padrão (Fz) e Czochralski Magnético (MCz) em dosimetria de altas doses de radiação gama.

No capítulo 2 desta dissertação são apresentados concisamente os objetivos deste projeto que estão relacionados essencialmente com o estudo comparativo de dois diodos aplicados a dosimetria gama de altas doses.

No capítulo 3 é apresentada uma introdução teórica com relação aos principais conteúdos acerca do trabalho como, por exemplo, materiais semicondutores, diodos, princípio de funcionamento dos diodos como dosímetros de radiação, entre outros.

A metodologia experimental e os resultados obtidos ao longo do desenvolvimento deste projeto bem como a análise dos mesmos são apresentados nos capítulos 4 e 5, respectivamente.

Por fim, no capítulo 6, são apresentadas as conclusões extraídas a partir do desenvolvimento e resultados obtidos ao longo do projeto. 


\section{OBJETIVOS}

- Estudo comparativo do desempenho de dosímetros de radiação gama baseados no emprego de diodos de $\mathrm{Si}$ produzidos pelos métodos de fusão zonal e Czchocralski magnético.

- Estudo de danos provocados por radiação eletromagnética nos diodos de $\mathrm{Si}$, priorizando a geração de correntes volumétricas e superficiais. 


\section{INTRODUÇÃO TEÓRICA}

\subsection{Principais Métodos de Crescimento de Cristais Semicondutores}

A seguir serão abordadas as principais características dos métodos de crescimento de cristais segundo os quais foram crescidos os dispositivos utilizados neste trabalho, Czochralski (Cz) e Fusão Zonal (Fz).

\subsubsection{Czochralski (Cz)}

O método de Czochralski foi assim nomeado segundo o nome de seu inventor em 1918 tendo sido aperfeiçoado por Teal e Buehler em 1952 [11]. Atualmente, a grande maioria dos dispositivos de Si disponíveis comercialmente são crescidos por este método, devido, sobretudo ao baixo custo de produção [12].

O aparato responsável pelo processo de crescimento dos cristais pelo método $\mathrm{Cz}$ é denominado puller e é constituído por três partes principais: conjunto de aquecimento, mecanismo de atração e controle de ambiente. No conjunto para aquecimento encontram-se um cadinho de sílica fundida, uma espécie de prato de grafite, um mecanismo de rotação e um elemento térmico. O mecanismo de atração do cristal é constituído por um porta-semente e um mecanismo de rotação. O controle de ambiente consiste em uma fonte de gás, como argônio, por exemplo, um controle de fluxo e um sistema exaustor.

O processo de crescimento se inicia com a fundição de certa quantidade de Silício (Si) policristalino no cadinho. Em seguida, encosta-se uma semente de Si, com orientação cristalina específica, na superfície presa na haste. O contato entre as regiões faz com que o Si fundido comece a se solidificar a partir da semente seguindo sua orientação cristalina. A fim de manter a continuidade do processo de solidificação, a semente é então puxada para cima sendo rotacionada no sentido contrário do cadinho, também rotacionado.

$\mathrm{O}$ diâmetro do cristal formado imediatamente no primeiro contato entre a semente e o material fundido é de poucos milímetros [12], a fim de garantir que certos defeitos, como deslocamentos, por exemplo, gerados desta interação propaguem-se ao longo de todo o cristal.

O Si fundido é preferencialmente extraído do quartzo $\left(\mathrm{SiO}_{2}\right)$ e por este motivo, o cadinho utilizado neste processo de crescimento é de quartzo, que dissolve gradualmente 
durante o processo de fundição, liberando grandes quantidades de oxigênio no material. Embora cerca de $99 \%$ [12] do oxigênio seja liberado sob a forma de $\mathrm{SiO}$ gasoso da superfície do material fundido, o restante pode se dissolver no cristal atuando como impureza do mesmo. Outra impureza presente nos cristais crescidos por este método é o carbono (C). O carbono se origina da interação do monóxido de $\mathrm{Si}(\mathrm{SiO})$ com o prato de grafite formando o monóxido de carbono (CO) que por sua vez é incorporado no material fundido.

A concentração de impurezas incorporadas no cristal é usualmente diferente da concentração de impurezas incorporadas no $\mathrm{Si}$ fundido, sendo estas concentrações definidas por $\mathrm{C}_{\mathrm{S}}$ e $\mathrm{C}_{\mathrm{L}}$ respectivamente. A razão entre estes coeficientes define o coeficiente de segregação de equilíbrio, $\mathrm{k}$.

As concentrações típicas das duas impurezas características deste processo de crescimento de cristais são $[\mathrm{O}] \approx 5-10 \times 10^{17} \mathrm{~cm}^{-3} \mathrm{e}[\mathrm{C}] \approx 5-50 \times 10^{15} \mathrm{~cm}^{-3}$ [12]. Embora a alta concentração de $\mathrm{O}$ no cristal contribua para a formação de defeitos eletricamente ativos, a mesma concentração contribui como agente de armadilhamento inibindo os efeitos dos danos de radiação em detectores de Si, tocante ao objetivo deste trabalho. Isso deve-se essencialmente ao fato de que a formação do defeito responsável pelas principais alterações na densidade de carga espacial dos dispositivos é inibida em materiais com elevadas concentrações de oxigênio.

Na FIG.3.1.1.1 é apresentado um diagrama esquemático do aparato para crescimento de cristais pelo método $\mathrm{Cz}$.

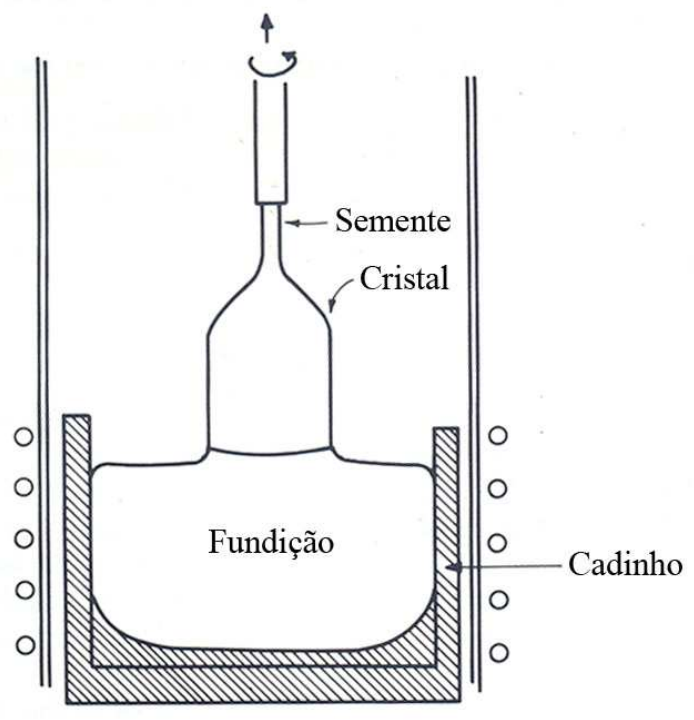

FIGURA 3.1.1.1 - Esquema do aparato utilizado para o processo de crescimento de cristais de Si pelo método $\mathrm{Cz}[13]$. 
Nas FIG.3.1.1.2 e 3.1.1.3 são apresentados um modelo de aparato no processo de crescimento do cristal e um cristal de aproximadamente $100 \mathrm{~mm}$ de diâmetro após o processo de crescimento, respectivamente.

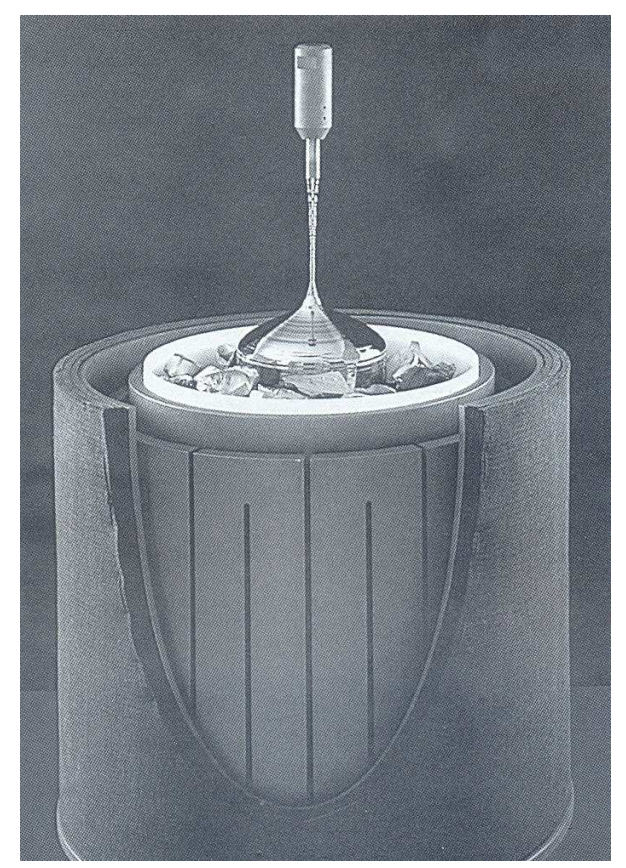

FIGURA 3.1.1.2 - Modelo de um aparato utilizado no processo de crescimento de cristais de Si pelo método $\mathrm{Cz}[13]$.

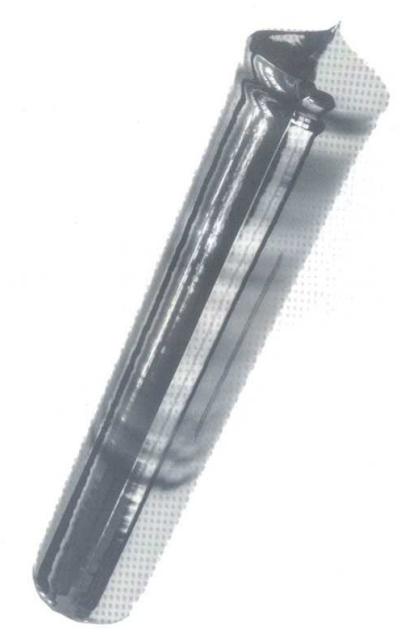

FIGURA 3.1.1.3 - Cristal de Si aproximadamente $100 \mathrm{~mm}$ de diâmetro crescido pelo método Cz [13].

Atualmente, um método de crescimento adicional ao $\mathrm{Cz}$ vem se tornando importante no campo da pesquisa dos danos de radiação em detectores de Si. Este método, denominado $\mathrm{MCz}$ (magnetic Czochralski), baseia-se essencialmente na aplicação de um 
campo magnético intenso vertical ou horizontal durante o processo convencional de crescimento. De uma forma geral, este método faz com que haja uma descontinuidade no material fundido gerando duas regiões distintas de forma que uma delas armadilhará mais oxigênio que a outra atrasando a migração desta impureza no cristal. Quando comparado ao método de crescimento padrão, o MCz apresenta melhora no tocante a diminuição da concentração de impurezas no cristal e da melhora na homogeneidade da distribuição das mesmas. Ressalta-se que, mesmo com o método de crescimento $\mathrm{MCz}$, podem ser produzidos detectores de radiação com altas concentrações de oxigênio.

\subsubsection{Fusão Zonal (Fz)}

O método de crescimento por Fusão Zonal (Fz) foi inventado por Theuerer em 1962 [12]. Neste método de crescimento, um tarugo de Si policristalino é fixado por meio de uma haste face a face e acima de uma semente de Si monocristalino onde se inicia a rotação de ambas as partes. Por meio da utilização de uma fonte de radiofrequiência, a semente e o tarugo são parcialmente fundidos. A semente é então trazida para cima de forma que as regiões fundidas entrem em contato originando uma única região de fundição, que é mantida sob esta forma devido à ação da fonte de radiofreqüência.

A região de material fundido é movida para cima fazendo com que cada parte da região deixada para trás solidifique-se a partir da semente de Si. Mediante este processo, cristais com alta resistividade e pureza podem ser obtidos. As concentrações de oxigênio e carbono resultantes no cristal crescido por $\mathrm{Fz}$ são menores que $5 \times 10^{15} \mathrm{~cm}^{-3}$. A elevada pureza obtida neste método deve-se essencialmente ao fato de que a região de Si fundido não entra em contato com quaisquer substâncias além do gás no ambiente de crescimento, que como mencionado anteriormente, é inerte [12]. O mesmo não ocorre com cristais crescidos pelo método $\mathrm{Cz}$, como visto anteriormente.

A FIG.3.1.2.1 apresenta um esquema do aparato utilizado para o crescimento de cristais pelo método Fz. 


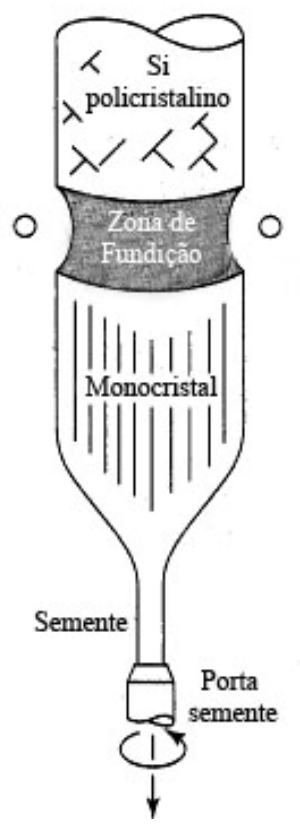

FIGURA 3.1.2.1 - Esquema do aparato utilizado para o processo de crescimento de cristais de Si pelo método Fz [14].

\subsection{Materiais Semicondutores}

Os materiais apresentados sob o estado sólido da matéria podem ser classificados quanto as suas características elétricas em isolantes, semicondutores e condutores. A FIG.3.2.1 indica a condutividade elétrica e correspondente resistividade associadas com alguns dos principais materiais pertencentes as três classes anteriormente mencionadas, isolantes, semicondutores e condutores.

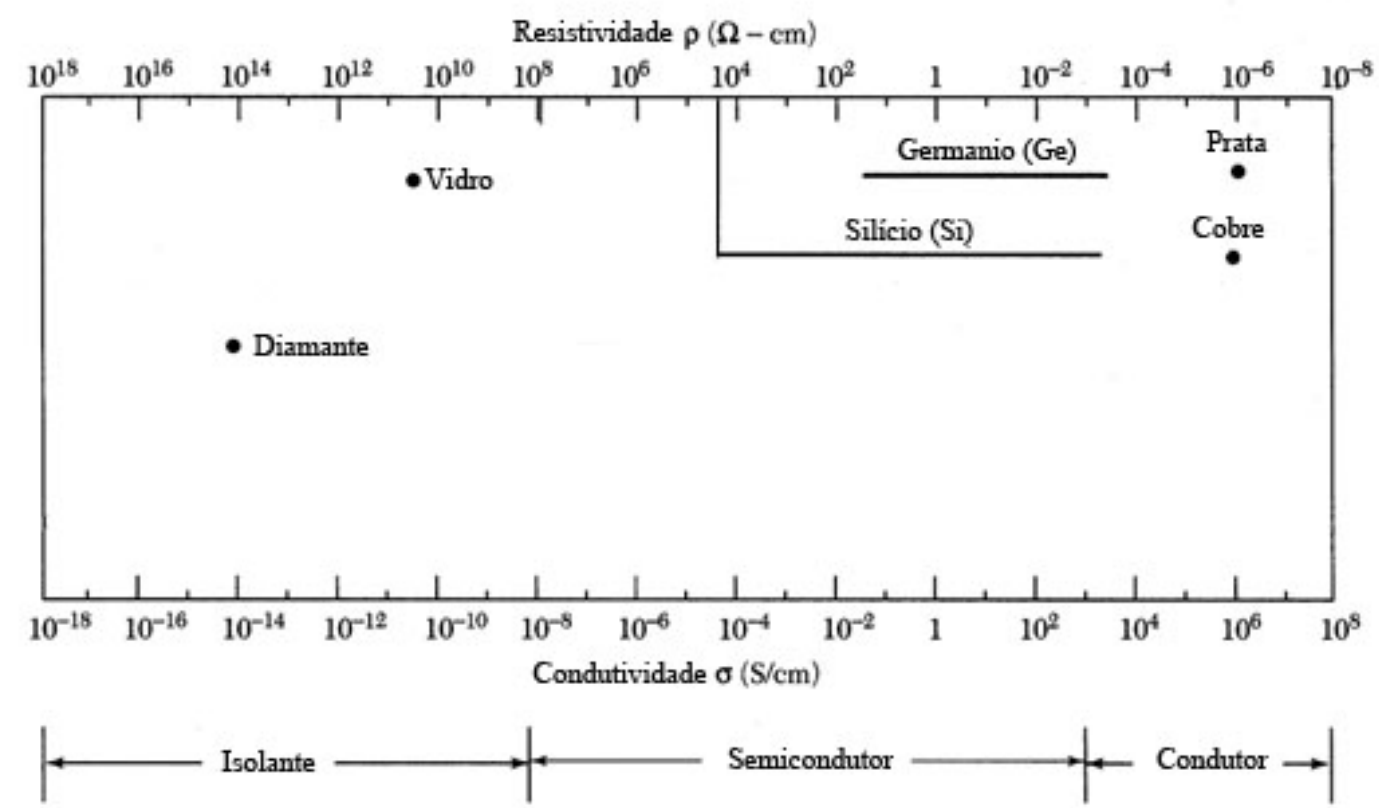

FIGURA 3.2.1 - Intervalo típico de condutividade para isolantes, semicondutores e condutores [15]. 
Como pode ser observado na FIG.3.2.1, os materiais isolantes possuem condutividade elétrica entre um $10^{-18}$ e $10^{-8} \mathrm{~S} / \mathrm{cm}$ enquanto que os materiais condutores possuem condutividade elétrica superior a $10^{4} \mathrm{~S} / \mathrm{cm}$. Desta forma pode-se definir os materiais semicondutores como aqueles cuja condutividade elétrica está compreendida entre os valores correspondentes aos dos isolantes e condutores, que como observado na FIG.3.2.1 corresponde a uma faixa entre $10^{-8}$ e $10^{3} \mathrm{~S} / \mathrm{cm}$.

A condutividade elétrica dos materiais semicondutores é sensível a certos fatores tais como: temperatura, luz, campo magnético e inserção de pequenas quantidades de impurezas. É justamente no âmbito da inserção de pequenas quantidades de impurezas que a aplicação dos materiais semicondutores se torna tão vasta no campo da eletrônica, como será visto mais adiante.

Os materiais semicondutores mais importantes quanto a sua aplicação eletrônica são o Silício ( $\mathrm{Si}$ ) e o Germânio $(\mathrm{Ge})$. Ambos são cristais únicos, ou seja, seus átomos são organizados em uma forma tridimensional periódica sendo a distribuição atômica periódica denominada de estrutura cristalina.

O Si e o Ge possuem uma estrutura cristalina semelhante a do diamante, que esta pode ser vista como uma rede cúbica de face centrada com base contendo dois átomos idênticos, sendo respectivamente suas localizações $(0,0,0)$ e $(1 / 4,1 / 4,1 / 4)$. A FIG.3.2.2 mostra uma rede cúbica de face centrada e a estrutura do diamante vista através de uma rede cúbica, respectivamente.

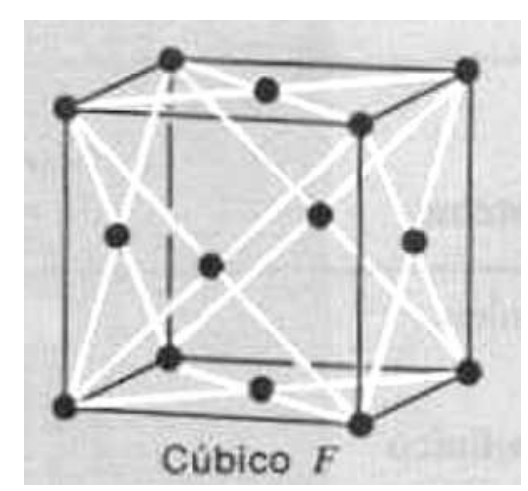

(a)

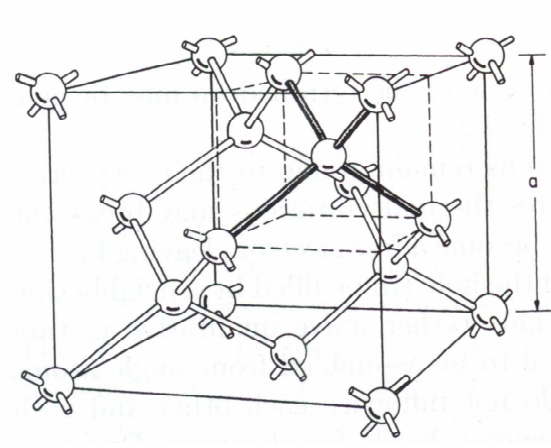

(b)

FIGURA 3.2.2 - Rede Cúbica de Face Centrada (a) [16], estrutura cristalina do diamante (b) [17]. 
As ligações presentes na estrutura tetraédrica do $\mathrm{Si}$ e $\mathrm{Ge}$ podem ser representadas por um diagrama bidimensional, como mostrado na FIG.3.2.3 para a estrutura do Si. Cada átomo da estrutura é tetravalente, ou seja, possui quatro elétrons de valência (órbita mais externa). Cada átomo compartilha seus quatro elétrons de valência com quatro átomos vizinhos mais próximos. Este tipo de compartilhamento é denominado ligação covalente e pode ocorrer entre átomos do mesmo elemento ou entre átomos de elementos diferentes, mas que possuam semelhantes configurações eletrônicas nos níveis energéticos mais externos. Devido ao tipo de ligações presentes na rede, o $\mathrm{Si}$ e o $\mathrm{Ge}$ compõe o grupo dos sólidos covalentes.

Como já mencionado anteriormente, os semicondutores possuem condutividade sensível à temperatura, isto é, para temperaturas próximas ao zero absoluto $(\mathrm{T}=0 \mathrm{~K})$, todos os elétrons estão ligados em suas respectivas estruturas. Entretanto, para temperaturas maiores a vibração térmica induzida na estrutura pode quebrar as ligações covalentes. Quando uma ligação é quebrada tem-se como resultado um elétron livre que poderá eventualmente participar da corrente de condução. A ligação quebrada permanece com uma deficiência de um elétron que poderá ser suprida caso um elétron proveniente de outra ligação ocupe o lugar vago. Neste caso, a deficiência de elétrons estará presente em outra ligação covalente. Esta espécie de deficiência ou simplesmente um lugar vago é denominado de lacuna e pode, em termos de locomoção, ser entendida como uma carga com propriedades semelhantes às do elétron, entretanto com carga positiva, FIG.3.2.3.

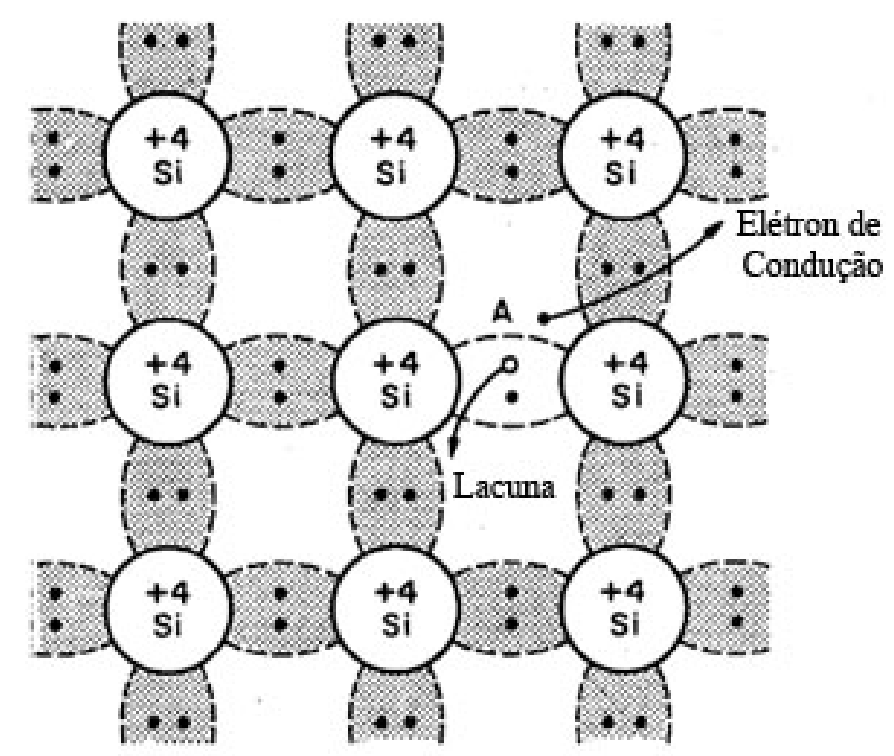

FIGURA 3.2.3 - Representação bidimensional das quatro ligações covalentes presentes na estrutura tetraédrica do Si e de uma lacuna nesta estrutura [15]. 
Em uma estrutura semicondutora, assim como nos sólidos em geral, há a formação de bandas contínuas de energias cujo princípio e comportamento pode ser descrito pela mecânica quântica. Entretanto, este comportamento pode ser intuitivamente entendido partindo-se, por exemplo, de um átomo isolado de Lítio (Li) cujo número atômico é $Z=3$. A configuração eletrônica destes três elétrons é $1 \mathrm{~s}^{2}$ e $2 \mathrm{~s}^{1}$, sendo que dois elétrons com spins opostos, devido ao princípio de exclusão de Pauli, ocupam o nível mais baixo de energia, 1s, e o terceiro elétron restante ocupa o nível $2 \mathrm{~s}$ de energia. Se uma molécula é formada a partir de dois átomos de Li a configuração inicial de cada átomo propõe que quatro elétrons estejam situados no mesmo nível de energia, 1s, mas, novamente devido ao princípio de exclusão de Pauli, sabe-se que esta configuração não é permitida. Assim, o problema é resolvido com a divisão do nível 1s em dois níveis muito próximos, entretanto, energéticamente diferentes, FIG.3.2.4. Assim, se um cristal de Li contendo $\mathrm{N}$ átomos é formado, o sistema possuirá $\mathrm{N}$ níveis de energia 1 s divididos. $\mathrm{A}$ diferença energética entre os níveis divididos mais próximos é da ordem de $10^{-22} \mathrm{eV}$ [18], e por este motivo pode-se assumir que existam bandas contínuas de energias. As bandas que são energéticamente disponíveis para receber um elétron são denominadas bandas permitidas enquanto que aquelas onde o contrário ocorre são denominadas bandas proibidas ou gap. Na FIG.3.2.4 o exemplo anteriormente mencionado é ilustrado com os níveis correspondentes a um único átomo de Li, posteriormente a divisão destes níveis para a formação de uma molécula e enfim o comportamento intuitivo na formação de um cristal.

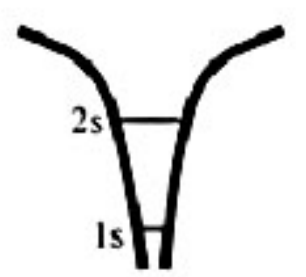

Atomo
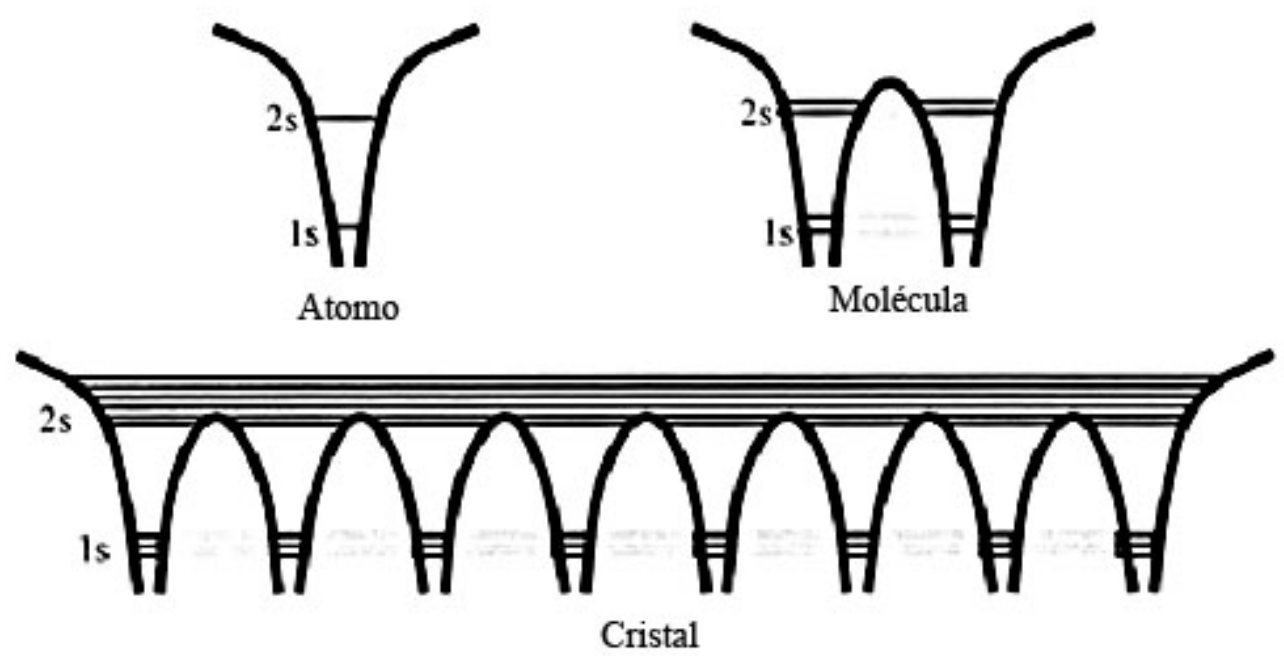

FIGURA 3.2.4 - Níveis de energias permitidos em um átomo, molécula hipotética e cristal de Li [18]. 
Um exemplo para o desdobramento dos níveis de energia pode ser observado na FIG.3.2.5, onde $N$ átomos de carbono são tomados de maneira que a separação interatômica diminua gradativamente para compor a estrutura sólida do diamante.

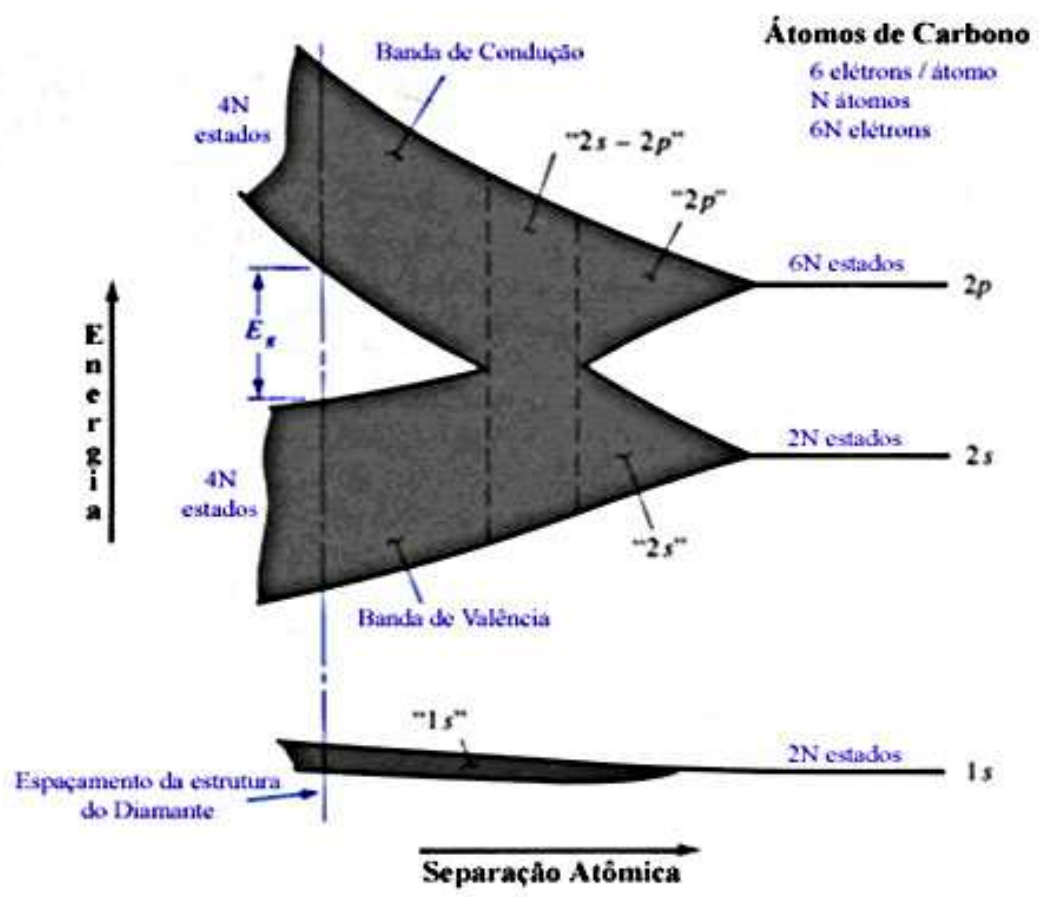

FIGURA 3.2.5 - Formação dos níveis de energia do diamante [1].

À temperatura de zero absoluto, os elétrons constituintes do sistema de bandas encontram-se em uma configuração estática e ocupam os estados de energias mais baixos, assim, a banda de energia inferior, banda de valência, estará totalmente ocupada e a banda superior, banda de condução, estará totalmente vazia. Para temperaturas maiores, os elétrons da banda de valência poderão ganhar energia suficiente para saltar para a banda de condução se a energia adquirida for maior que a energia do gap. Se a banda de energia estiver completamente cheia, não se comportará como uma banda permitida a menos que um de seus elétrons constituintes adquira energia suficiente para saltar para uma banda permitida, deixando uma lacuna em seu local de origem. Diz-se então que foi gerado aí um par elétron-lacuna. Pares elétron-lacuna podem ser gerados termicamente, desde que a energia adquirida pelo elétron seja maior que a energia da banda proibida.

Uma maneira de classificar os sólidos, também relacionada com a classificação quanto à condutividade dos materiais, é levando em consideração o valor energético de sua banda proibida. Quando a banda de valência e a banda de condução estiverem suficientemente longe uma da outra de maneira que a energia do gap seja grande, o sólido 
determina um isolante (FIG.3.2.6a). Mas se a banda de valência e a banda de condução encontram-se superpostas, o sólido determina assim um condutor (FIG.3.2.6c). Contudo, se as duas bandas, a de valência e a de condução, estiverem distantes entre si a um valor intermediário àquele de um condutor e de um isolante, de maneira que a energia do gap também assuma um valor intermediário, o sólido determina um semicondutor (FIG.3.2.6b), como o próprio nome sugere.

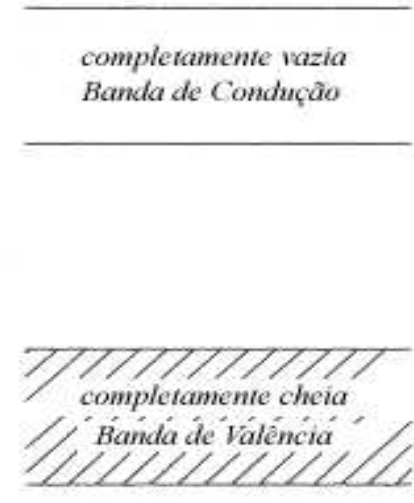

a)

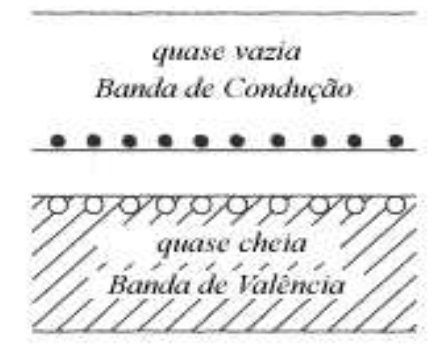

b)

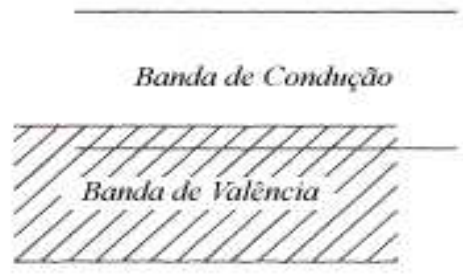

c)

FIGURA 3.2.6 - (a) Isolantes, (b) Semicondutores, (c) Condutores [1].

Os materiais semicondutores classificam-se ainda em intrínsecos ou extrínsecos quanto à quantidade de impurezas presentes em sua estrutura.

\subsubsection{Semicondutores Intrínsecos}

Os semicondutores intrínsecos são aqueles que não apresentam impurezas em sua estrutura e, portanto, são considerados puros. Na prática, admite-se que um semicondutor intrínseco possua impurezas, porém em quantidades muito baixas quando comparadas com o número de átomos do material semicondutor.

\subsubsection{Semicondutores Extrínsecos}

Os semicondutores intrínsecos são raramente utilizados em dispositivos. Além disso, na maioria dos casos altera-se intencionalmente as propriedades elétricas do semicondutor, como sua condutividade, por exemplo, introduzindo em sua estrutura impurezas tornando-o extrínseco. Para tanto, as impurezas são introduzidas em baixas concentrações e de forma controlada durante ou após o processo de crescimento do cristal. 
Quanto à natureza eletrônica da impureza introduzida, um semicondutor extrínseco pode ser classificado em tipo p ou tipo n.

\subsubsection{Semicondutor do Tipo p}

Um semicondutor do tipo $\mathrm{p}$ pode ser obtido adotando, por exemplo, uma amostra de $\mathrm{Si}$, onde todos os átomos presentes compõem a estrutura realizando quatro ligações covalentes entre si, e introduzindo uma impureza trivalente como o boro (B).

Ao ser introduzido na estrutura do $\mathrm{Si}$, um átomo de $\mathrm{B}$ realiza três ligações covalentes com os seus vizinhos mais próximos, sendo que a quarta e última ligação é completada quando um elétron é capturado do Si pelo B, pois este é mais eletronegativo. A captura de um elétron de um dos átomos de Si origina o aparecimento de uma lacuna na estrutura que em termos de locomoção, pode ser interpretada como uma carga com características iguais as do elétron, porém positiva. Este tipo de material é caracterizado por possuir excesso de lacunas, sendo os átomos que o constituem denominados aceitadores.

Outros materiais comumente empregados como impureza para a constituição de um semicondutor do tipo p são: índio, alumínio e gálio. A FIG.3.2.2.1.1 ilustra a introdução de uma impureza de B na estrutura do semicondutor intrínseco de Si formando o semicondutor do tipo $\mathrm{p}$.

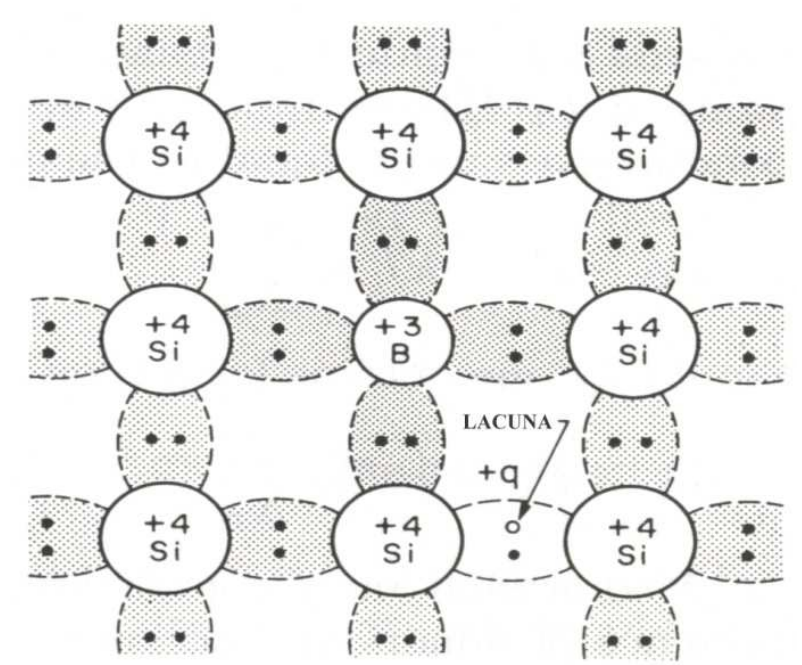

FIGURA 3.2.2.1.1 - Representação de um semicondutor do tipo p [15].

Em termos do modelo de bandas de energias, a inserção de impurezas em um semicondutor conduz a criação de níveis localizados de energias na banda proibida. Para 
um semicondutor do tipo p, onde átomos aceitadores são introduzidos na estrutura, um nível de energia é criado na banda proibida, próximo a banda de valência. À temperatura ambiente os elétrons que ocupam a banda de valência adquirem energia suficiente para saltar para o nível de energia aceitador introduzido conduzindo ao aparecimento de lacunas na banda de valência. A FIG.3.2.2.1.2 ilustra a criação de níveis aceitadores na banda proibida além da configuração usual para o semicondutor intrínseco.

Intrínseco
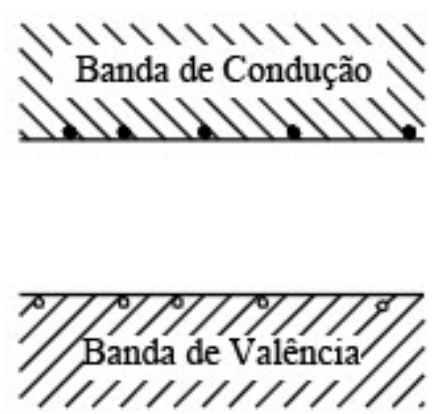

$\oplus \oplus \odot \odot \odot \odot \oplus \odot \odot \odot \odot \odot$ ions

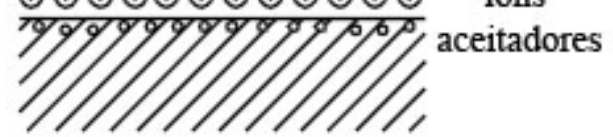

FIGURA 3.2.2.1.2 - Representação da criação de um nível aceitador de energia em um semicondutor do tipo $\mathrm{p}[15]$.

\subsubsection{Semicondutor do Tipo n}

Se, em uma estrutura de Si como aquela utilizada no exemplo anterior, forem introduzidas impurezas pentavalentes temos então a formação de um semicondutor do tipo n. Um átomo de Fósforo (P), por exemplo, ao ser introduzido na estrutura como impureza realizará quatro ligações covalentes com seus vizinhos mais próximos, porém um dos elétrons constituintes da sua camada de valência ficará fracamente ligado à estrutura atômica comportando-se como um elétron de condução. Este material é caracterizado por possuir excesso de elétrons sendo os átomos que o constituem denominados doadores. $\mathrm{Na}$ FIG.3.2.2.2.1, pode-se observar a introdução da impureza de $\mathrm{P}$ na estrutura do semicondutor intrínseco formando o semicondutor do tipo $\mathrm{n}$. 


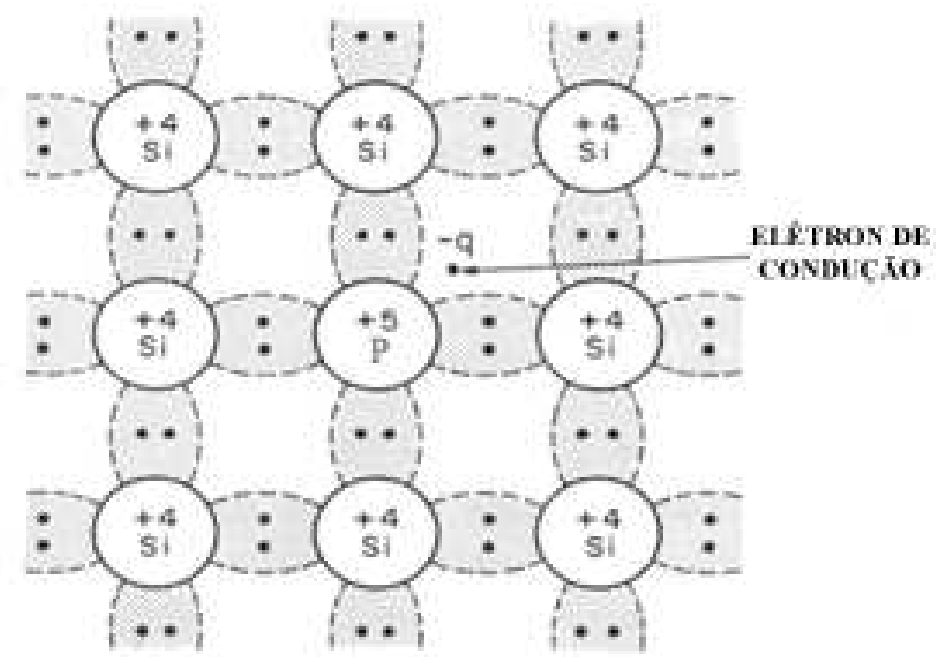

FIGURA 3.2.2.2.1 - Representação de um semicondutor do tipo n [15].

Outros materiais comumente empregados como impureza para a constituição de um semicondutor do tipo n são: antimônio e arsênio.

Novamente, em termos do modelo de bandas de energias, tem-se que para um semicondutor do tipo n, onde átomos doadores são introduzidos na estrutura, um nível de energia é criado na banda proibida, próximo à banda de condução. À temperatura ambiente, os elétrons fracamente ligados aos átomos doadores e situados no nível de energia doador introduzido na estrutura adquirem energia suficiente para saltar para a banda de condução. A FIG.3.2.2.2.2 ilustra a criação de níveis doadores na banda proibida além da configuração usual para o semicondutor intrínseco.

Tipo $n$
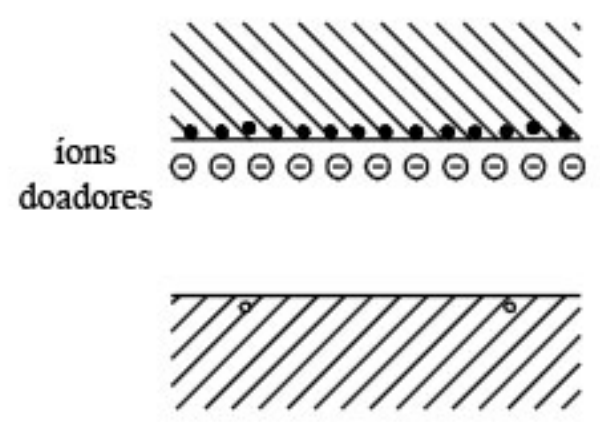

Intrinseco
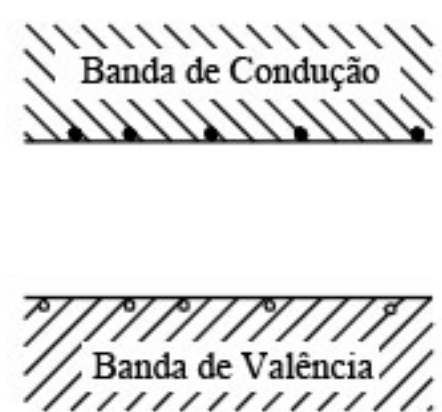

FIGURA 3.2.2.2.2 - Representação da criação de um nível doador de energia em um semicondutor do tipo $n$ [15].

\subsubsection{Movimento dos Portadores de Carga}

Os principais processos de movimento de portadores de cargas em um material semicondutor são descritos a seguir. 


\subsubsection{Mobilidade}

Como mencionado anteriormente, os portadores de cargas nos semicondutores, elétrons na banda de condução e lacunas na banda de valência, podem se locomover ao longo da estrutura cristalina e, portanto, possuem três graus de liberdade. Por este motivo a energia cinética média dos elétrons é igual a $3 / 2 k T$, onde $k$ é a constante de Boltzman e $T$ é a temperatura absoluta.

Assim, no regime livre de campos externos, os elétrons movem-se rapidamente em todas as direções sofrendo espalhamentos devido a colisões com átomos constituintes da estrutura, por exemplo. O movimento aleatório dos elétrons conduz a um deslocamento médio líquido igual a zero. A distância média percorrida pelos elétrons entre cada colisão é denominada caminho livre médio.

Quando um campo elétrico externo é aplicado na amostra, os elétrons são submetidos à força elétrica devido ao campo e tendem a movimentar-se na direção oposta ao campo, entre as colisões. Desta forma, uma componente de velocidade é adicionada a velocidade térmica dos elétrons. Esta componente é denominada velocidade de deriva (drift) e conduz a um deslocamento médio líquido diferente de zero na direção oposta ao campo elétrico aplicado.

A velocidade de deriva pode ser obtida das inter-relações abaixo para elétrons na banda de condução e lacunas na banda de valência respectivamente.

$$
\begin{gathered}
v_{n}=-\mu_{n} \cdot E \\
v_{p}=\mu_{p} \cdot E
\end{gathered}
$$

onde $v_{n}$ e $v_{p}$ são as velocidades de deriva para os elétrons e lacunas, $\mu_{n}$ e $\mu_{p}$ as mobilidades para os elétrons e lacunas e $E$ a intensidade do campo elétrico aplicado.

\subsubsection{Concentração de Portadores de Carga}

Uma maneira bastante eficaz de se medir a concentração de portadores de cargas em um semicondutor é utilizando uma técnica baseada no Efeito Hall. Isso porque os materiais semicondutores são sensíveis aos efeitos da aplicação de campos magnéticos externos, entretanto, quando bem entendidos tais efeitos não interferem no bom funcionamento do dispositivo utilizado. 
Quando submetido a um campo magnético externo, o aparecimento da força de Lorentz na região dos portadores de carga gera a separação dos mesmos, elétrons e lacunas, em extremidades distintas do dispositivo. Assim, o material se comporta como uma espécie de capacitor de placas paralelas e por este motivo a concentração de portadores de cargas pode ser muito bem determinada.

\subsubsection{Difusão}

O movimento de difusão soma-se ao de deriva, na ausência de campos elétricos e magnéticos, devido a não homogeneidade de um material semicondutor. Considerando a possível existência de uma região com maior concentração de elétrons e outra com maior concentração de lacunas, ambos os tipos de portadores tendem a se difundir da região com menor concentração para a região com maior concentração de cada portador.

No movimento de difusão, segundo as características descritas anteriormente, o fluxo de elétrons, $F_{n}$, e de lacunas, $F_{p}$ podem ser descritos pelas Eq.3.2.3.3.1 e 3.2.3.3.2:

$$
\begin{aligned}
& F_{n}=-D_{n} \cdot \nabla n \\
& F_{p}=-D_{p} \cdot \nabla p
\end{aligned}
$$

onde $D_{n}, \nabla n, D_{p}$ e $\nabla p$ representam a constante de difusão e o gradiente de concentração de portadores para elétrons e lacunas, respectivamente.

Na FIG.3.2.3.3.1 são apresentadas medidas típicas da mobilidade e constante de difusão no Si como função da concentração de impurezas à temperatura ambiente. Os valores de mobilidade e constante de difusão atingem um valor máximo para baixas concentrações de impurezas e decrescem com o aumento desta concentração. 


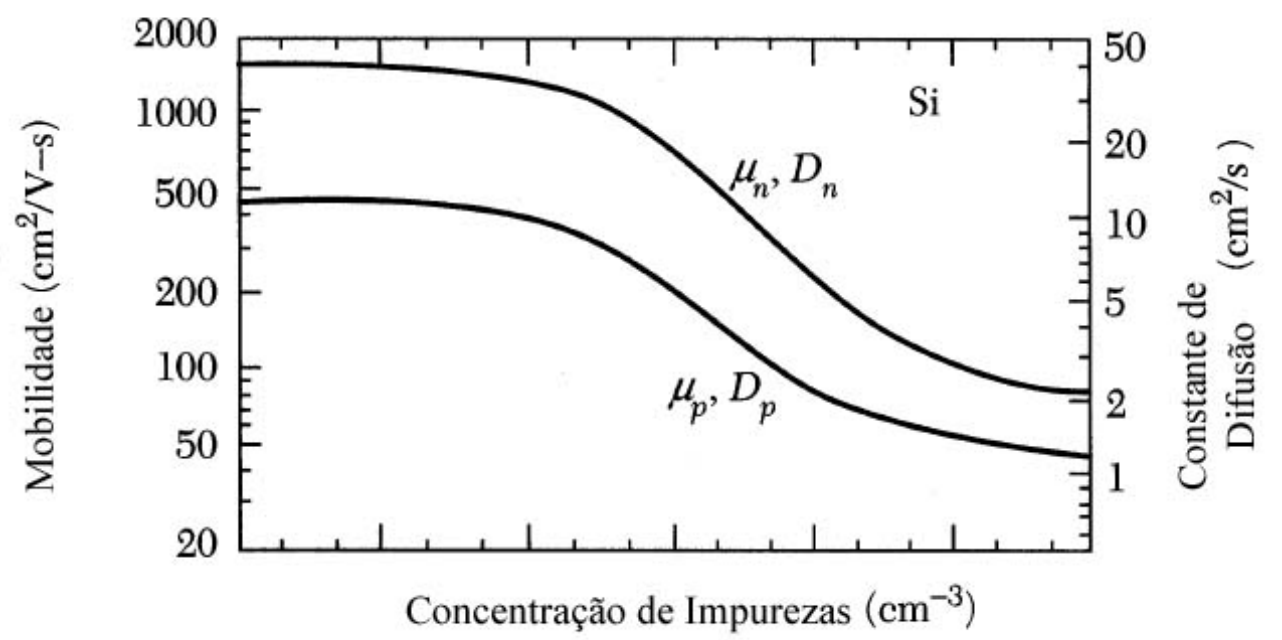

FIGURA 3.2.3.3.1 - Mobilidade e coeficiente de difusão para o Si à temperatura ambiente em função da concentração de impurezas [15].

\subsubsection{Principais Processos de Geração e Recombinação de Portadores de Cargas}

Como mencionado anteriormente, um dos processos para geração de portadores de carga, par elétron-lacuna, é devido ao efeito da temperatura sobre o material semicondutor. Este processo é mais significativo para detectores semicondutores, onde a ocorrência do mesmo gera um ruído sobreposto ao sinal gerado pela interação da radiação com o meio.

A probabilidade de transição direta para o elétron, ou seja, adquirir energia suficiente para saltar da banda de valência diretamente para a banda de condução é baixa, entretanto, se estados intermediários forem criados na banda proibida, a probabilidade da transição descontinuada é maior. Na grande maioria dos detectores semicondutores são utilizados materiais dopados, como será visto adiante, e por este motivo, estados intermediários de energia são facilmente criados na banda proibida aumentando a probabilidade de criação de portadores de carga por efeito térmico.

Outra maneira de se gerar portadores de cargas em um material semicondutor é por meio da incidência de radiação, seja ela de origem eletromagnética ou partículas carregadas.

No caso da incidência de radiação eletromagnética, como é o caso deste trabalho, se a energia do fóton incidente é menor do que a energia da banda proibida, o elétron será deslocado para um estado intermediário de energia, dentro da banda proibida, 
e posteriormente se moverá em direção as bordas desta região, emitindo energia sob a forma de vibrações na rede (fônons) ou de fótons de menor energia.

Mesmo com a existência de estados intermediários de energia na banda proibida, há a possibilidade do elétron ser conduzido diretamente da banda de valência à banda de condução caso a energia do fóton absorvido seja superior a energia da banda proibida.

Devido aos processos de geração de portadores de cargas, portadores minoritários podem ser criados em um material semicondutor, ou seja, elétrons sendo criados em um semicondutor do tipo p, por exemplo. Neste caso, diz-se que o material não encontra-se mais na situação de equilíbrio térmico, sendo necessário para o retorno a tal condição, a recombinação dos portadores minoritários com os portadores majoritários, ou seja, elétrons com lacunas como no exemplo dado.

\subsection{Junção pn}

A junção pn consiste na ligação de uma região semicondutora do tipo p com outra do tipo n, mantendo a continuidade do retículo cristalino. Para tal união existem três métodos muito utilizados:

- Processo de crescimento: a implantação de impurezas é realizada durante o processo de crescimento do diodo.

- Processo de liga: a impureza é fundida sobre uma pastilha semicondutora.

- Processo de difusão: um gás de impureza difunde-se numa amostra de material semicondutor, mantido a alta temperatura.

A FIG.3.3.1 mostra as etapas da fabricação de um diodo de junção pn através do processo de difusão [17]. A primeira etapa consiste na preparação da pastilha semicondutora, o substrato (FIG.3.3.1a), fabricado neste caso com alta concentração de impurezas do tipo $\mathrm{n}$, sendo assim denominado $\mathrm{n}^{+}$. A pastilha é obtida pelo corte em fatias de um bastão de Si, por exemplo, com as superfícies polidas. O bastão semicondutor é obtido através do crescimento de um cristal. Há diversos métodos para crescimento de cristais, dentre eles pode-se destacar aqueles cujo princípio básico foram descritos anteriormente neste trabalho, Czochralski (Cz) e Fusão Zonal (Fz).

Na FIG.3.3.1b, que representa a segunda etapa do processo de produção da junção pn pelo método da difusão, é ilustrado o crescimento de uma camada com impurezas do tipo n, porém com menor concentração, sobre o substrato. A seguir, a pastilha é conduzida a um forno cujo interior encontra-se preenchido com oxigênio para a 
formação de uma camada, com espessura de aproximadamente $1 \mu \mathrm{m}$, de dióxido de silício $\left(\mathrm{SiO}_{2}\right)$, ilustrada na FIG.3.3.1c. Na terceira etapa uma película de resina foto-resistiva é aplicada sobre a camada de óxido e levada a um forno para secar. A seguir uma máscara é colocada sobre a resina como uma espécie de molde, sendo então aplicada a técnica de fotolitografia que consiste na polimerização da resina por incidência de luz ultra-violeta através da máscara (FIG.3.3.1d). A polimerização é realizada em partes da resina tornandoa resistente contra certos solventes capazes de dissolvê-la. Na FIG.3.3.1e é ilustrado o conjunto após a aplicação de um solvente para remover a resina não polimerizada, onde obtém-se como resultado uma janela na camada de óxido através da qual são difundidas impurezas do tipo p. A finalização do processo se dá com a deposição de filmes metálicos que serão responsáveis pelo contato ôhmico do diodo.

\section{Camada epitaxial}

Substrato

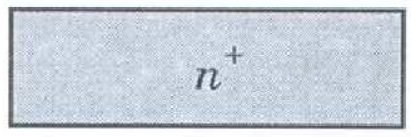

(a)

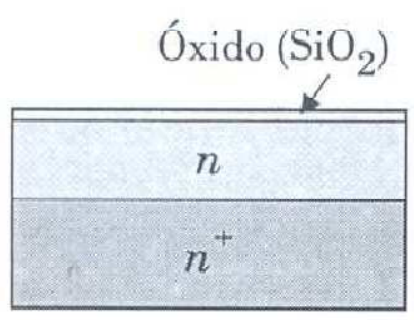

(c)

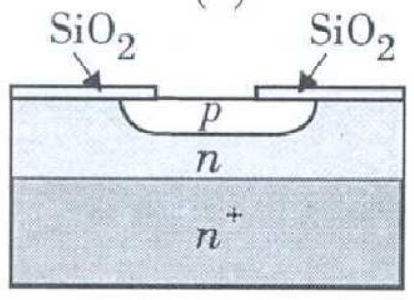

(e)

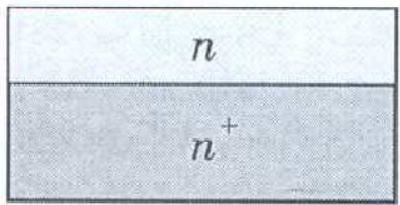

(b)

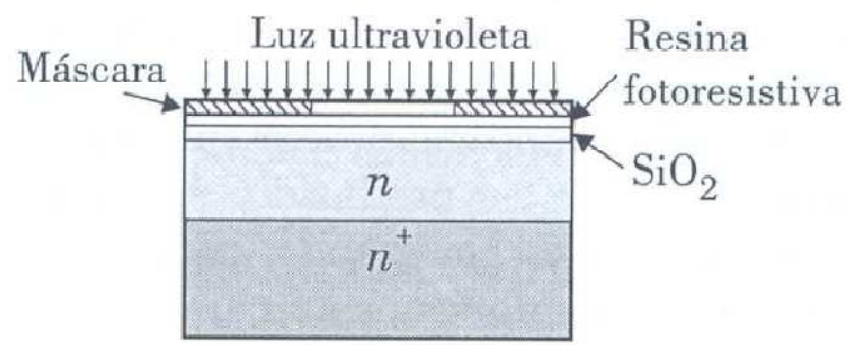

(d)

Contato metálico

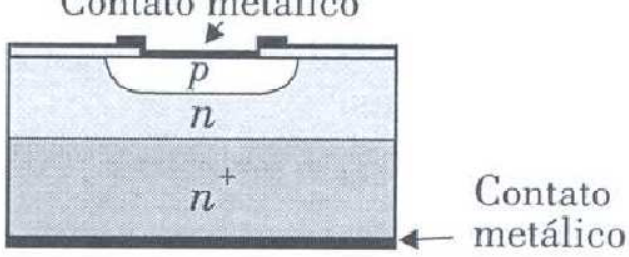

(f)

Figura 3.3.1 - Processo de produção da junção pn de um diodo de Si através do método de difusão [17].

Utilizando quaisquer dos processos de fabricação indicados neste item, quando a junção é produzida, os elétrons da região tipo $\mathrm{n}$ migrarão para a região tipo $\mathrm{p}$, ocasionando o aparecimento de íons positivos na região tipo n. Assim como os elétrons, as 
lacunas também migrarão da região tipo $\mathrm{p}$ para a região tipo $\mathrm{n}$, ocasionando $\mathrm{o}$ aparecimento de íons negativos na região tipo p.

O movimento das lacunas e elétrons das regiões $\mathrm{p}$ para $\mathrm{n}$ e $\mathrm{n}$ para $\mathrm{p}$, respectivamente geram uma corrente denominada difusão. Devido a presença de íons negativos na região tipo $\mathrm{p}$ e íons positivos na região tipo $\mathrm{n}$ surge um campo elétrico dirigido de n para p, como é possível observar na FIG.3.3.2. A ilustração é apenas uma representação estática dos movimentos ocorridos na junção pn.

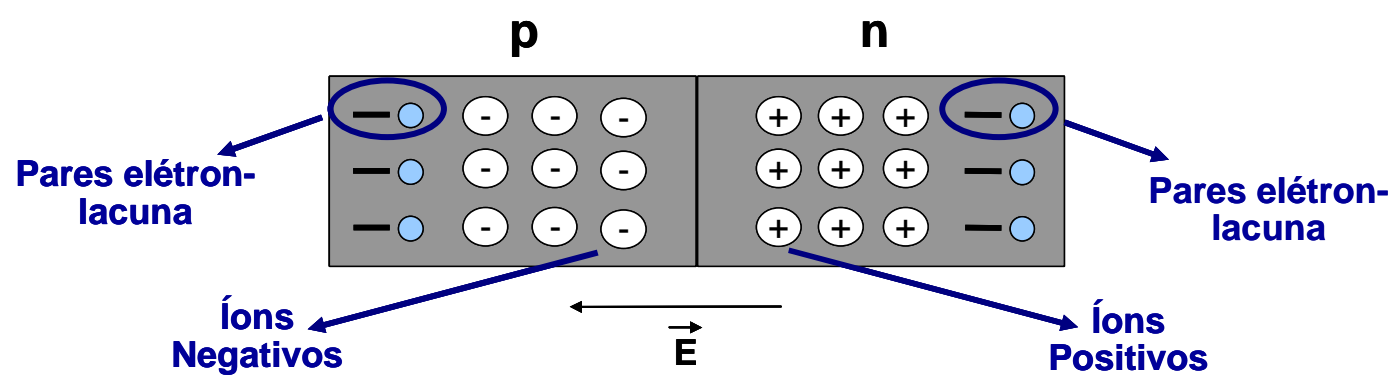

FIGURA 3.3.2 - Representação da junção pn com o movimento de difusão.

A presença do campo elétrico na junção fará com que as lacunas retornem para região tipo $\mathrm{p}$ e os elétrons para a região tipo n. Este novo movimento que se opõe ao movimento de difusão gera uma corrente denominada deriva, ou simplesmente corrente de fuga.

Em regime de equilíbrio térmico, ou seja, quando a produção de pares elétronlacuna por efeito da temperatura é praticamente desprezível, as correntes de difusão e deriva se anulam originando um sistema estacionário representado pela FIG.3.3.3:

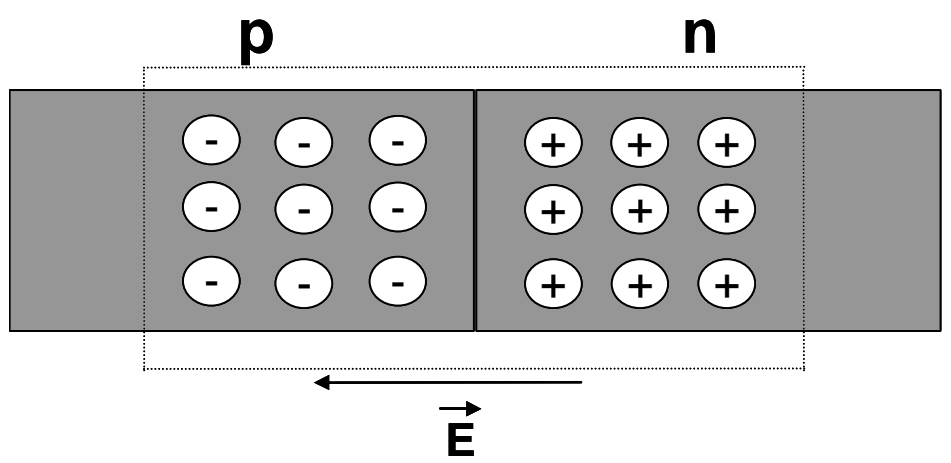

FIGURA 3.3.3 - Regime estacionário da junção pn devido ao equilíbrio térmico.

A região pontilhada indicada na FIG.3.3.3 representa a zona de depleção, caracterizada como uma região que se estende em ambos os lados da junção onde não 
existem cargas livres. De acordo com o eletromagnetismo, sabemos que a presença de um campo elétrico determina uma diferença de potencial, assim, se estabelece um potencial de contato denominado $V_{0}$ na junção pn.

Atualmente, a construção de muitos dispositivos eletrônicos é baseada na utilização de uma ou mais junções do tipo pn. Um dispositivo bastante conhecido cujo funcionamento é baseado em uma junção pn é o diodo. O diodo é um dispositivo de dois terminais que quando introduzido num circuito elétrico simples se comporta como uma chave aberta, não permitindo a passagem da corrente elétrica em um determinado sentido, ou uma chave fechada fazendo com que a corrente elétrica flua normalmente entre seus terminais. Outra utilização comum destes dispositivos é a retificação de sinais alternados em seus terminais. Um outro tipo de diodo bastante conhecido é o LED, light-emitting diode, ou simplesmente diodo emissor de luz, comumente empregado na confecção de displays em aparelhos eletrônicos. Os diodos emissores de luz são dispositivos constituídos por junções pn e emitem espontaneamente radiação na região ultravioleta, visível ou infravermelho.

A simbologia para os diodos comuns e a correspondência com a terminologia utilizada são ilustradas na FIG.3.3.4.

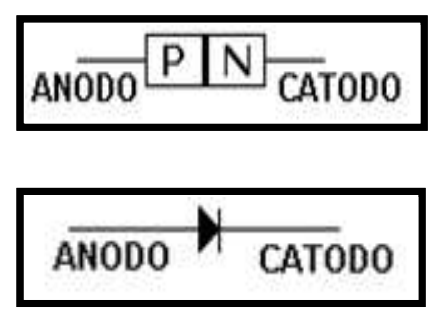

FIGURA 3.3.4 - Simbologia e terminologia dos diodos.

De uma forma geral a utilização dos diodos em circuitos elétricos pode ser de dois tipos: polarização direta ou polarização reversa. A mais comum aplicação, em termos de detecção da radiação e caracterização do dispositivo em termos de sua capacitância, é a de polarização reversa.

O diodo é polarizado diretamente quando a região do tipo p é polarizada positivamente e a região do tipo $\mathrm{n}$ é polarizada negativamente. Nesta condição, se a diferença de potencial externa é superior a tensão de contato do dispositivo o campo elétrico efetivo na junção p-n diminui ocasionando um aumento da corrente de difusão com uma inibição parcial da corrente de fuga. Na FIG.3.3.5 é representado um diagrama 
esquemático do campo elétrico externo e interno do dispositivo para a situação de polarização direta.

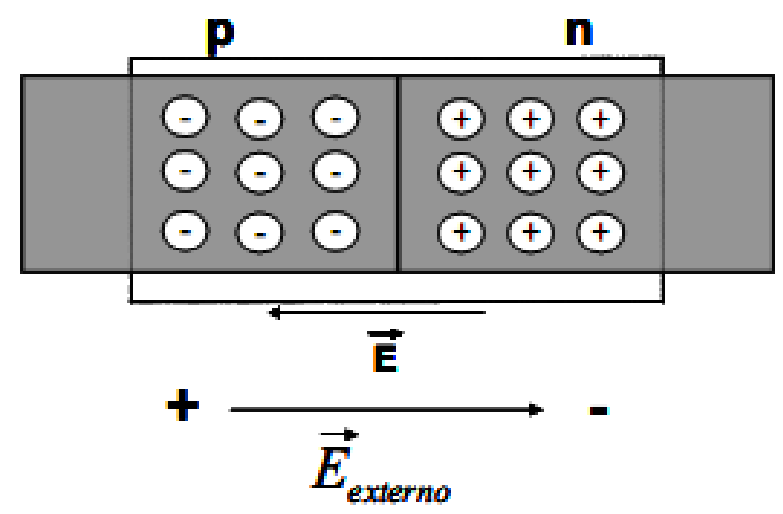

FIGURA 3.3.5 - Representação esquemática da polarização direta na junção pn.

A polarização reversa ocorre exatamente em um processo inverso ao da polarização direta, ou seja, quando o diodo é acoplado a uma fonte de tensão externa de modo que o campo elétrico efetivo na junção aumente, dificultando a passagem da corrente elétrica externa por seus terminais. Na junção, a região tipo p é polarizada negativamente e a região tipo $n$ é polarizada positivamente. Com o aumento do campo elétrico efetivo na junção, a corrente de difusão é parcialmente inibida com o aumento da corrente de fuga. Na FIG.3.3.6 é representado um diagrama esquemático do campo elétrico externo e interno do dispositivo para a situação de polarização reversa.

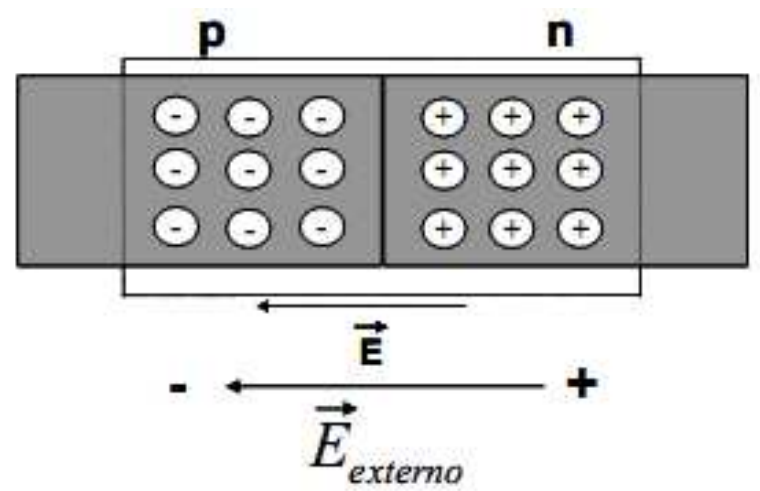

FIGURA 3.3.6 - Representação esquemática da polarização reversa na junção pn.

O comportamento da junção pn na condição de polarização reversa permite a análise da capacitância na região através de sua equivalência a um capacitor de placas paralelas. 
De acordo com a definição de capacitância para um capacitor de placas paralelas tem-se que:

$$
C=\frac{d Q}{d V}=\varepsilon \cdot \frac{A}{d}
$$

onde, $C$ é a capacitância total da junção, $Q$ é a carga total acumulada na região, $V$ é a tensão de polarização da junção, $\varepsilon$ é a constante de rigidez dielétrica do material, $A$ é a área compreendida pela junção e $d$ é a espessura da camada de depleção.

Sendo $x_{n}$ e $x_{p}$ as espessuras da camada de depleção estendida para as regiões $\mathrm{n}$ e p respectivamente, e $N_{D}$ e $N_{A}$ de átomos doadores (região n) e aceitadores (região p) respectivamente, pode-se ilustrar a camada de depleção da seguinte maneira:

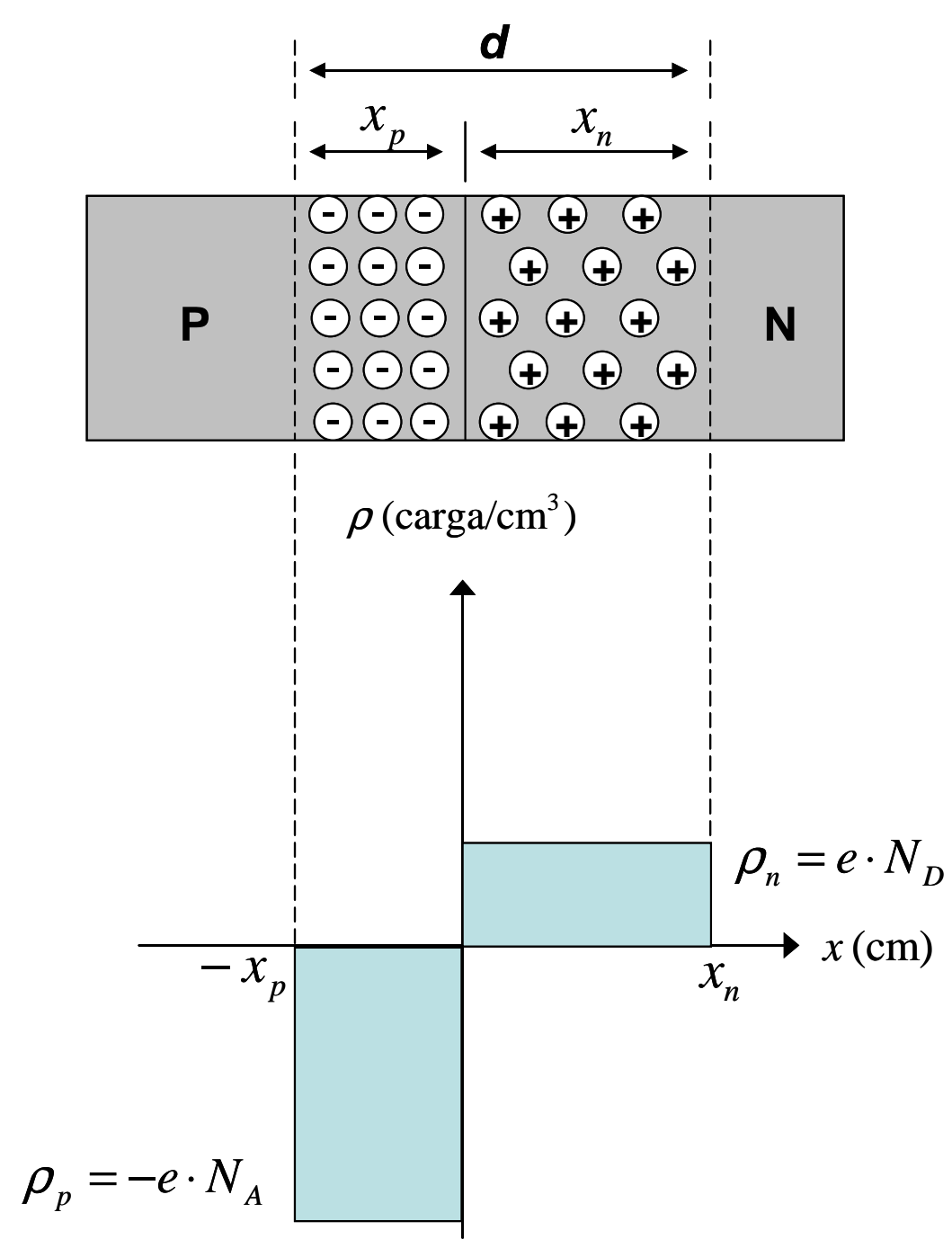

FIGURA 3.3.7 - Representação da distribuição volumétrica de cargas na camada de depleção. 
Aplicando a equação de Poisson, pode-se determinar o potencial em cada uma das regiões representadas:

$$
\nabla^{2} V=\frac{d^{2} V}{d x^{2}}=-\frac{\rho}{\varepsilon}
$$

onde, $\rho$ representa a densidade volumétrica de cargas.

Assim, para cada uma das regiões tem-se que:

$$
\begin{aligned}
\frac{d^{2} V_{n}}{d x^{2}} & =-\frac{e \cdot N_{D}}{\varepsilon} \\
\frac{d^{2} V_{p}}{d x^{2}} & =\frac{e \cdot N_{A}}{\varepsilon}
\end{aligned}
$$

Integrando-se as Eq.3.3.3 e 3.3.4 obtém-se o campo elétrico $E$ correspondente a cada uma das regiões representadas.

Para a região n:

$$
\begin{gathered}
\int d^{2} V_{n}=\int-\frac{e \cdot N_{D}}{\varepsilon} d x^{2} \\
-\frac{d V_{n}}{d x}=E_{n}=\frac{e \cdot N_{D}}{\varepsilon} \cdot x-C_{1}
\end{gathered}
$$

onde $C_{1}$ representa uma constante de integração, que pode ser determinada a partir da condição de contorno abaixo extraída da definição do sentido do campo elétrico na junção:

$$
x=x_{n} \Rightarrow \frac{d V_{n}}{d x}=E_{n}=0
$$

Assim, tem-se que:

$$
\begin{gathered}
\frac{e \cdot N_{D}}{\varepsilon} \cdot x_{n}-C_{1}=0 \\
C_{1}=\frac{e \cdot N_{D}}{\varepsilon} \cdot x_{n}
\end{gathered}
$$


O resultado obtido na Eq.3.3.9, aplicado à Eq.3.3.6 fornece enfim o valor do campo elétrico para a região n.

$$
-\frac{d V_{n}}{d x}=E_{n}=\frac{e \cdot N_{D}}{\varepsilon} \cdot\left(x-x_{n}\right) ; 0<x<x_{n}
$$

Analogamente, para a região p, tem-se:

$$
-\frac{d V_{p}}{d x}=E_{p}=-\frac{e \cdot N_{A}}{\varepsilon} \cdot\left(x+x_{p}\right) ;-x_{p}<x<0
$$

Integrando-se as Eq.3.3.10 e 3.3.11, obtém-se o potencial nas regiões $n$ e $p$, respectivamente.

Para a região n, tem-se que:

$$
\begin{gathered}
\int-d V_{n}=\int \frac{e \cdot N_{D}}{\varepsilon} \cdot\left(x-x_{n}\right) d x \\
V_{n}=-\frac{e \cdot N_{D}}{2 \cdot \varepsilon} \cdot\left(x-x_{n}\right)^{2}+B_{1}
\end{gathered}
$$

onde $B_{1}$ representa uma constante de integração, que pode ser determinada a partir da condição de contorno abaixo, extraída da definição de potencial elétrico na junção, onde $V$ representa a tensão de polarização da junção:

$$
x=x_{n} \Rightarrow V_{n}=V
$$

Assim, tem-se que:

$$
\begin{gathered}
V=-\frac{e \cdot N_{D}}{2 \cdot \varepsilon} \cdot\left(x_{n}-x_{n}\right)^{2}+B_{1} \\
B_{1}=V
\end{gathered}
$$

Utilizando o resultado obtido na Eq.3.3.16 para a determinação do potencial na região n, de acordo com a Eq.3.3.13 tem-se que:

$$
V_{n}=-\frac{e \cdot N_{D}}{2 \cdot \varepsilon} \cdot\left(x-x_{n}\right)^{2}+V
$$


Para a região p:

$$
\begin{gathered}
\int-d V_{p}=\int-\frac{e \cdot N_{A}}{\varepsilon} \cdot\left(x+x_{p}\right) d x \\
V_{p}=\frac{e \cdot N_{A}}{2 \cdot \varepsilon} \cdot\left(x+x_{p}\right)^{2}+B_{2}
\end{gathered}
$$

sendo $B_{1}$ uma constante de integração que pode ser determinada a partir da condição de contorno abaixo:

$$
x=-x_{p} \Rightarrow V_{p}=0
$$

Portanto, o potencial na região p é dado por:

$$
V_{p}=\frac{e \cdot N_{A}}{2 \cdot \varepsilon} \cdot\left(x+x_{p}\right)^{2}
$$

Como na junção $(x=0)$ o potencial da região $\mathrm{p}$ se iguala ao potencial da região n, pode-se escrever, nesta condição:

$$
-\frac{e \cdot N_{D}}{2 \cdot \varepsilon} \cdot x_{n}{ }^{2}+V=\frac{e \cdot N_{A}}{2 \cdot \varepsilon} \cdot x_{p}{ }^{2} \Rightarrow \frac{2 \cdot \varepsilon \cdot V}{e}=N_{A} \cdot x_{p}{ }^{2}+N_{D} \cdot x_{n}{ }^{2}
$$

Como o movimento efetivo no cristal é ocasionado pelos elétrons sendo o movimento atribuído às lacunas uma conseqüência do primeiro, pode-se afirmar que a carga positiva devida aos íons positivos na região de depleção é igual a carga negativa nesta mesma região devida aos íons negativos. Porém, para que a afirmação anterior seja válida, deve existir um compromisso entre o produto das espessuras das regiões n e p com suas respectivas concentrações de cargas, assim em módulo:

$$
N_{A} \cdot x_{p}=N_{D} \cdot x_{n}
$$

Substituindo a Eq.3.3.23 no resultado obtido na Eq.3.3.22, tem-se que:

$$
\frac{2 \cdot \varepsilon \cdot V}{e}=N_{D} \cdot x_{n} \cdot x_{p}+N_{D} \cdot x_{n}^{2} \Rightarrow \frac{2 \cdot \varepsilon \cdot V}{e}=N_{D} \cdot x_{n} \cdot\left(x_{p}+x_{n}\right)
$$


Considerando que a espessura $d$ da camada de depleção é dada por:

$$
d=x_{n}-\left(-x_{p}\right)=x_{n}+x_{p}
$$

Pode-se reescrever a Eq.3.3.24 como:

$$
\frac{2 \cdot \varepsilon \cdot V}{e}=N_{D} \cdot x_{n} \cdot d
$$

Assim, como mostrado na Eq.3.3.23, se a concentração de átomos aceitadores for muito maior que a concentração de átomos doadores $\left(N_{A} \gg>N_{D}\right)$, a espessura da região p será muito menor que a espessura da região $\mathrm{n}\left(x_{p} \ll<x_{n}\right)$, então:

$$
d \cong x_{n} \Rightarrow d^{2}=\frac{2 \cdot \varepsilon \cdot V}{e \cdot N_{D}} \Rightarrow d=\sqrt{\frac{2 \cdot \varepsilon \cdot V}{e \cdot N_{D}}}
$$

Enfim, pode-se obter a capacitância total da junção pn dada por:

$$
C=\varepsilon \cdot \frac{A}{d}=\varepsilon \cdot A \cdot\left(\frac{e \cdot N_{D}}{2 \cdot \varepsilon \cdot V}\right)^{1 / 2}=\sqrt{\frac{e \cdot \varepsilon \cdot N_{D}}{2 \cdot V}} \cdot A
$$

Pode-se também definir a capacitância da junção por unidade de área, que neste caso será dada por:

$$
C_{A}=\sqrt{\frac{e \cdot \varepsilon \cdot N_{D}}{2 \cdot V}}
$$

Mediante a análise da Eq.3.3.29, pode-se concluir que o aumento da tensão de polarização reversa provoca uma diminuição da capacitância total na junção em virtude do crescimento da espessura da camada de depleção.

O método utilizado neste trabalho para a determinação da tensão de depleção total dos diodos analisados baseia-se caracterização elétrica dos mesmos, sobretudo quanto comportamento da curva da capacitância em função da tensão de polarização reversa (Curva $\mathrm{C}-\mathrm{V}$ ), pois através desta curva é possível verificar o valor limiar de tensão a partir 
do qual o dispositivo encontra-se totalmente depletado, ou seja, com a maior espessura possível da camada de depleção. De acordo com a Eq.3.3.29 um dispositivo estará totalmente depletado, quando para diferentes valores de tensão de polarização reversa sua capacitância permanece praticamente constante. A Figura 3.3.8 representa o comportamento típico da curva do inverso do quadrado da capacitância em função da tensão de polarização reversa para um diodo, ressaltando o ponto limiar em tensão que define o valor da tensão de depleção total do dispositivo.

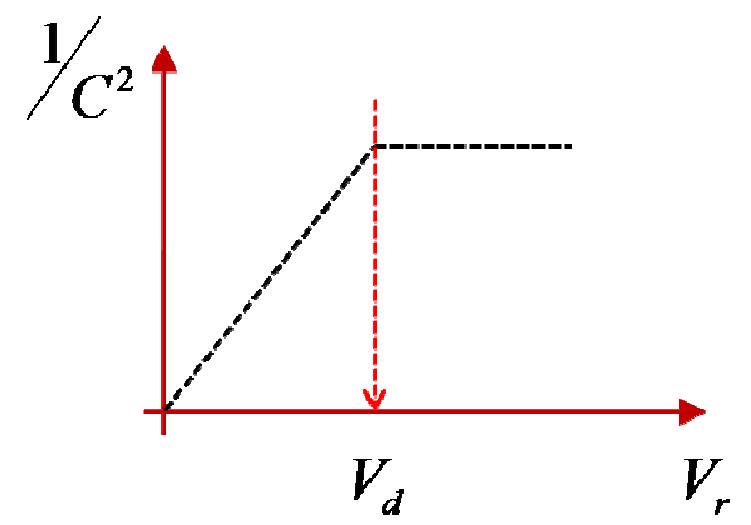

FIGURA 3.3.8 - Esquema para obtenção gráfica dos valores de tensão de depleção total das amostras.

\subsection{Princípio de Funcionamento de Diodos de Si como Dosímetros de Radiação}

Para a grande maioria das aplicações em dosimetria das radiações, os diodos têm sido utilizados no modo fotovoltaico, ou seja, sem a aplicação de uma polarização externa, e introduzidos em circuitos com impedância praticamente nula. Deste modo, o diodo age como uma fonte de corrente direta e deve exibir uma resposta linear com a taxa de dose [19-21].

Quando a radiação incide em um diodo de Si interagirá com a região de depleção do dispositivo de acordo com os processos característicos usuais. Por exemplo, a radiação gama proveniente de uma fonte de ${ }^{60} \mathrm{Co}\left(\mathrm{E}_{\gamma} \cong 1 \mathrm{MeV}\right)$, como é utilizada neste trabalho, incidindo em diodo de $\mathrm{Si}(\mathrm{Z}=14)$ interagirá com a camada de depleção do dispositivo essencialmente por efeito Compton, como pode ser observado na FIG.3.4.1. 


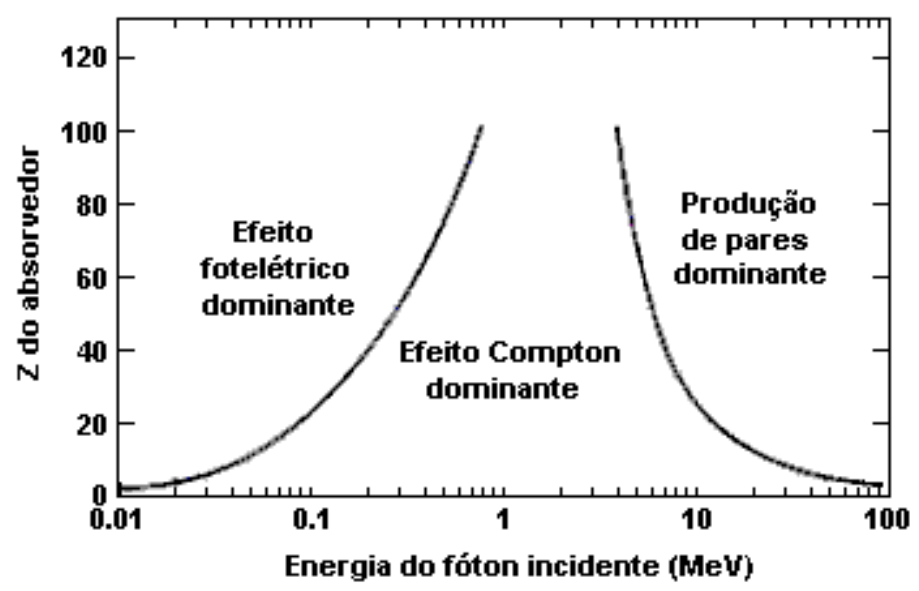

FIGURA 3.4.1 - Relação entre o número atômico $\mathrm{Z}$ e a energia da radiação incidente com os predominantes processos de interação.

O processo de interação por efeito ou espalhamento Compton ocorre entre um fóton da radiação gama incidente com um elétron do absorvedor. No espalhamento Compton, o fóton incidente que interage com um elétron do alvo, é defletido a um ângulo $\theta$ qualquer com a direção de incidência. $\mathrm{O}$ fóton transfere parte da sua energia inicial para o elétron que recua a um dado ângulo $\varphi$ com a direção de incidência do fóton. Devido à grande possibilidade de valores que os ângulos de interação podem assumir, a energia transferida do fóton para o elétron pode variar desde zero a grandes frações de sua energia inicial.

A FIG.3.4.2 ilustra esquematicamente um processo de interação por espalhamento Compton.

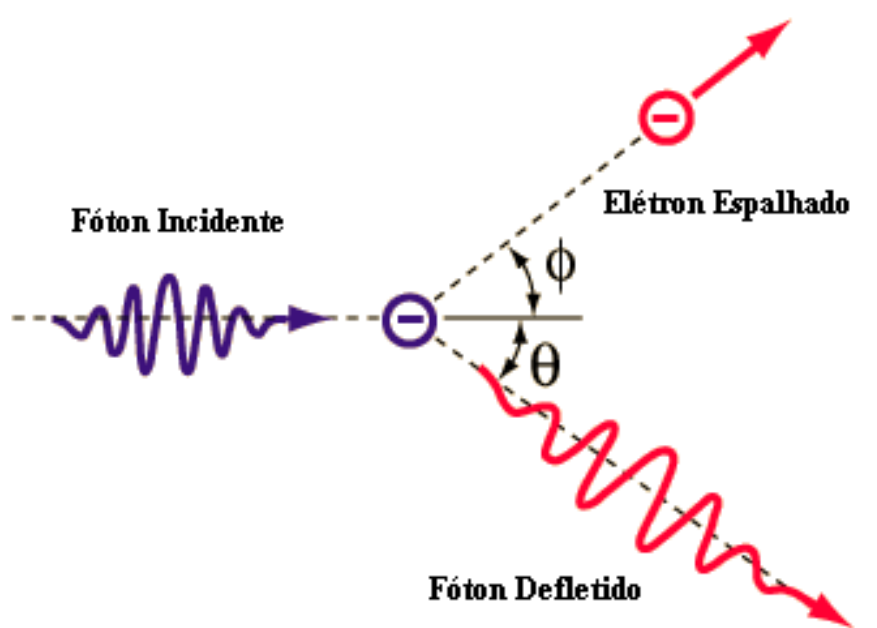

FIGURA 3.4.2 - Processo de interação por espalhamento Compton 
A expressão que fornece o valor da energia transferida para o elétron, bem como o ângulo de espalhamento para um dado meio de interação, pode ser obtida através de equações simultâneas de conservação de energia e momento. As expressões finais são dadas por:

$$
\begin{gathered}
E_{\gamma}{ }^{\prime}=\frac{E_{\gamma}}{1+\left[\frac{E_{\gamma}}{m_{0} \cdot c^{2}} \cdot(1-\cos \theta)\right]} \\
T=E_{\gamma}-E_{\gamma}{ }^{\prime}
\end{gathered}
$$

onde $m_{0} \cdot c^{2}$ representa a energia de repouso do elétron, $E_{\gamma}{ }^{\prime}$ a energia do fóton defletido, $E_{\gamma}$ a energia do fóton incidente e $T$ a energia cinética do elétron deslocado. Assim, o compromisso entre o ângulo de espalhamento e a energia transferida pelo fóton incidente ao elétron, estabelece que para ângulos pequenos o valor de energia transferido também é pequeno.

A probabilidade de interação dos raios gama com a matéria por espalhamento Compton depende do número de elétrons disponíveis no alvo e, conseqüentemente, aumenta linearmente com o número atômico $Z$ do meio de interação.

Na FIG.3.4.3 é representado um diagrama esquemático da interação da radiação com um diodo de junção. Para o exemplo adotado da radiação gama proveniente de uma fonte de ${ }^{60} \mathrm{Co}$, os elétrons gerados por espalhamento Compton serão os responsáveis pela interação com a região de depleção do dispositivo.

Os elétrons gerados por efeito Compton irão transferir energia aos elétrons de valência do meio de maneira que se o valor transferido for superior ao valor da energia de gap, o elétron migrará da banda de valência para a banda de condução, formando assim um par elétron-lacuna. 


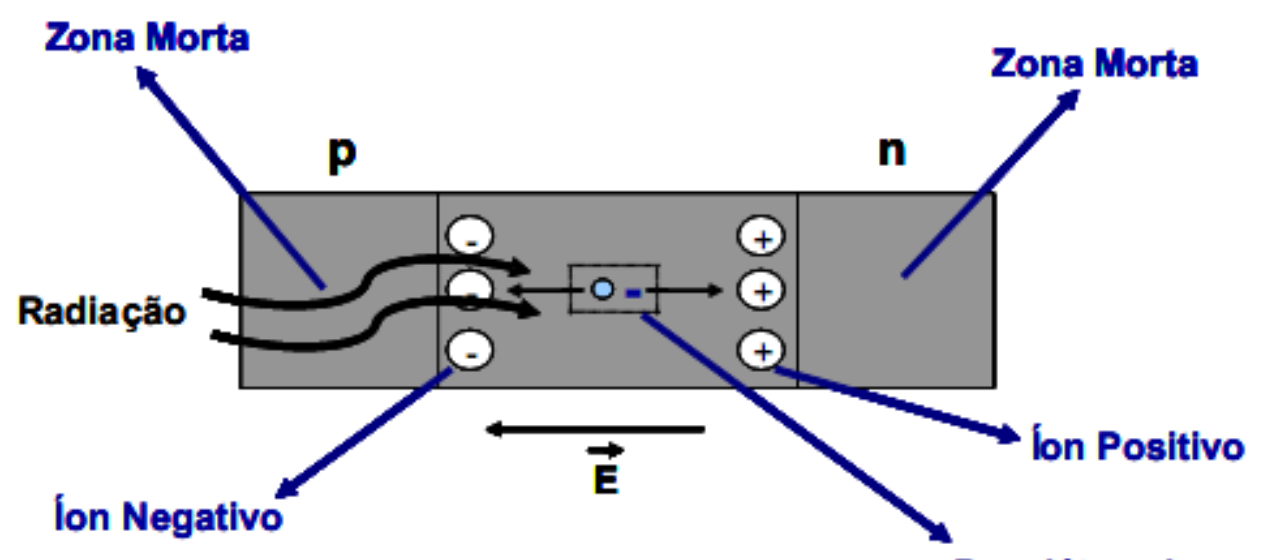

Par elétron-lacuna

FIGURA 3.4.3 - Diodo como dosímetro de radiação.

Pode-se notar na FIG.3.4.3 que além da região de carga espacial é indicada também uma região denominada de zona morta do dispositivo. Esta região não é sensível para o processo de detecção e afeta a resposta do sistema, pois é responsável pela dispersão e degradação da energia da radiação antes que atinja o volume sensível do dispositivo. Para a radiação gama que é utilizada neste trabalho, esta dispersão não é levada em consideração visto que a energia dos fótons emitidos pela fonte é elevada o suficiente para que estes atravessem esta região inativa sem que ocorra grande dispersão.

A irradiação com fótons produzirá então pares elétron-lacuna no dispositivo. Os pares gerados dentro da região de carga espacial serão imediatamente separados pelo campo elétrico na região de depleção, gerando assim uma parcela da corrente induzida pela radiação. Além disto, os portadores minoritários (elétrons na região tipo p e lacunas na região tipo n) existentes fora da região de depleção podem difundir para dentro desta mesma região e serem também coletados, contribuindo também para a geração da corrente induzida por fótons, denominada fotocorrente [19].

A largura da região sensível do diodo pode então ser definida segundo a Eq.3.4.3 [1].

$$
L_{n}+L_{p}+d
$$

onde $d, L_{n}$ e $L_{p}$ representam respectivamente a largura da região de depleção, a extensão da difusão dos elétrons da região tipo p e a extensão da difusão das lacunas da região tipo n.

Assumindo então a situação em que um diodo é irradiado homogeneamente com fótons e operado no modo de curto-circuito, ou seja, sem polarização externa, a 
corrente induzida pode ser calculada por deduções matemáticas que resultam em (Eq.3.4.4) [1]:

$$
J_{S C}=-q \cdot G_{L} \cdot\left(L_{n}+L_{p}+d\right)
$$

onde $q$ e $G_{L}$ representam respectivamente a carga gerada pela irradiação e a taxa de geração por unidade de volume, que pode ser relacionada com a taxa de dose.

Assim, como mencionado anteriormente, a fotocorrente gerada é proporcional a taxa de dose com a qual o diodo está sendo irradiado. Para baixas taxas de dose, onde a fotocorrente gerada é pequena, a contribuição da corrente de fuga por efeitos de temperatura, entre outros, deve ser levada em consideração. Por outro lado, quando a fotocorrente é muito maior que a corrente de fuga gerada, para altas taxas de dose, por exemplo, esta contribuição pode ser desprezada.

Um dos fatores que vêm sendo estudado acerca dos diodos de Si em dosimetria de altas doses é a influência da radiação na estrutura do dispositivo, sobretudo os danos induzidos nesta estrutura.

Ao incidir sobre a estrutura do diodo de $\mathrm{Si}$, a radiação não interage somente com os elétrons da estrutura, mas também com os núcleos presentes e, portanto, com a estrutura como um todo. Os principais processos que conduzem a danos na estrutura são [12]:

- Deslocamento dos átomos da estrutura gerando interstícios (átomos situados em posições irregulares na estrutura) e vacâncias (ausência de um átomo na estrutura);

- Interações com os núcleos (transmutação nuclear, por exemplo);

- Processos secundários gerados por átomos primariamente deslocados (defeitos em cascata denominados cluster).

Muitos destes defeitos não são estáveis e podem se mover pela estrutura sob efeito, por exemplo, da temperatura. Assim, sob efeito de temperatura alguns defeitos como interstícios e vacâncias podem se aniquilar conduzindo ao efeito de annealling dos danos [1].

Para o deslocamento de átomos da estrutura, uma energia mínima de aproximadamente $15 \mathrm{eV}$ é requerida para o recuo do átomo que será deslocado. Entretanto, este limiar depende fortemente da direção de deslocamento do átomo na estrutura. Se a direção de deslocamento aponta para a direção de um átomo vizinho este limiar de energia 
requerido é muito maior. O valor de energia com a qual o átomo será efetivamente recuado na rede, $\mathrm{E}_{\mathrm{d}}$, é determinado para cada material semicondutor como o valor para o qual a probabilidade de recuo de um átomo seja igual a 0,5 [1] (para o $\mathrm{Si}_{\mathrm{d}}=25 \mathrm{eV}$ ). O valor da energia de recuo é tomado como limiar para a ocorrência de diferentes efeitos na estrutura do material.

Para energias de recuo abaixo de aproximadamente 1-2 keV somente defeitos isolados ou defeitos pontuais serão criados enquanto que para energias entre 2-12 keV há a ocorrência de defeitos cluster. Além deste parâmetro energético, a formação de defeitos primários na estrutura cristalina depende também do tipo de radiação incidente. Para o caso em estudo, com irradiação gama, sabe-se que apenas defeitos pontuais são produzidos, uma vez que os elétrons gerados por efeito Compton terão energia cinética máxima de aproximadamente $1 \mathrm{MeV}$ cujo valor é insuficiente para conduzir à formação de defeitos cluster [2,7,22-23].

A presença dos defeitos induzidos pela radiação no cristal pode alterar as propriedades elétricas macroscópicas dos dispositivos, tais como o aumento da corrente reversa (fuga) do diodo, a alteração da densidade de carga espacial (alteração da tensão de depleção) e armadilhamento dos sinais de carga. Para este trabalho são considerados somente os efeitos tocantes a alteração da densidade de carga espacial e aumento da corrente reversa.

\section{Tensão de Depleção:}

Existem diferentes mecanismos de danos que conduzem a alteração da densidade de carga espacial e, portanto, a alteração da tensão de depleção do dispositivo.

A captura dos dopantes usuais como boro ou fósforo por defeitos complexos é um exemplo de mecanismo que conduz a alteração da tensão de depleção do dispositivo. Se um destes dopantes é capturado, perde sua função inicial como doador ou aceitador e assume um estado de carga na região de carga espacial diferente do estado inicial. No caso do fósforo, por exemplo, pode ser transformado em vacância (fósforo) sendo alterada, de positiva para neutra, a carga espacial. Outras substâncias, além dos dopantes iniciais, como oxigênio ou carbono, também podem sofrer este tipo de processo.

Estudos mostram que o Si enriquecido com oxigênio apresenta uma melhora com relação a alteração de densidade de carga espacial quando comparado com estruturas puras. Isto pode ser devido essencialmente ao fato de que a inserção de oxigênio na 
estrutura suprime os defeitos complexos responsáveis pela carga espacial negativa induzida pela radiação [7].

A FIG.3.4.4 mostra a dependência da tensão de depleção total (relacionada com concentração efetiva de carga espacial) com a dose de radiação gama para dispositivos crescidos pelos métodos de fusão zonal padrão (STFz) e com difusão de oxigênio (DOFz) ambos do tipo n e com elevada resistividade [7].

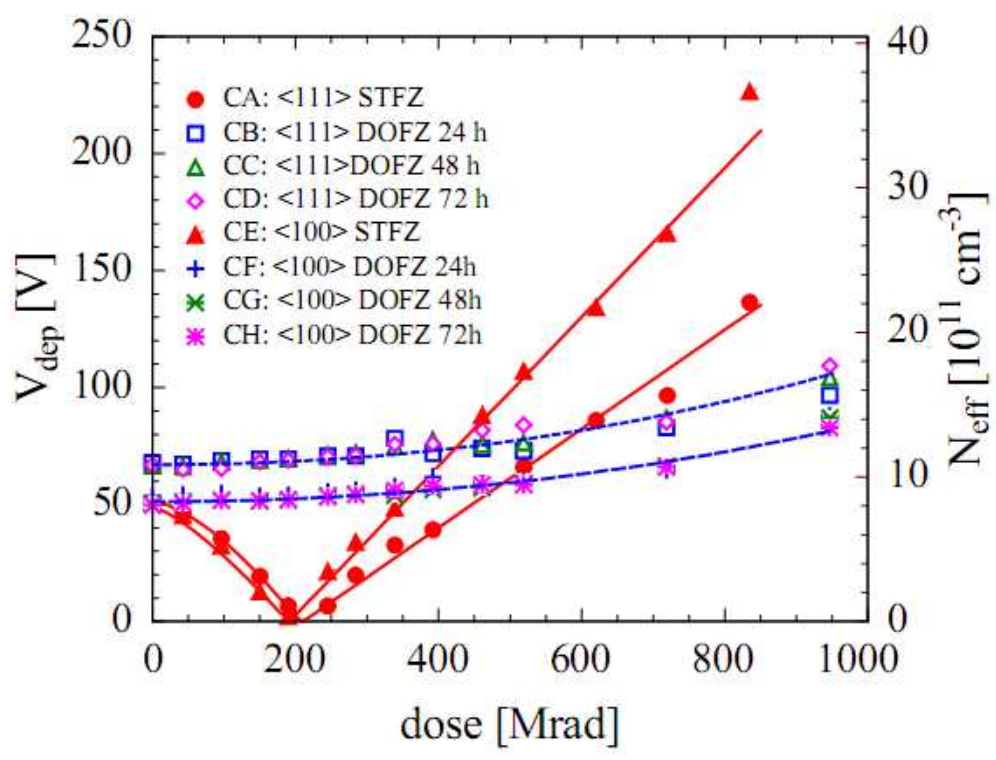

FIGURA 3.4.4 - Dependência da tensão de depleção total com a dose de radiação gama [7].

De acordo com a FIG.3.4.4, pode-se notar que para as amostras do tipo Fz suas tensões de depleção e, portanto, o dopante efetivo, decrescem com a dose de radiação tornando o material intrínseco para um valor de aproximadamente 2 MGy (200 Mrad). Acima deste valor, o dopante efetivo aumenta com a dose de radiação mostrando que o material inicialmente do tipo $\mathrm{n}$ sofre o denominado fenômeno de inversão de tipo tornando-se então do tipo p.

Este mesmo comportamento não é observado para os diodos do tipo DOFz, como sugerido anteriormente devido a contribuição do oxigênio.

O comportamento observado para a inversão de tipo é condizente com os mecanismos esperados de criação de níveis aceitadores e remoção de doadores.

\section{Corrente Reversa (Fuga):}

Na região de carga espacial, os defeitos criados pela radiação podem alterar seu estado de carga em intervalos de tempo pequenos, capturando e emitindo alternadamente 
elétrons e lacunas. Esta emissão alternativa é responsável pela corrente reversa gerada no dispositivo.

O aumento desta corrente reversa é linear com a dose de radiação para nêutrons e elétrons até a inversão de tipo [1] como mostra a FIG.3.4.5. Para radiação gama o comportamento linear foi observado para diodos do tipo DOFz enquanto o mesmo não foi observado para diodos do tipo Fz [7] como mostra a FIG.3.4.6.

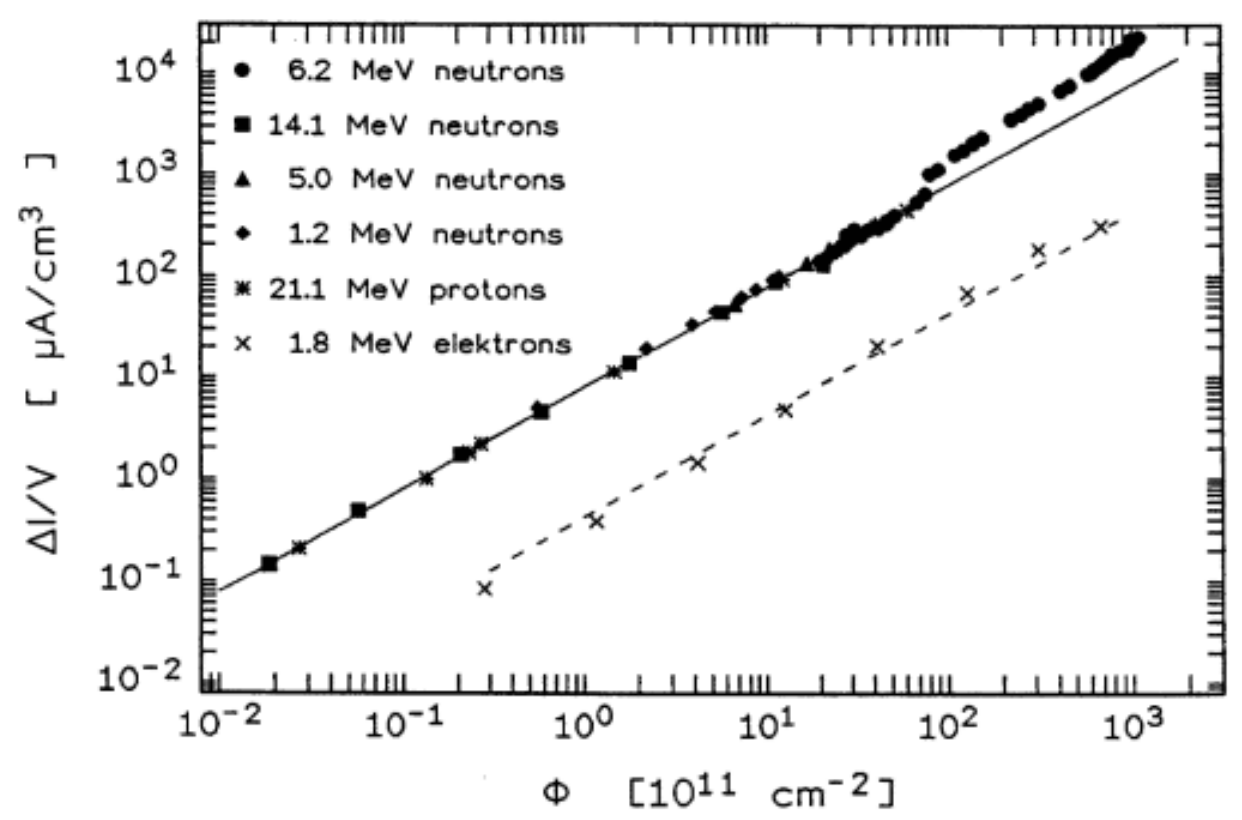

FIGURA 3.4.5 - Variação da corrente de fuga por unidade de volume com a fluência equivalente de nêutrons $[1]$.

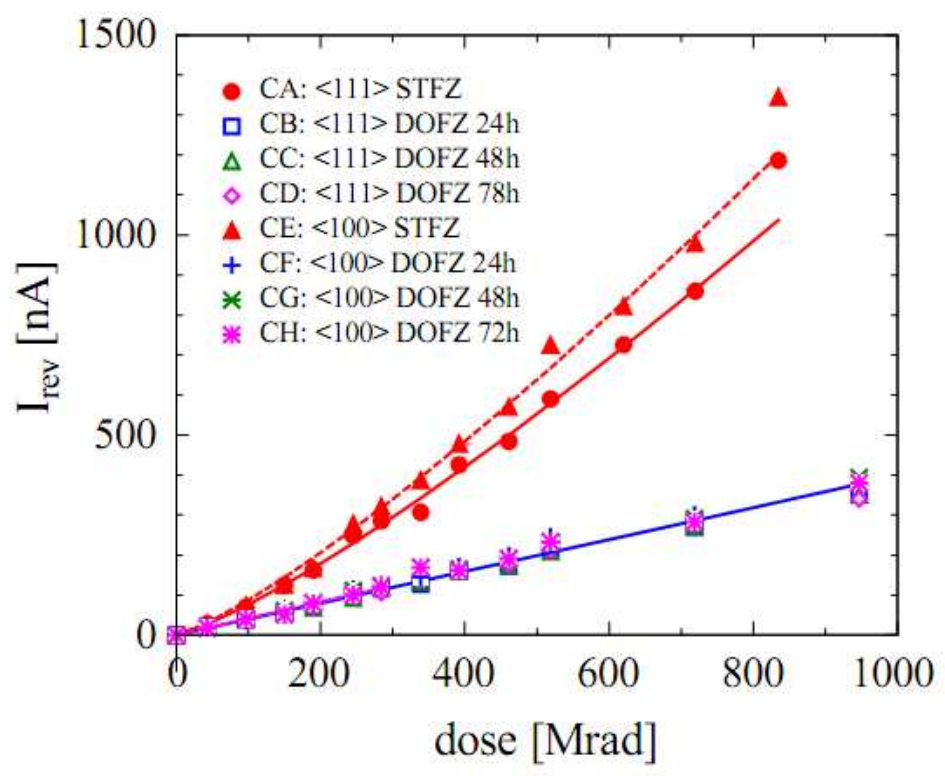

FIGURA 3.4.6 - Variação da corrente de fuga coma dose de radiação gama [7]. 


\section{MATERIAIS E MÉTODOS}

Os diodos utilizados neste trabalho foram crescidos pelos métodos de Fusão Zonal Padrão (Fz) e Czochralski Magnético $(\mathrm{MCz})$ e processados no Centro de Microeletrônica da Universidade Tecnológica de Helsinque (Finlândia) e nos foram doados dentro da colaboração estabelecida entre este centro e o nosso grupo de pesquisas.

Ambos os diodos possuem uma estrutura de 16 anéis de guarda como pode ser observado nas FIG.4.1a e 4.1b com as fotos obtidas no Laboratório de Microeletrônica da Escola Politécnica da USP (LME/Poli-USP). No centro do diodo, mostrado na FIG.4.1a, observa-se um círculo mais escuro onde não há metalização da face do dispositivo, pois esta região é destinada à incidência de laser para estudos de danos de radiação.

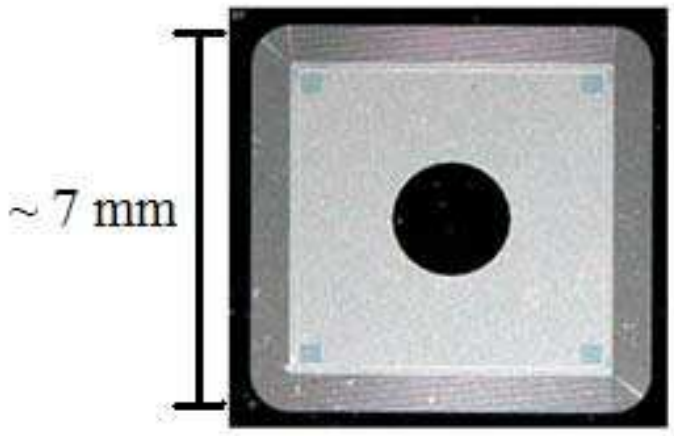

(a)

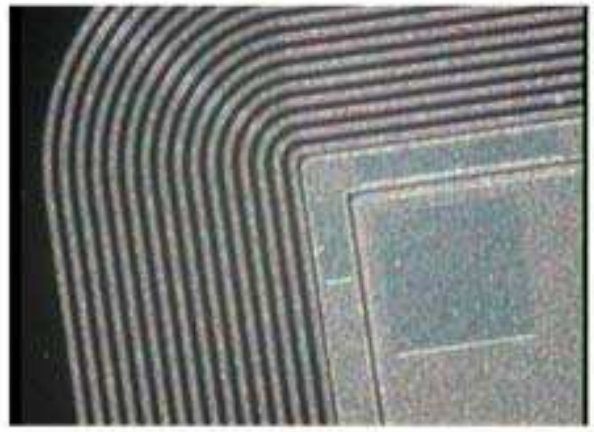

(b)

FIGURA 4.1 - (a) Fotografia da face frontal do diodo; (b) detalhamento do conjunto de 16 anéis de guarda e do pad de contato do eletrodo coletor de sinais do diodo.

As características dos diodos utilizados, como tensão de depleção total, corrente de fuga à tensão de depleção total e tipo do diodo, estão indicadas na TAB.4.1.

TABELA 4.1 - Características dos diodos.

\begin{tabular}{cccc}
\hline Diodo\#Amostra & $\mathbf{V}_{\text {depleção }}(\mathbf{V})$ & $\mathbf{I}_{\text {fuga }}(\mathbf{n A})$ & Tipo \\
\hline FZ\#67 & 25 & 7,0 & $\mathrm{n}$ \\
MCz\#26 & 350 & 0,4 & $\mathrm{n}$ \\
\hline
\end{tabular}


Os números atribuídos às amostras foram fornecidos pelo fabricante dos dispositivos e estão diretamente relacionados com a posição destas amostras na pastilha inicial de Si.

Os dispositivos foram fornecidos sem os terminais elétricos e por este motivo foi necessário o desenvolvimento de uma base para permitir a ligação dos eletrodos de polarização e extração de sinais. Esta base foi projetada e construída com o auxílio da equipe do Laboratório de Microeletrônica da Escola Politécnica da USP (LME/Poli-USP) dentro de um projeto de doutorado [24] concluído recentemente em nosso grupo e o processo básico de fabricação é descrito a seguir.

A confecção da base para montagem dos diodos foi realizada em lâminas de cerâmica (alumina) com dimensões de 1" x 1" e 0,7 mm de espessura. Estas lâminas passaram por um processo químico de limpeza (tricloro, acetona e álcool isopropanol) e em seguida foram metalizadas pelo processo de sputtering para a formação de um filme fino de níquel cromo para aderência da camada de ouro (2 a $3 \mu \mathrm{m})$ eletrodepositada (FIG.4.2a).

Para a confecção do layout de montagem do diodo, aplicou-se fotoresiste sobre a lâmina submetendo-a ao processo de fotogravação empregando o fotolito apresentado na FIG.4.2b. Posteriormente, as lâminas foram corroídas quimicamente (retirando toda metalização onde a luz incidiu), limpas e cortadas, formando a base para montagem dos diodos (FIG.4.2c).

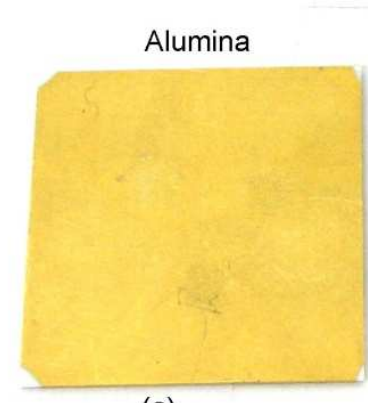

(a)

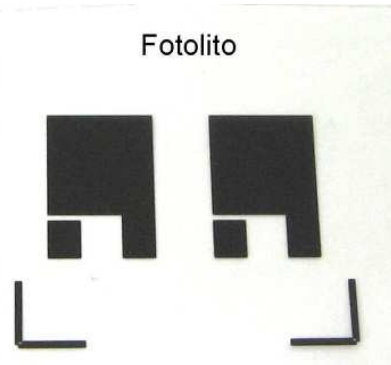

(b)

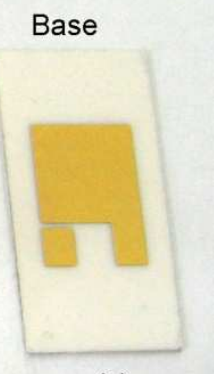

(c)

FIGURA 4.2 - (a) Lâmina de alumina com fina camada de ouro; (b) fotolito com layout (c) base para montagem dos diodos.

Os diodos foram fixados sobre as bases de alumina empregando-se uma substância auto-adesiva (epóxi condutora) para que o backplane (face $\mathrm{n}^{+}$) do diodo pudesse ser polarizado durante o procedimento de caracterização elétrica. A extração do sinal durante os processos de irradiação foi feita por meio de um eletrodo microsoldado na face 
$\mathrm{p}^{+}$. O processo de microsoldagem dos eletrodos dos dispositivos foi realizado no Centro de Tecnologia da Informação - Renato Archer em Campinas. Na FIG.4.3 é apresentada a fotografia de uma amostra montada na base de cerâmica evidenciando a região com a microsolda.

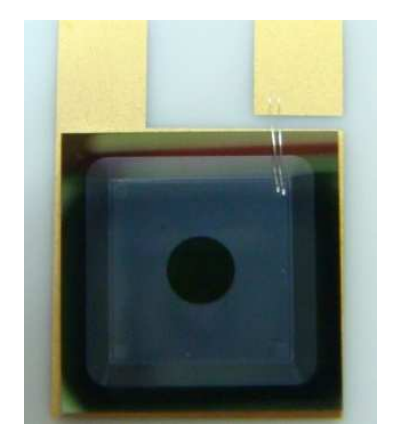

FIGURA 4.3 - Diodo montado na base de alumina.

Após a montagem na base de cerâmica, o diodo foi fixado em uma sonda acrílica preta projetada para possibilitar a extração de sinais, proteger o diodo contra a luz ambiente e fornecer ao aparato resistência mecânica. A extração do sinal foi realizada utilizando um conector do tipo LEMO $^{\circledR}$ de engate rápido permitindo independência da estrutura com relação ao cabo de ligação, evitando assim que a vibração sofrida pelo cabo fosse transmitida para o dispositivo e, eventualmente, rompesse as microsoldas. Além disso, após a montagem do diodo cobriu-se a sonda com uma fita plástica preta com aproximadamente $0,15 \mathrm{~mm}$ de espessura para uma melhor vedação contra luz. Na FIG.4.4 são apresentadas as fotografias da sonda descrita, sem a tampa e pronta para irradiação.

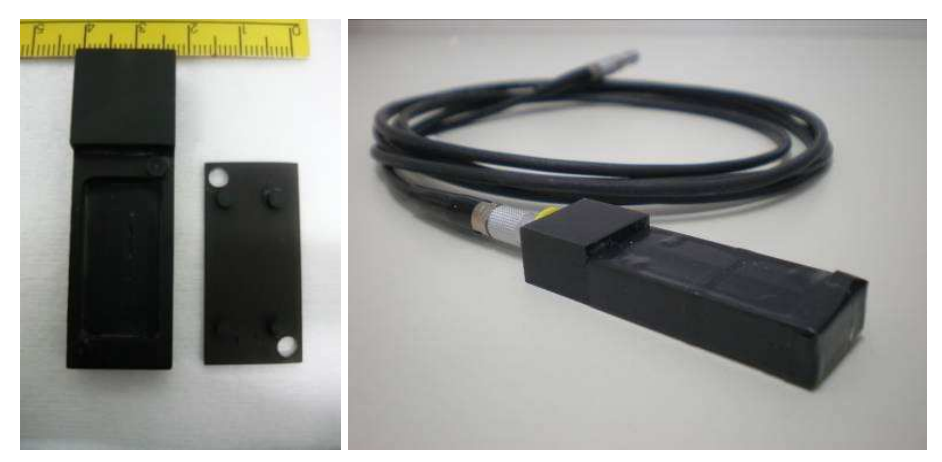

FIGURA 4.4 - Sonda dosimétrica.

O sistema de irradiação utilizado nas medidas foi o irradiador gama de ${ }^{60} \mathrm{Co}$, Gammacell 220, da Nordion, que possui uma câmara de irradiação com capacidade útil de 3,6 L e apresenta formato cilíndrico com 26 lápis constituídos individualmente por 7 pastilhas de ${ }^{60} \mathrm{Co}$. A taxa de dose no centro da câmara, de $4,03 \mathrm{kGy} / \mathrm{h}$, foi determinada por 
dosimetria Alanina em 01/11/2004, segundo o programa de certificação da Agência Internacional de Energia Atômica (IDAS-IAEA), com uma incerteza de 1,7 \%. Portanto, para cada medida foi necessário realizar a correção da taxa de dose pelo fator de decaimento da fonte, uma vez que o irradiador foi certificado em data diferente daquela em que se realizou a medida. Esta correção é habitualmente realizada mensalmente pelos responsáveis pela instalação irradiadora.

A sonda dosimétrica foi montada na posição central de um cilindro de isopor com dimensões praticamente iguais às da câmara de irradiação, a uma altura de $10 \mathrm{~cm}$ da base da câmara até o centro do diodo, para garantir o posicionamento da sonda na região do irradiador onde a taxa de dose é constante. Ao lado da sonda dosimétrica foi colocado um termopar do tipo $\mathrm{K}$, para monitorar a temperatura no início e fim do processo de irradiação. A fonte Gammacell e o aparato utilizado para a irradiação são mostrados respectivamente nas FIG.4.5a e 4.5b.

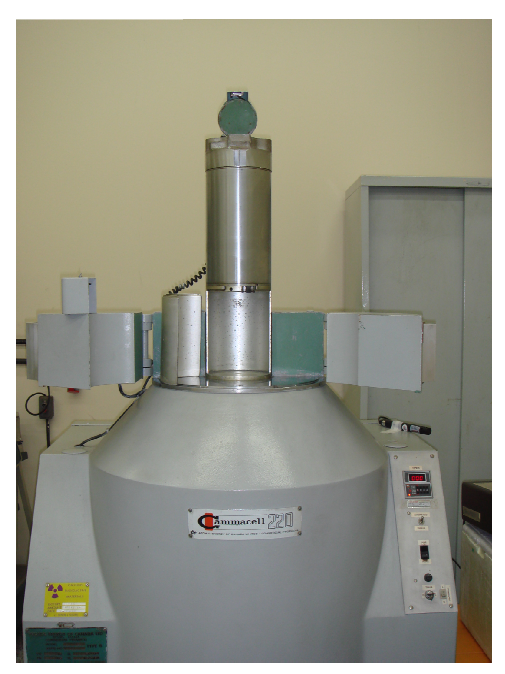

(a)

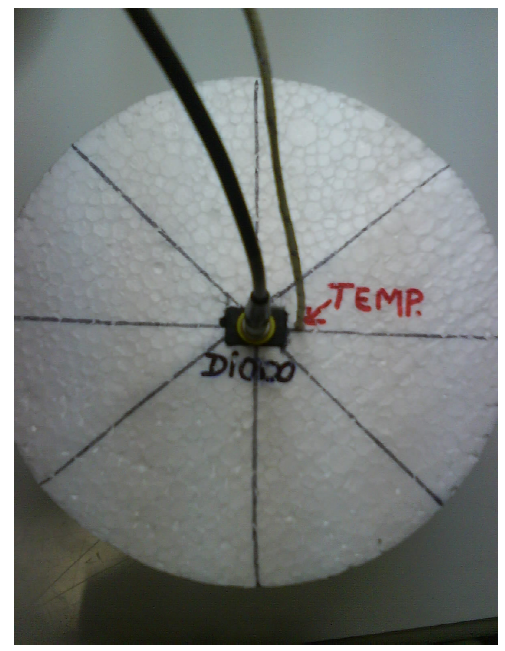

(b)

FIGURA 4.5 - (a) Irradiador Gammacell 220 - Nordion e (b) cilindro de isopor com sonda dosimétrica e termopar acoplados.

As fotocorrentes induzidas no diodo pela radiação gama durante a irradiação foram medidas pela sonda dosimétrica acoplada diretamente ao eletrômetro Keithley 617 operando no modo fotovoltaico (curto-circuito). As medidas da fotocorrente foram registradas em intervalos de tempo compatíveis aos limites de armazenagem de dados do eletrômetro utilizado.

A FIG.4.6 mostra a fotografia do aparato experimental utilizado nas medidas durante a irradiação dos diodos. 


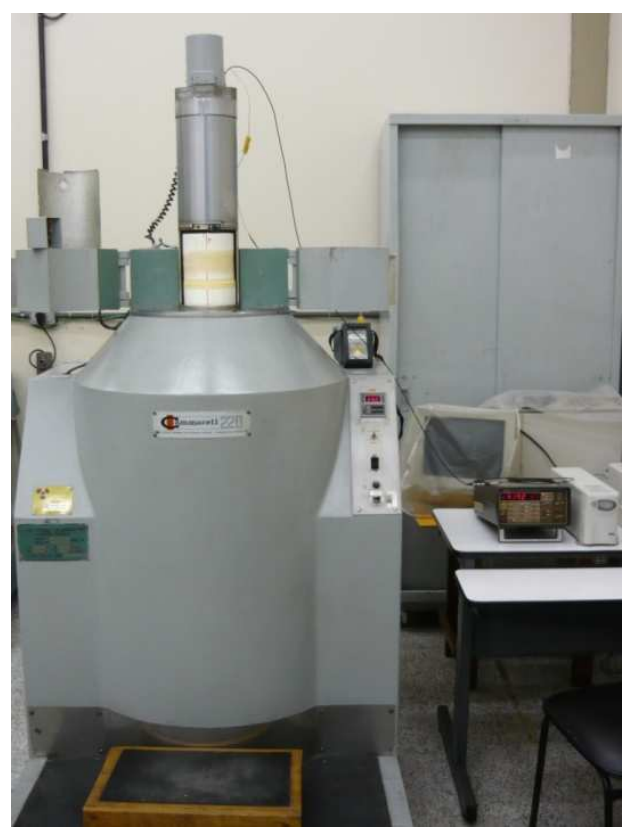

FIGURA 4.6 - Equipamentos empregados durante a irradiação para a obtenção das fotocorrentes.

Ambas as amostras (Fz\#67 e MCz\#26) foram irradiadas segundo o mesmo procedimento até uma dose de 873 kGy para a investigação da influência da pré-dose nestes dispositivos. Em seguida realizou-se um teste de repetitibilidade, irradiando as amostras consecutivamente treze vezes por um mesmo período de tempo (doses iguais) a fim de verificar a compatibilidade do valor do coeficiente de variação obtido com o estabelecido pelas normas vigentes [25].

Para a avaliação das alterações nas propriedades elétricas das amostras foi empregado um circuito projetado e construído com base no sistema de amplificação de sinais OPA656U [26] que permite a medida indireta de corrente reversa mediante um conversor tensão-corrente. Por meio da amplificação de um sinal proveniente de um oscilador externo, o circuito permite ainda a medida da capacitância dos diodos, uma vez que o ganho do amplificador é função da reatância capacitiva dos dispositivos [26]. Os valores de corrente de fuga foram obtidos a partir da relação ôhmica simples [26]:

$$
I_{f}=\frac{V_{D C}}{R}
$$

onde $V_{D C}$ e $R$ representam a tensão contínua medida e a resistência interna do circuito respectivamente.

Os valores de capacitância foram obtidos a partir da relação: 


$$
C=\frac{V_{A C}}{R \cdot 2 \cdot \pi \cdot f_{\text {in }} \cdot V_{\text {in }}}
$$

onde $V_{A C}, R, f_{i n}$ e $V_{i n}$ representam a amplitude do sinal na saída do circuito, a resistência interna do circuito, a frequêencia e amplitude do sinal injetado na entrada do circuito, respectivamente.

A injeção de um sinal alternado senoidal, com frequiência de aproximadamente $10 \mathrm{kHz}$, no circuito foi feita mediante a utilização do gerador de funções Minipa MFG4220. Para as medidas de tensão contínua utilizou-se o multímetro Keithley 2000, enquanto a polarização da amostra no circuito foi feita pela fonte de tensão Ortec 659. O osciloscópio Tektronix TDS3034 foi utilizado para monitorar as formas de onda na entrada e saída do circuito medidor.

A imagem do aparato experimental utilizado no processo de caracterização elétrica das amostras é mostrada na FIG.4.7.

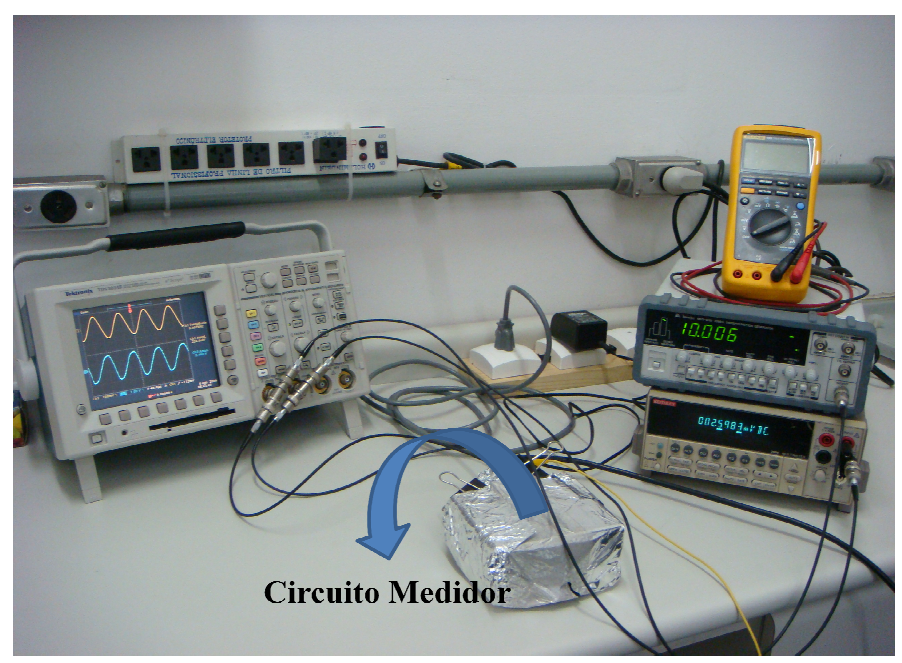

FIGURA 4.7 - Aparato experimental utilizado no processo de caracterização elétrica das amostras. 


\section{RESULTADOS EXPERIMENTAIS E ANÁLISES}

\subsection{Estudo dos Danos Induzidos pela Radiação - Caracterização Elétrica}

Após cada etapa de irradiação realizou-se a caracterização elétrica das amostras a fim de verificar possíveis alterações macroscópicas das características dos diodos devido à influência dos defeitos induzidos pela radiação em suas estruturas. As curvas I-V (corrente de fuga em função da tensão de polarização) são mostradas nas FIG.5.1.1 e 5.1.2 para as amostras Fz\#67 e MCz\#26, respectivamente. Todos os valores de corrente apresentados foram corrigidos para a temperatura de referência $\left(20^{\circ} \mathrm{C}\right)$ segundo as Eq.5.1.1 e 5.1.2 [27-28].

$$
\begin{gathered}
\frac{I_{20}}{I_{T}}=\left(\frac{293,2}{273,2+T}\right)^{2} \cdot e^{y} \\
y=\left[\frac{0,62}{k_{B}} \cdot\left(\frac{1}{273,2+T}-\frac{1}{293,2}\right)\right]
\end{gathered}
$$

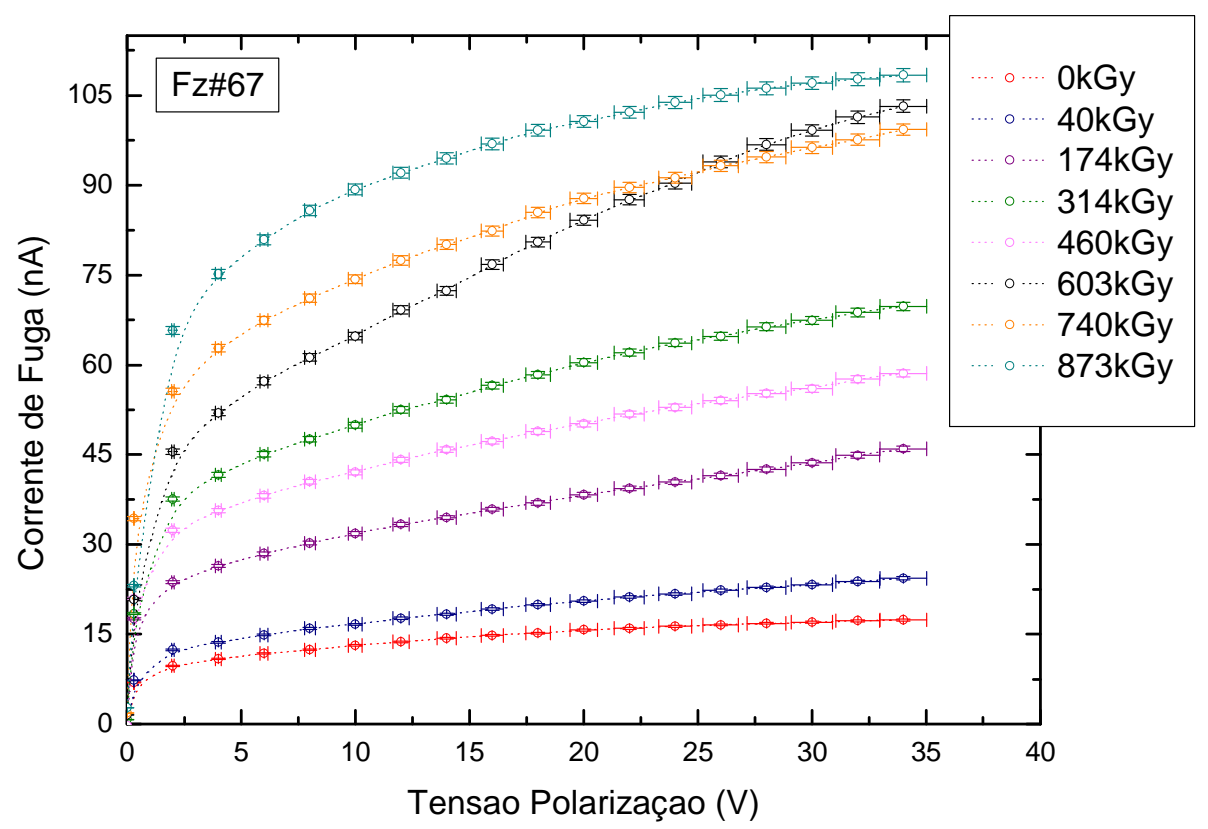

FIGURA 5.1.1 - Curvas I-V da amostra Fz\#67 para diferentes doses absorvidas. 


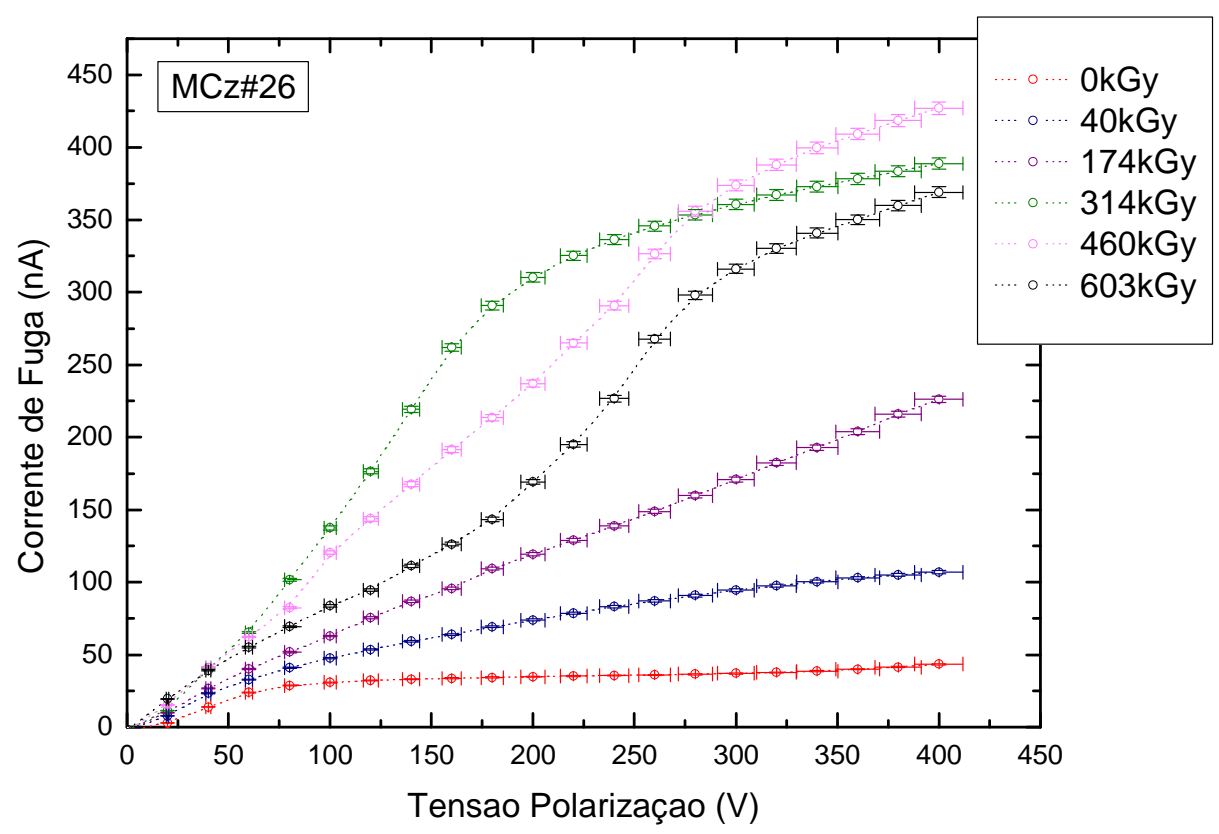

FIGURA 5.1.2 - Curvas I-V da amostra MCz\#26 para diferentes doses absorvidas.

Como mencionado anteriormente, os valores de corrente de fuga foram obtidos mediante a relação (Eq.4.1) entre os valores de tensão medidos e a resistência interna do circuito para cada valor de tensão de polarização reversa. Assim, as incertezas dos valores de corrente de fuga foram propagadas a partir das incertezas do multímetro digital, onde realizou-se a leitura da tensão, e da resistência interna do circuito [25]. As incertezas nos valores de tensão de polarização reversa foram obtidas a partir das incertezas associadas com a linearidade da fonte utilizada segundo o fabricante.

A primeira caracterização elétrica da amostra Fz\#67 foi realizada uma semana após sua irradiação e por este motivo, para padronização, os demais procedimentos também foram realizados neste intervalo de tempo, tendo-se mantidas as amostras sob temperatura ambiente.

Em geral, como observado nas FIG.5.1.1 e 5.1.2, a corrente de fuga dos diodos aumenta com o acúmulo de dose absorvida pelos dispositivos. Este efeito está relacionado com a quantidade de defeitos gerados na estrutura do cristal que permitem a emissão de elétrons e lacunas; contribuindo assim para o aumento da corrente de fuga do dispositivo.

Após acumular 603 kGy de dose, os contatos de ouro da amostra MCz\#26, eletrodepositados, começaram a evaporar durante os processos de soldagem do dispositivo à sonda. Este desgaste está relacionado à retirada e recolocação dos dispositivos na sonda 
dosimétrica a cada etapa de caracterização elétrica. Por esta razão, a amostra não foi mais caracterizada evitando assim um desgaste maior da estrutura.

O estudo dos danos de radiação na capacitância dos diodos em função da tensão de polarização também foi realizado após cada etapa de irradiação. As curvas da variação do inverso do quadrado da capacitância em função da tensão de polarização das amostras nas diferentes etapas de irradiaçao são mostradas nas FIG.5.1.3 e 5.1.4.

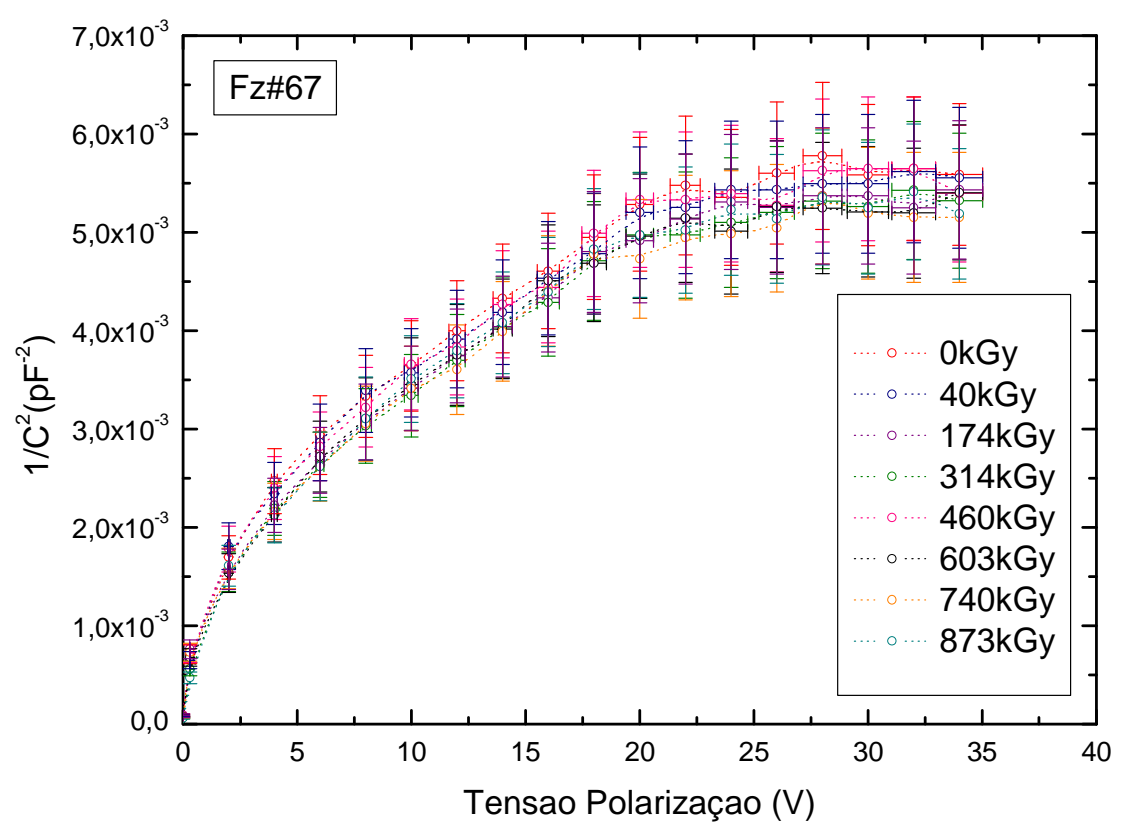

FIGURA 5.1.3 - Curva CV da amostra Fz\#67 para diferentes doses absorvidas.

As incertezas nos valores de capacitância foram obtidas mediante a propagação das incertezas correspondentes aos parâmetros utilizados no cálculo (Eq.4.2), fornecidas pelo fabricante de cada equipamento utilizado para as devidas medidas. 


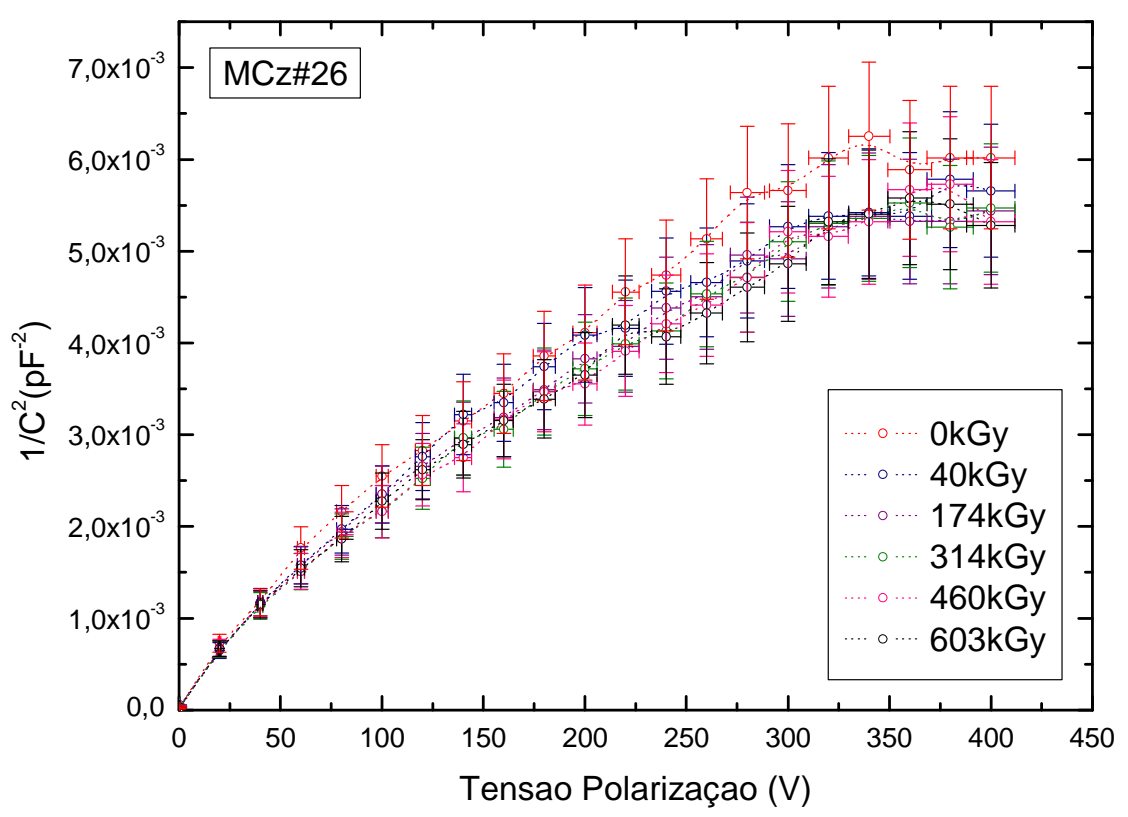

FIGURA 5.1.4 - Curva CV da amostra MCz\#26 para diferentes doses absorvidas.

A partir da análise das FIG.5.1.3 e 5.1.4 pode-se obter a tensão de depleção total das amostras [28-29], que é definida como a tensão mínima para o qual a capacitância assume valores constantes. Um dos possíveis efeitos macroscópicos dos danos induzidos pela radiação na estrutura de Si é a alteração da tensão de depleção total do dispositivo conduzindo ao fenômeno de inversão de tipo [1]. A fim de verificar se este efeito é observado nos casos em estudo, construiu-se as curvas da tensão de depleção total em função da dose acumulada para as amostras Fz\#67 e MCz\#26, representadas nas FIG.5.1.5 e 5.1.6 respectivamente. 


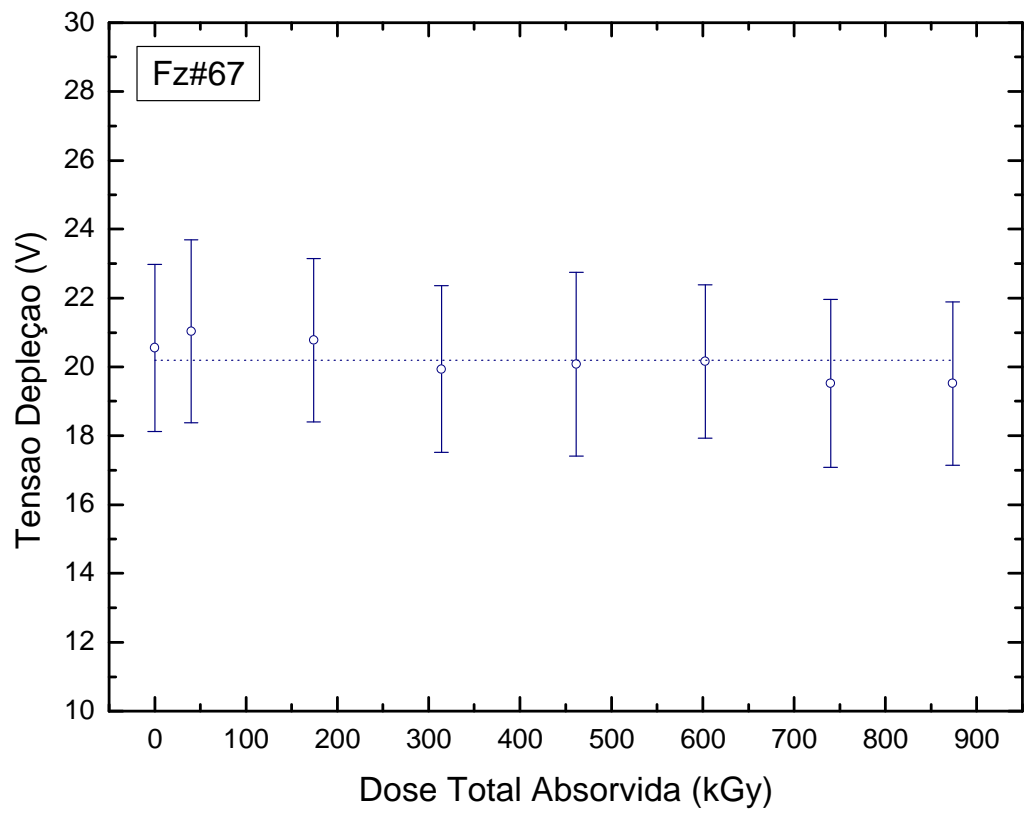

FIGURA 5.1.5 - Variação da Tensão de depleção total com a dose absorvida para a amostra Fz\#67.

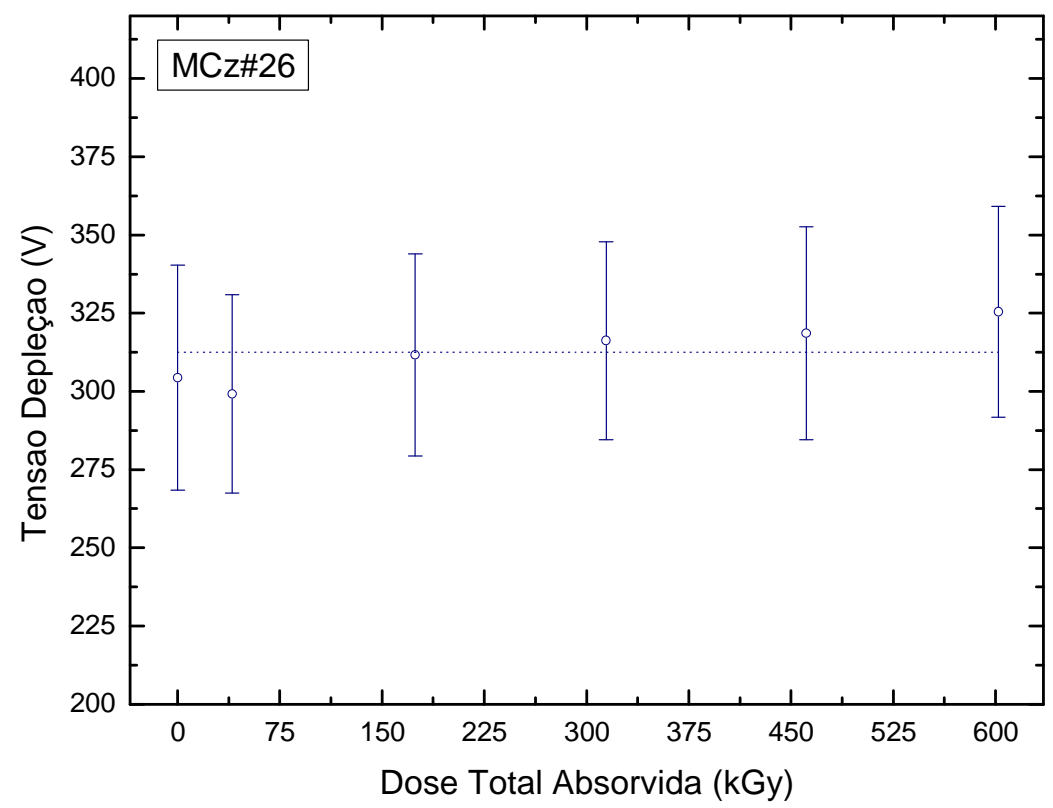

FIGURA 5.1.6 - Variação da Tensão de depleção total com a dose absorvida para a amostra MCz\#26.

As incertezas associadas aos valores de tensão de depleção total foram obtidas a partir da propagação das incertezas das retas ajustadas nas curvas de capacitância a fim de determinar o ponto a partir do qual os valores de capacitância permanecem praticamente constantes, como mencionado anteriormente neste trabalho. Os ajustes foram feitos com 
auxílio do programa gráfico utilizado (ORIGIN® Pro 8), e são apresentados, como exemplo, nas FIG.5.1.7 e 5.1.8 para as amostras Fz\#67 e MCz\#26 com relação aos dados referentes a caracterização anterior aos processos de irradiação.

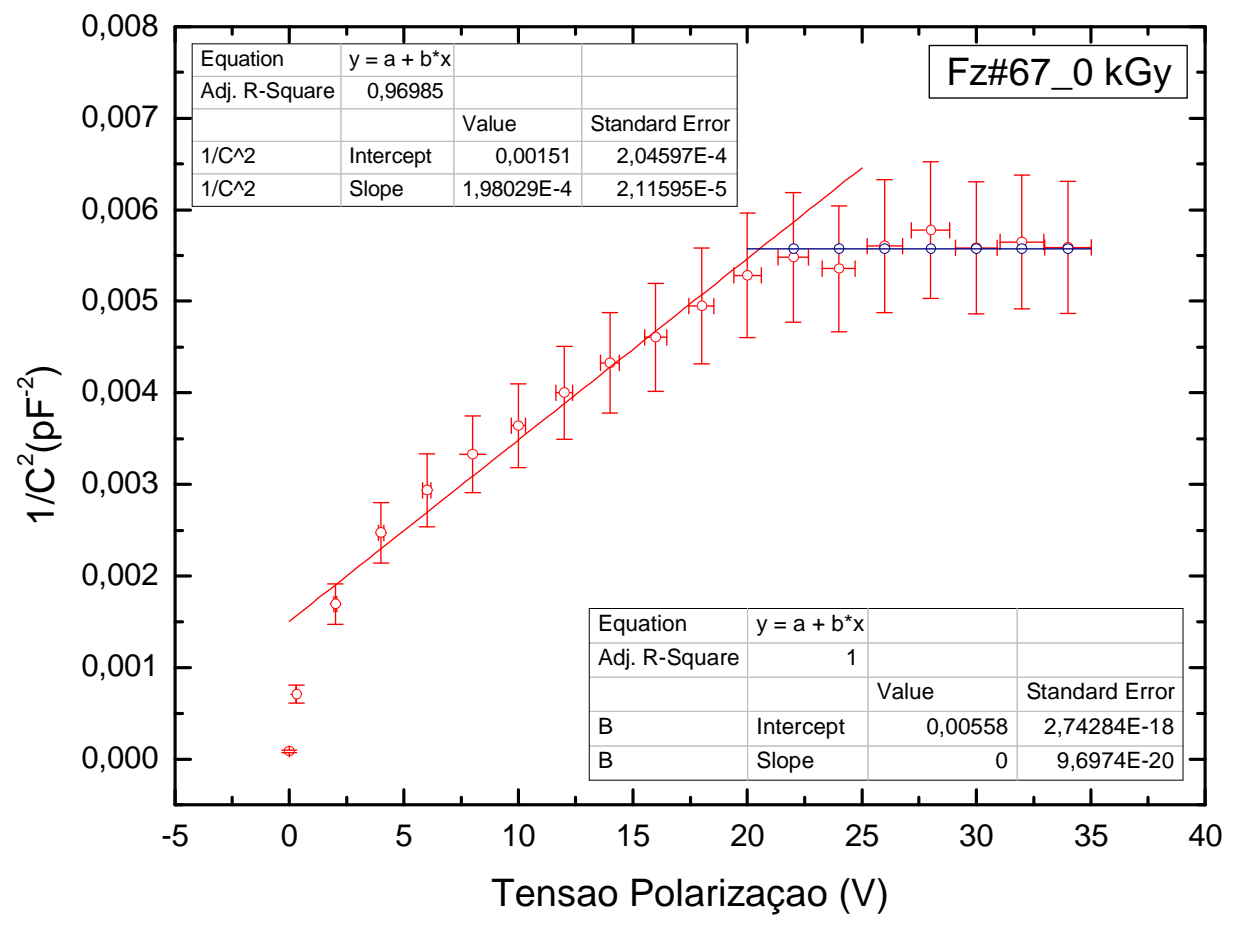

FIGURA 5.1.7 - Curva CV da amostra Fz\#67 obtida anteriormente aos processos de irradiação e os respectivos ajustes realizados pelo programa gráfico. 


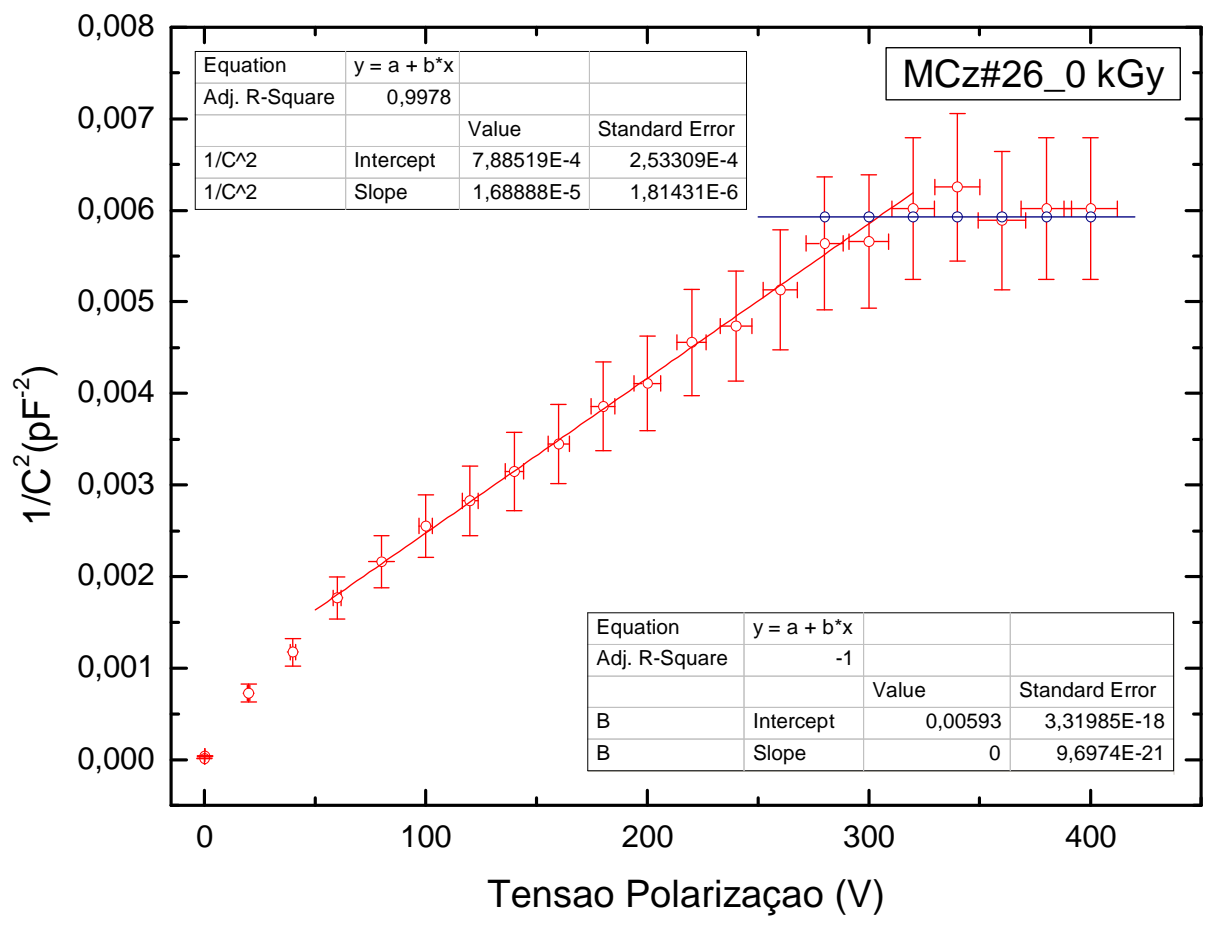

FIGURA 5.1.8 - Curva CV da amostra MCz\#26 obtida anteriormente aos processos de irradiação e os respectivos ajustes realizados pelo programa gráfico.

A análise das curvas apresentadas nas FIG.5.1.5 e 5.1.6 evidencia que as tensões de depleção total das amostras são praticamente constantes dentro do erro experimental e que, portanto, o fenômeno de inversão de tipo não ocorreu [30]. Este fato já era esperado visto que, em acordo com a literatura, existe um limiar de dose de 2 MGy para a ocorrência de inversão de tipo de diodo do tipo Fz [7] e nenhum limiar conhecido, dentro dos limites estudados, para o diodo do tipo MCz.

\subsection{Resposta dos Diodos como Dosímetros de Radiação}

As curvas das fotocorrentes em função do tempo obtidas durante o processo de pré-dose são mostradas nas FIG.5.2.1 e 5.2.2 para as amostras Fz\#67 e MCz\#26, respectivamente. A irradiação da amostra Fz\#67 foi realizada nos meses de maio $(2,18$ $\mathrm{kGy} / \mathrm{h})$, junho $(2,16 \mathrm{kGy} / \mathrm{h})$ e julho $(2,14 \mathrm{kGy} / \mathrm{h})$ sendo as fotocorrentes, mostradas na FIG. 5.2.1, corrigidas para o mês de maio. A irradiação da amostra $\mathrm{MCz}$ 26 foi realizada nos meses de julho $(2,14 \mathrm{kGy} / \mathrm{h})$ e agosto $(2,11 \mathrm{kGy} / \mathrm{h})$ sendo as fotocorrentes, mostradas na FIG.5.2.2, corrigidas para o mês de julho. 


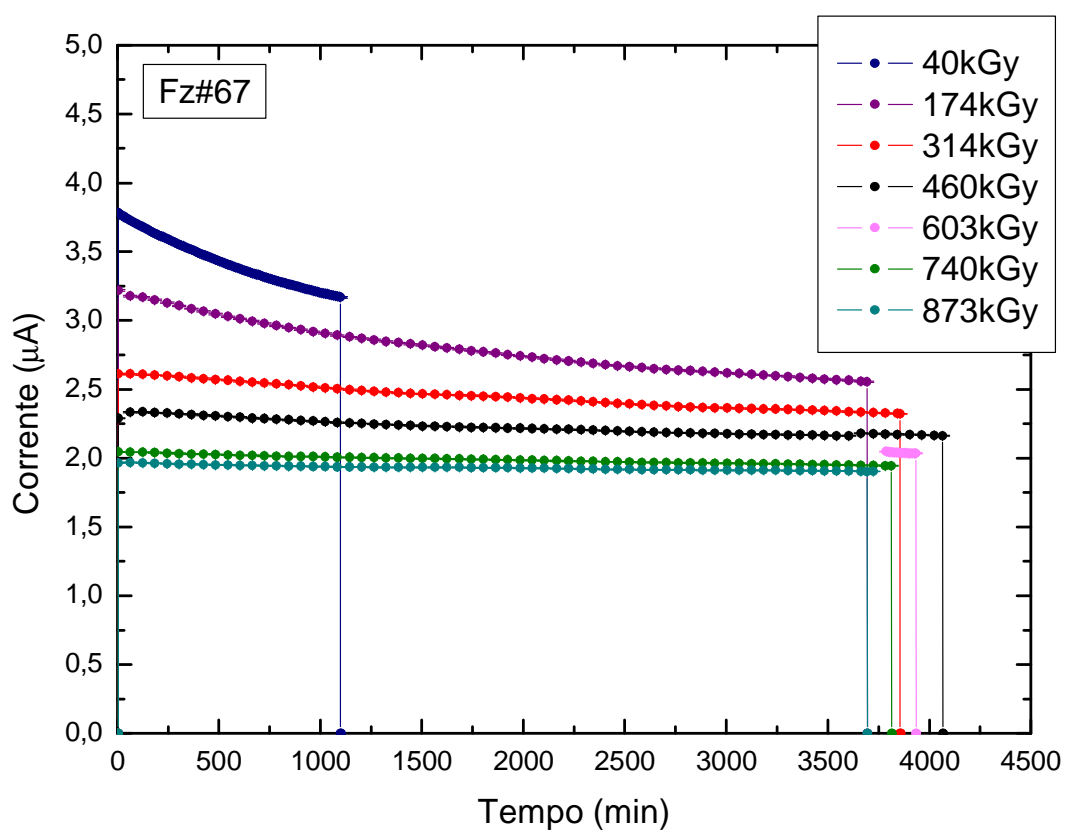

FIGURA 5.2.1 - Curva das fotocorrentes em função do tempo obtidas durante as etapas de pré-dose da amostra Fz\#67.

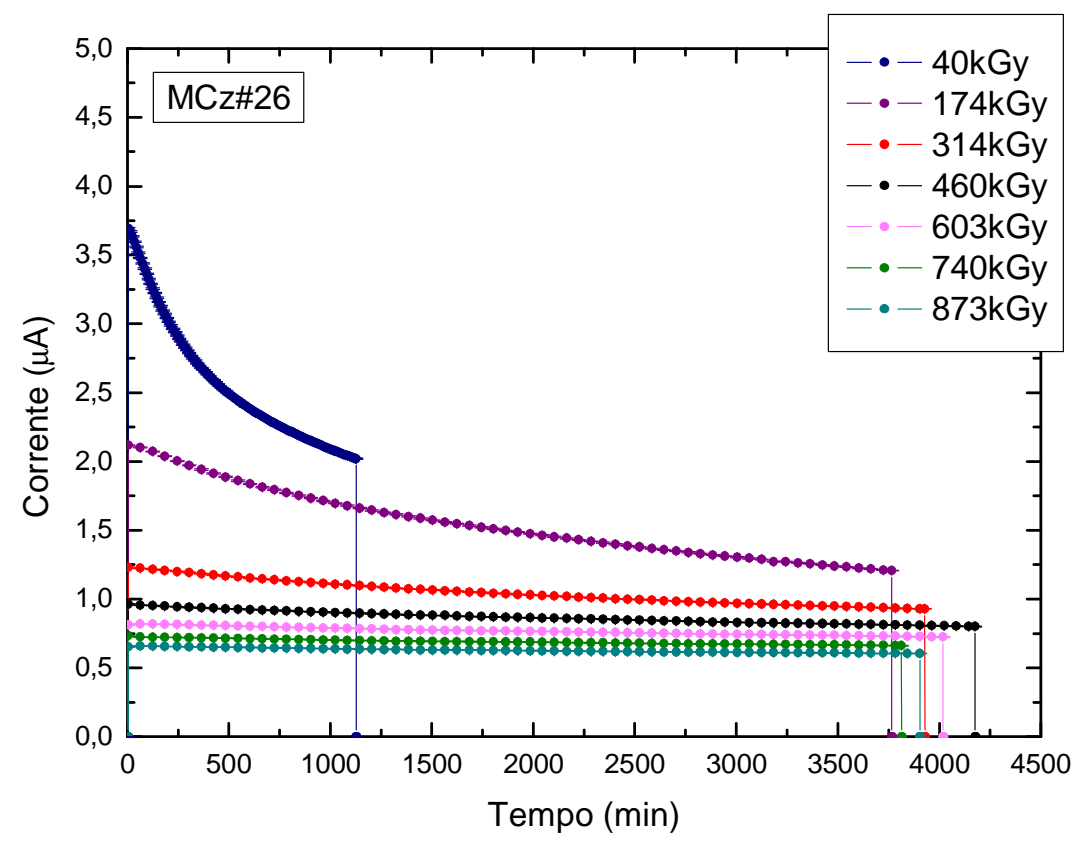

FIGURA 5.2.2 - Curva das fotocorrentes em função do tempo obtidas durante as etapas de pré-dose da amostra MCz\#26.

As incertezas associadas aos valores de fotocorrente foram obtidas mediante os dados do equipamento utilizado para as medidas, fornecidos pelo fabricante. 
Durante o processo de irradiação do diodo Fz\#67, onde o mesmo acumularia $603 \mathrm{kGy}$ de dose, houve um problema no fornecimento de energia elétrica e o nobreak ao qual o eletrômetro estava conectado não exerceu a função esperada. Consequentemente, os dados foram perdidos, sendo resgatados apenas aqueles referentes ao fim da irradiação.

A diminuição da fotocorrente com o aumento da dose absorvida é prevista, devido essencialmente à formação de centros de armadilhamento de cargas na região de carga espacial dos diodos. Estes centros podem capturar elétrons e/ou lacunas formados pela incidência da radiação, reduzindo a fotocorrente gerada. A formação de defeitos que agem como centros de armadilhamento, entretanto, tende a uma saturação e por este motivo espera-se uma estabilização dos valores de fotocorrente para um limiar de dose [1].

$\mathrm{Da}$ análise das curvas anteriores, é possível notar que a amostra MCz\#26 apresenta uma queda mais acentuada nos valores de fotocorrente quando comparada à amostra Fz\#67 essencialmente para as duas primeiras etapas de irradiação (40 kGy, 174 kGy). Para uma comparação mais efetiva entre as amostras os dados são apresentados em um mesmo gráfico, FIG.5.2.3, sendo as fotocorrentes corrigidas para a taxa de dose inicial das medidas $(2,18 \mathrm{kGy} / \mathrm{h})$ referente ao mês de maio.

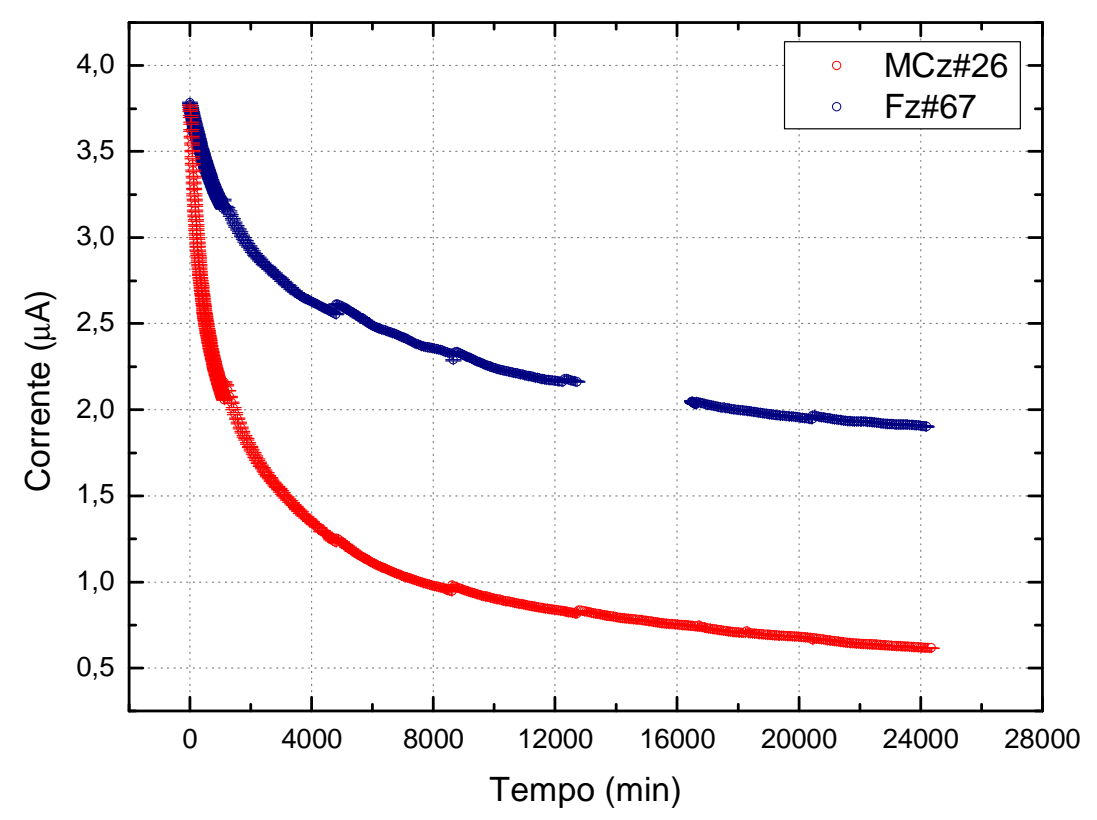

FIGURA 5.2.3 - Curva das fotocorrentes em função do tempo obtidas durante a pré irradiação das amostras Fz\#67 e MCz\#26. 
A partir da FIG.5.2.3 pode-se notar que, embora os diodos analisados sejam diferentes quanto as suas propriedades intrínsecas, ambos têm um valor inicial de fotocorrente coincidente. Como mencionado anteriormente e comprovado mediante a análise da FIG.5.2.3, a amostra MCz\#26 apresenta uma redução mais acentuada nos valores de fotocorrente quando comparada com a amostra Fz\#67.

Na FIG.5.2.4 são apresentadas as medidas normalizadas pelos valores iniciais de fotocorrente para os diodos Fz\#67 e MCz\#26.

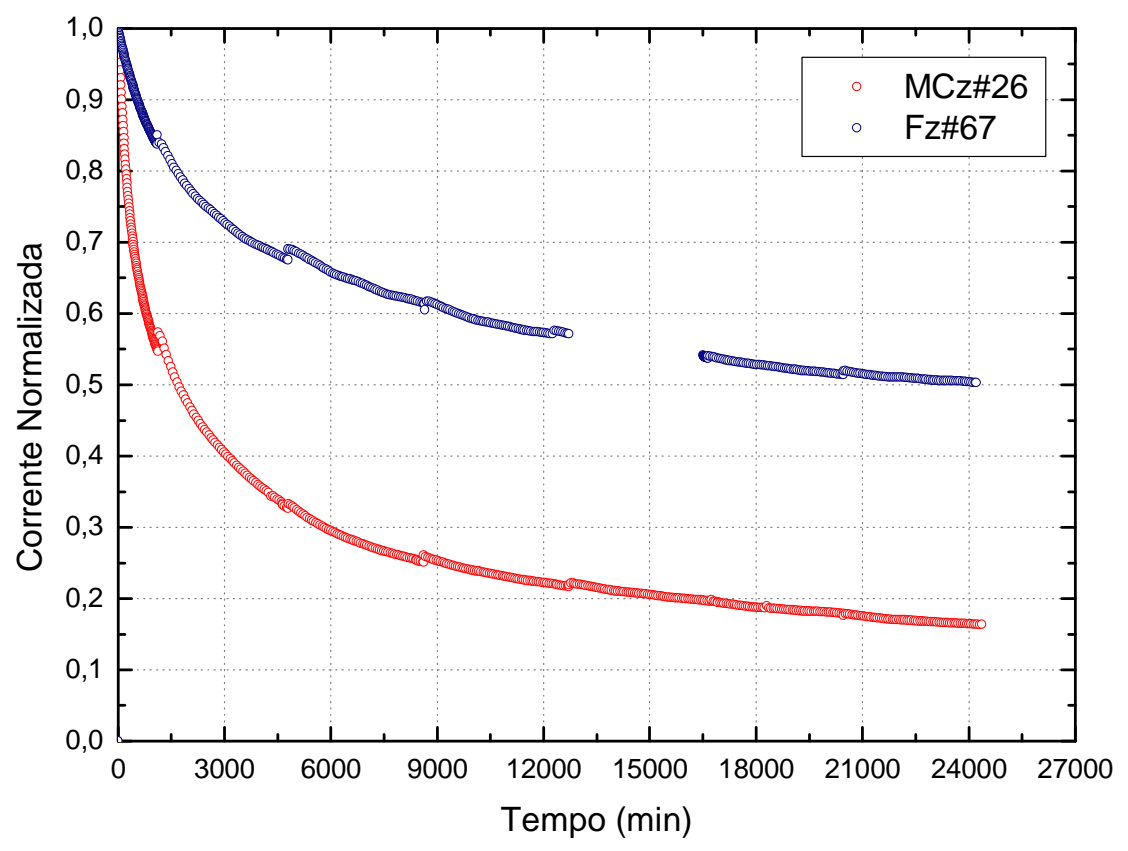

FIGURA 5.2.4 - Curva das fotocorrentes normalizadas em função do tempo obtidas durante a pré irradiação das amostras Fz\#67 e MCz\#26.

Em termos de estabilidade de resposta cabe ressaltar que para a última etapa de irradiação onde as amostras acumularam aproximadamente 873 kGy, a amostra MCz\#26 apresenta uma variação da fotocorrente igual a 8\% enquanto a amostra Fz\#67 apresenta variação de 3\%. Isto mostra que a amostra Fz\#67 é relativamente mais estável que a amostra MCz\#26 para os valores de dose acumulada mencionados.

A variação total das fotocorrentes, até o acúmulo de $873 \mathrm{kGy}$ de dose, foi de aproximadamente $84 \%$ para a amostra MCz\#26 e 50\% para a amostra Fz\#67, evidenciando novamente uma menor variação de sensibilidade de resposta para a amostra Fz\#67 quando comparada com a amostra MCz\#26. Além disto, uma vez que as fotocorrentes foram 
corrigidas para uma mesma taxa de dose pode-se afirmar que a amostra Fz\#67 apresentou uma diminuição mais tênue de sensibilidade quando comparada com a amostra MCz\#26.

Integrando-se as curvas de fotocorrente em função do tempo podem-se obter as cargas coletadas nos dispositivos em cada processo de irradiação. Assim, uma curva da carga acumulada à cada etapa de irradiação em função da dose, para cada uma das amostras estudadas, fornece a resposta acumulada dos diodos que é diretamente relacionada com os efeitos dos danos induzidos pela radiação em suas estruturas. As FIG.5.2.5 e 5.2.6 mostram as respostas dos diodos Fz\#67 e MCz\#26 mediante o registro da carga gerada em cada dispositivo em função da dose absorvida.

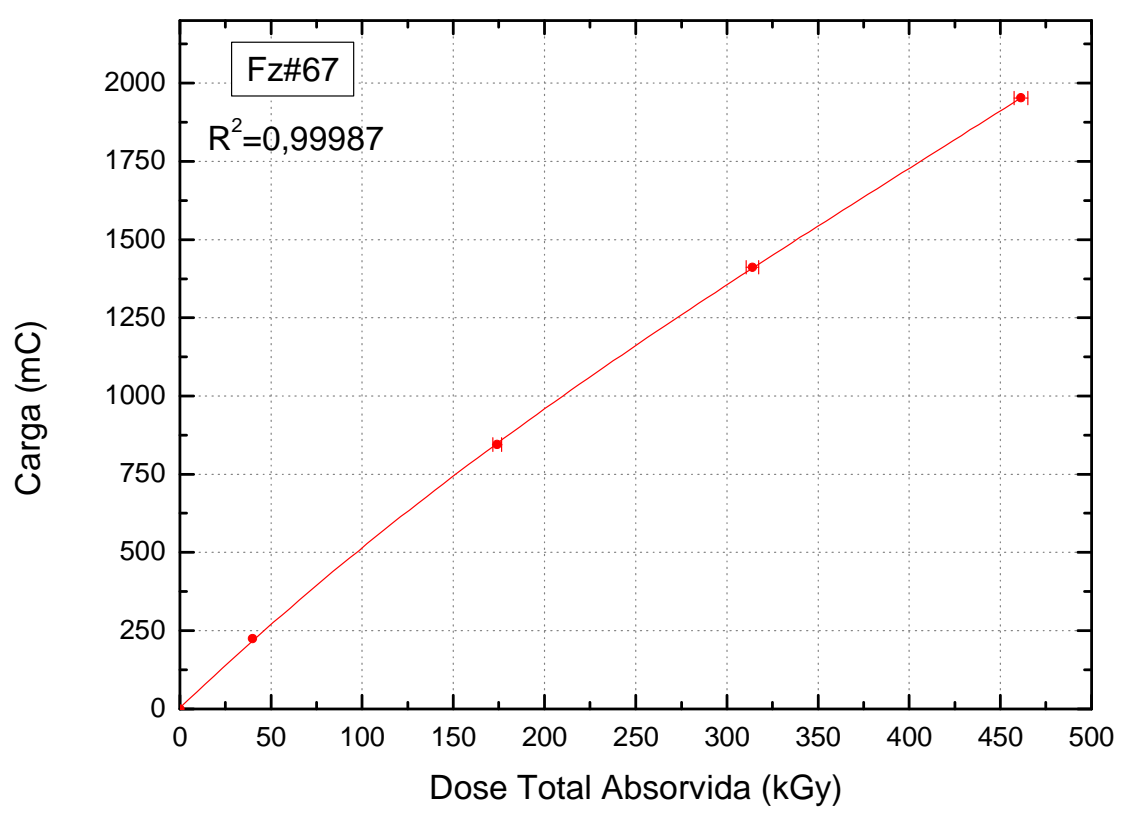

FIGURA 5.2.5 - Resposta em carga da amostra Fz\#67.

As incertezas associadas aos valores de dose foram obtidas a partir da incerteza na taxa de dose fornecida pela instalação irradiadora, 1,7\%, como mencionado anteriormente.

Devido ao problema com o fornecimento de energia e a perda dos dados da irradiação da amostra Fz\#67, como mencionado anteriormente, a resposta do diodo foi obtida somente até a dose total de $460 \mathrm{kGy}$.

Resultados anteriores obtidos em nosso grupo demonstraram que a resposta em carga do diodo não é linear com a dose, entretanto, não é conhecido o modelo desta 
resposta. Por este motivo ajustou-se uma função polinomial nos parâmetros de forma a obter o melhor valor de $\mathrm{R}^{2}$, levando-se em consideração os graus de liberdade disponíveis para o ajuste. Esta análise foi feita pelo programa gráfico utilizado (ORIGIN@ Pro 8) e resultou em ajustes polinomiais de grau três para a amostra Fz\#67 e grau seis para a amostra MCz\#26.

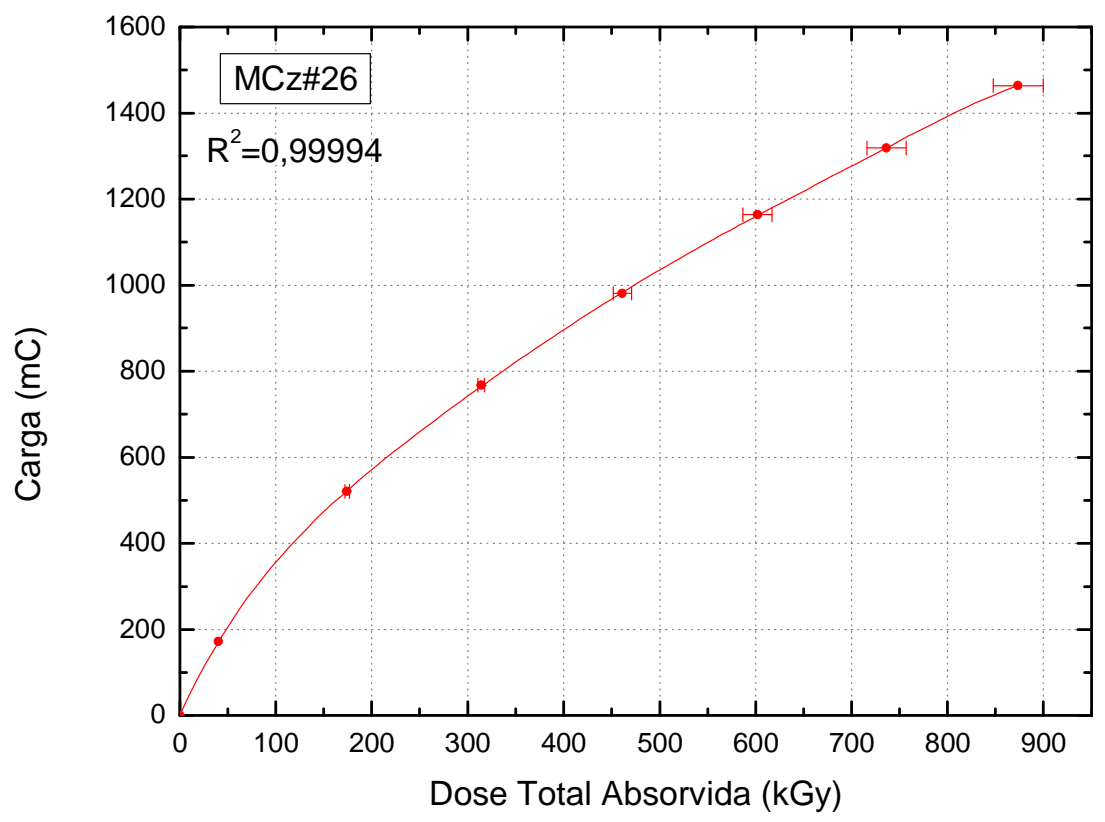

FIGURA 5.2.6 - Resposta em carga da amostra MCz\#26.

Para efeitos comparativos na FIG.5.2.7 são mostradas as curvas da carga em função da dose total absorvida para as amostras estudadas. 


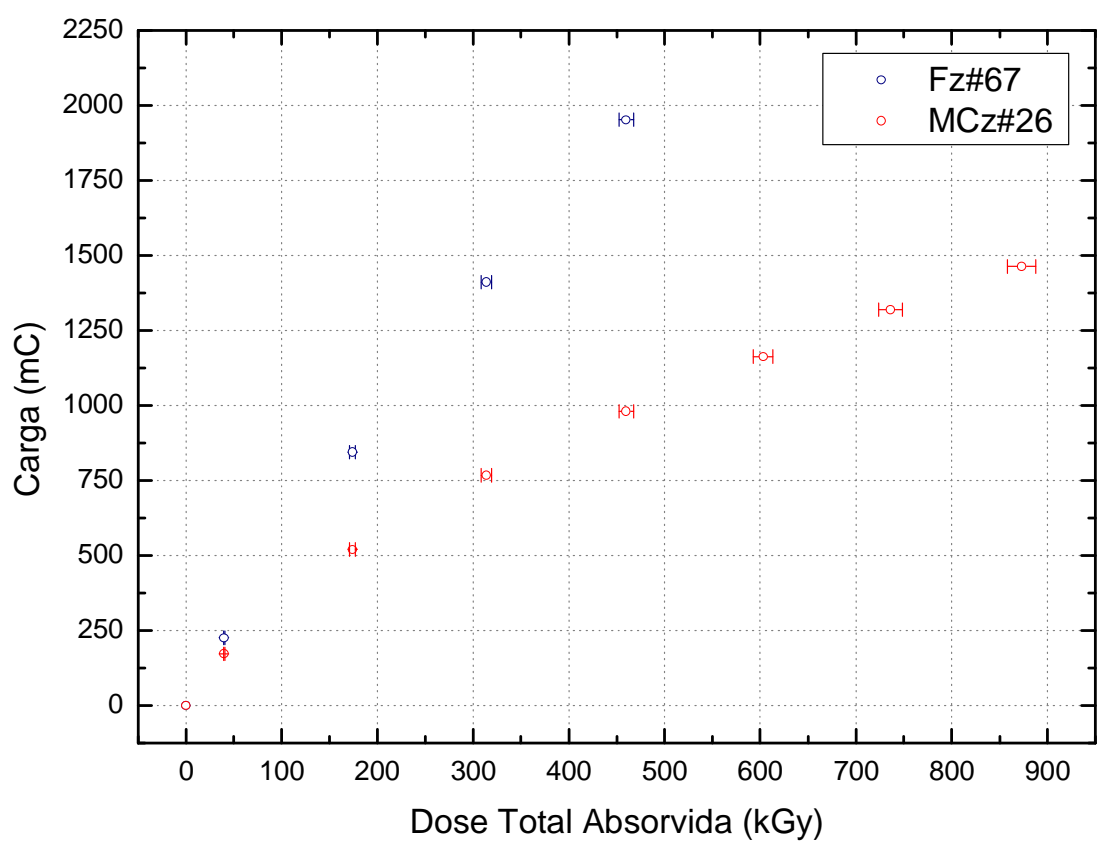

FIGURA 5.2.7 - Resposta em carga das amostras Fz\#67 e MCz\#26.

O comportamento das curvas apresentadas na FIG.5.2.7 evidencia mais uma vez a maior sensibilidade da amostra Fz\#67. Este fato pode ser explicado, entre outros fatores, pela menor resistividade do diodo Fz\#67 quando comparada àquela do dispositivo $\mathrm{MCz} \# 26$.

A fim de finalizar o estudo comparativo das amostras, estudou-se a repetitibilidade dos dispositivos. Os parâmetros de irradiação, tais como dose e número de repetições da medida foram escolhidos arbitrariamente de acordo com a disposição e agenda da instalação irradiadora, de forma que a dose recebida em cada uma das treze etapas fosse igual a $15 \mathrm{kGy}$. As fotocorrentes registradas em função do tempo para as etapas realizadas são mostradas nas FIG.5.2.8 e 5.2.9 para as amostras Fz\#67 e MCz\#26, respectivamente. 


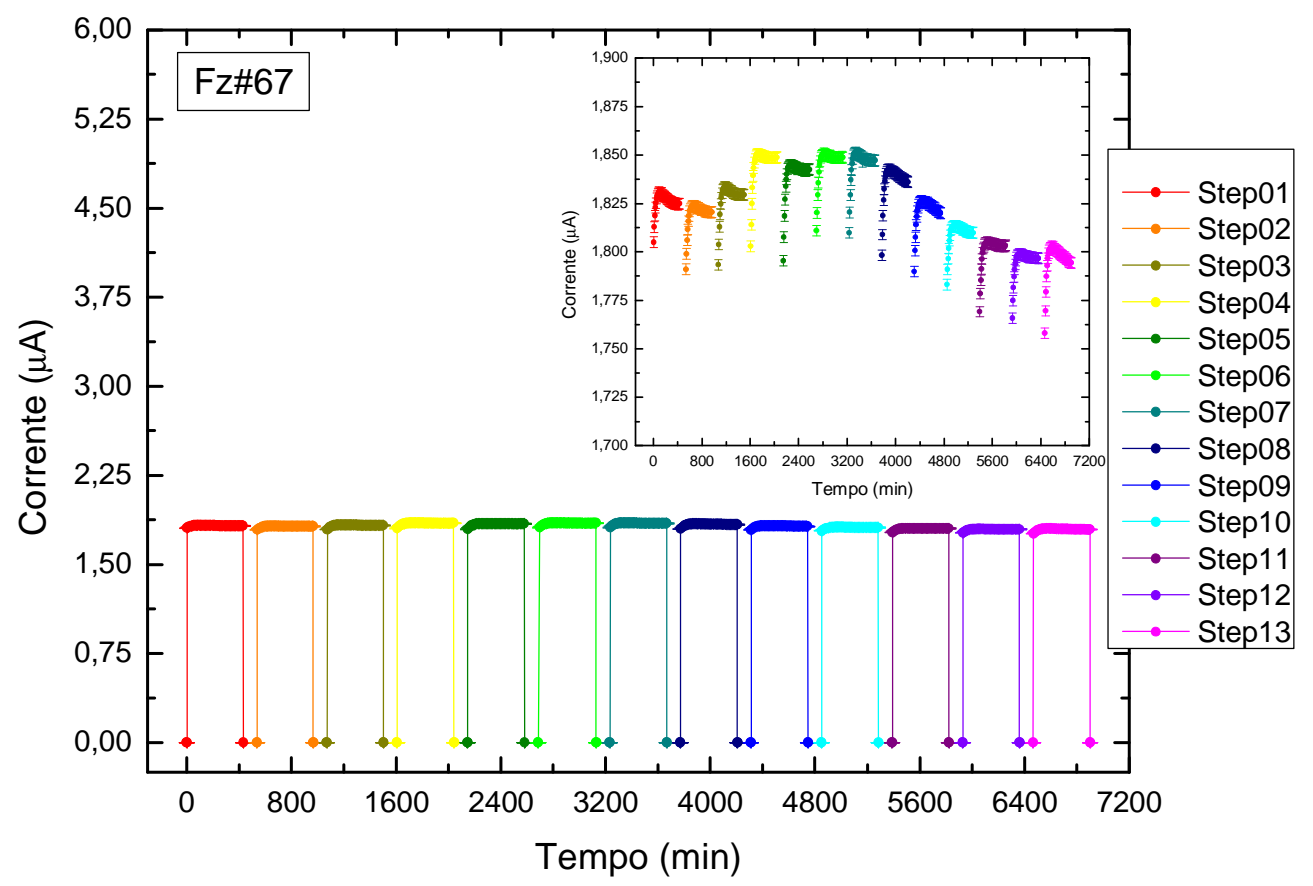

FIGURA 5.2.8 - Corrente em função do tempo para as etapas do teste de repetitibilidade da amostra Fz\#67 com destaque para a ampliação da região de patamar das fotocorrentes.

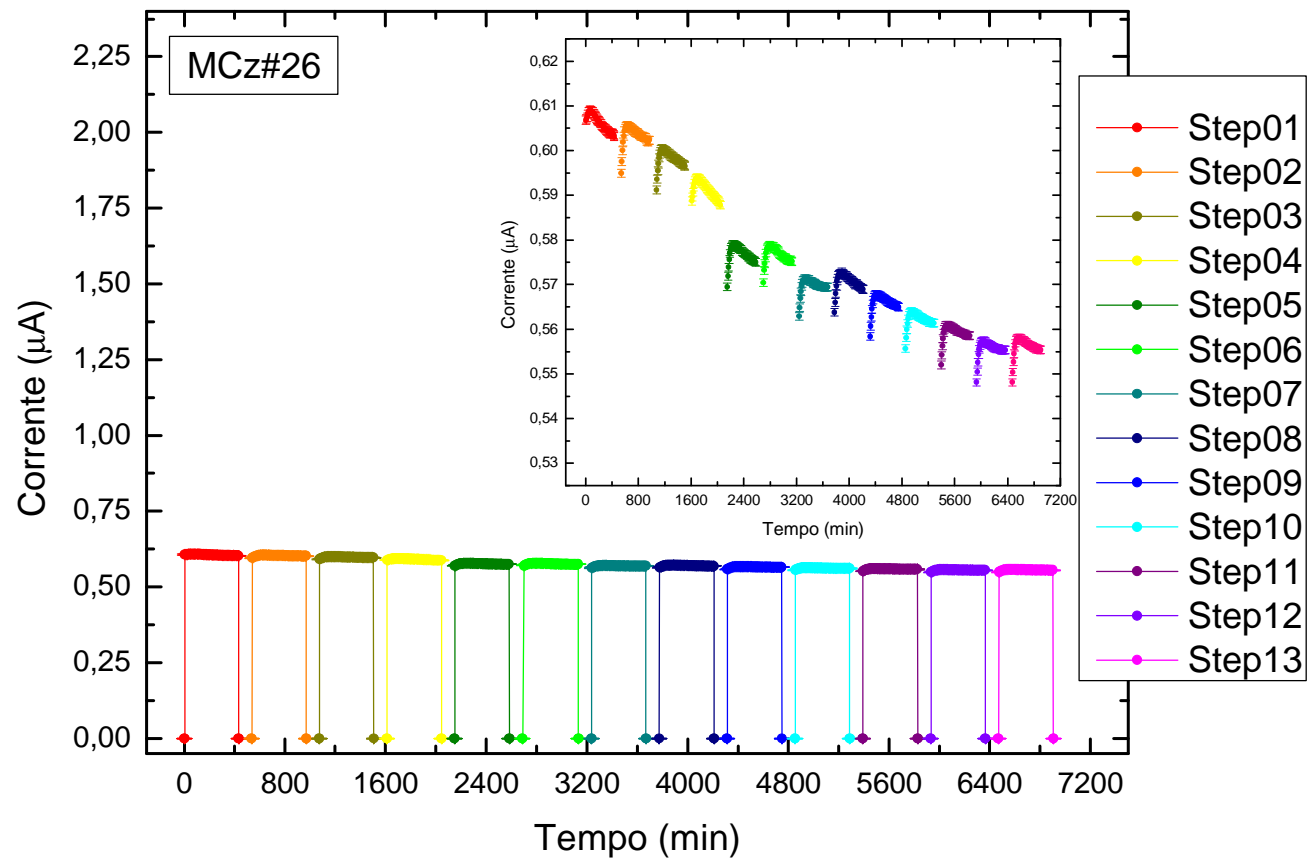

FIGURA 5.2.9 - Corrente em função do tempo para as etapas do teste de repetitibilidade da amostra MCz\#26 com destaque para a ampliação da região de patamar das fotocorrentes. 
Nas FIG.5.2.8 e 5.2.9 o espaçamento temporal entre as etapas de irradiação é somente ilustrativo. A corrente média obtida ao longo de todas as etapas foi de 1,82 $\mu \mathrm{A}$ para a amostra Fz\#67 e 0,58 $\mu \mathrm{A}$ para a amostra MCz\#26. A variação máxima obtida entre as fotocorrentes médias de cada etapa individual foi de 2,76\% para a amostra Fz\#67 e 8,31\% para a amostra MCz\#26. Nota-se a partir das FIG.5.2.8 e 5.2.9 que no início de cada etapa de irradiação a corrente aumenta com o tempo, por um período aproximadamente igual para cada etapa, atingindo então um valor estável. Este comportamento pode ser observado também nas etapas de pré irradiação da amostra sendo o fenômeno devido aos níveis de defeitos ativos à temperatura ambiente. Estes níveis podem capturar portadores de carga inicialmente gerados da interação da radiação com o diodo, e na situação onde estes níveis são totalmente preenchidos a fotocorrente atinge um valor estável [31].

A repetitibilidade da resposta em carga das amostras Fz\#67 e MCz\#26 podem ser observadas mediante as curvas da dose em função da carga obtida em cada etapa de irradiação. Estas curvas são mostradas nas FIG.5.2.10 e 5.2.11 para as amostras Fz\#67 e MCz\#26 respectivamente.

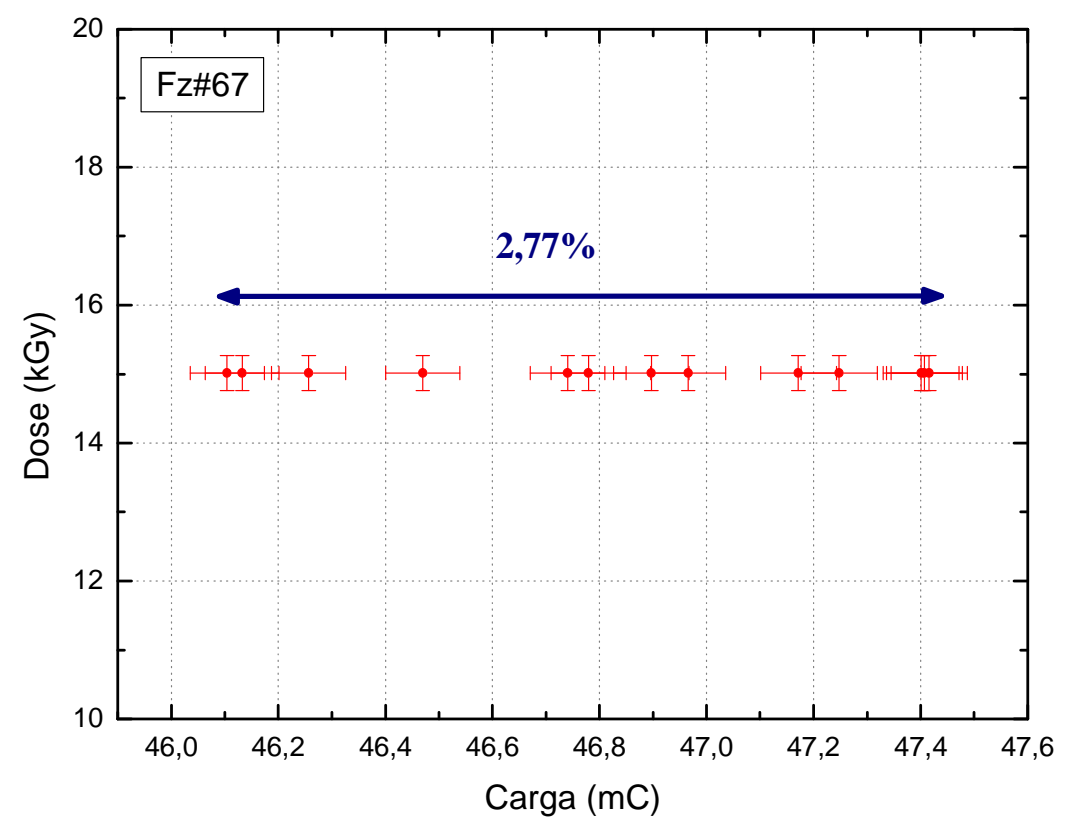

FIGURA 5.2.10 - Dose em função da carga obtida em cada etapa de irradiação da amostra Fz\#67. 


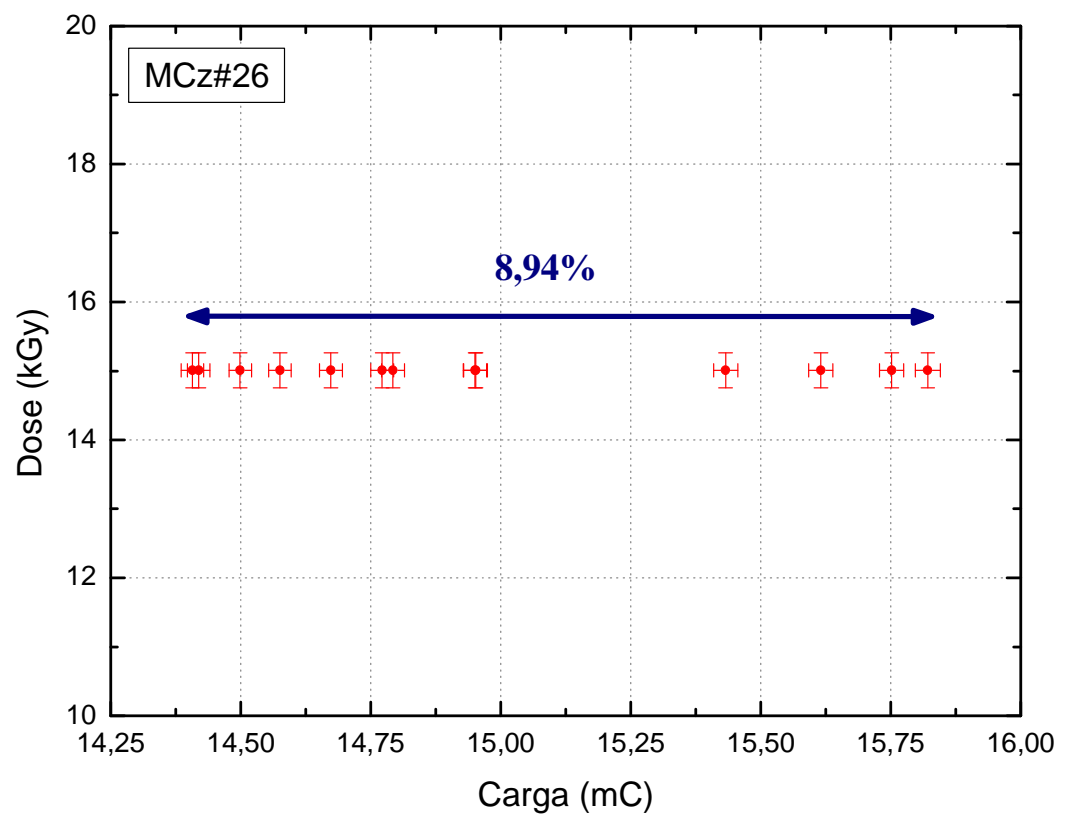

FIGURA 5.2.11 - Dose em função da carga obtida em cada etapa de irradiação da amostra MCz\#26.

Das FIG.5.2.10 e 5.2.11 é possível notar que a variação da carga ao longo das etapas de irradiação foi de 2,77\% para a amostra Fz\#67 e 8,94\% para a amostra MCz\#26. Os resultados do estudo da repetitibilidade das amostras também podem ser observados estatisticamente, mediante os histogramas mostrados nas FIG.5.2.12 e 5.2.13. 


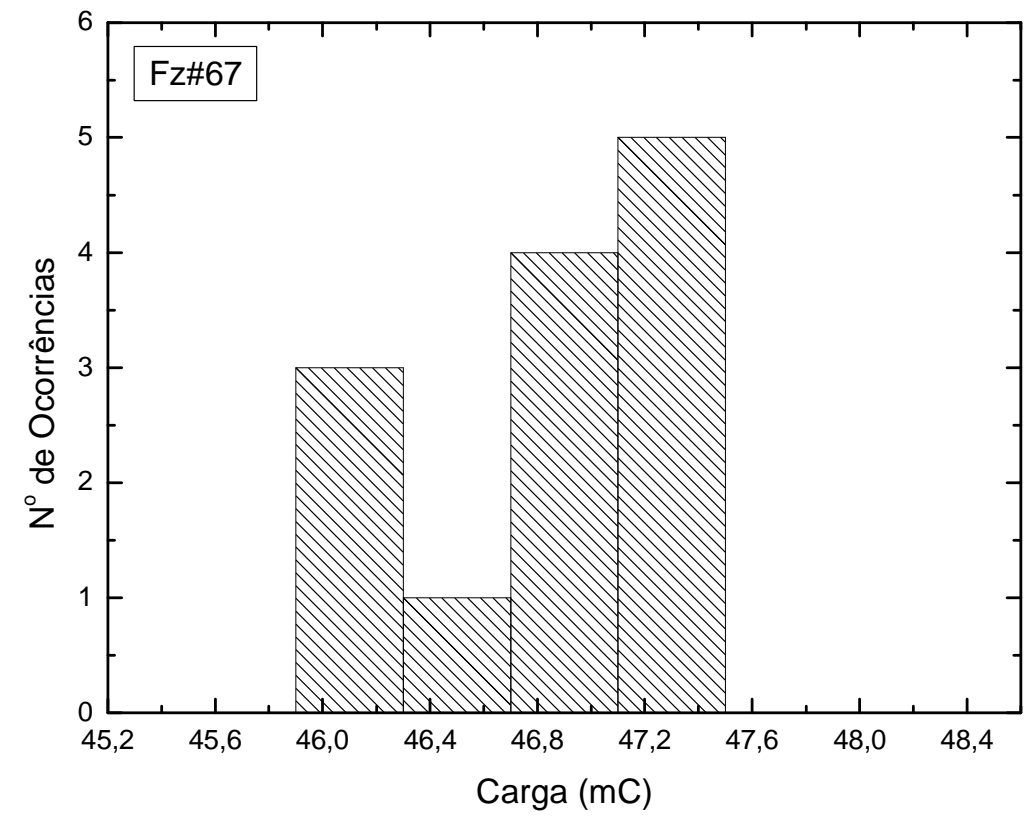

FIGURA 5.2.12 - Histograma das cargas obtidas nas etapas de irradiação do teste de repetitibilidade da amostra Fz\#67.

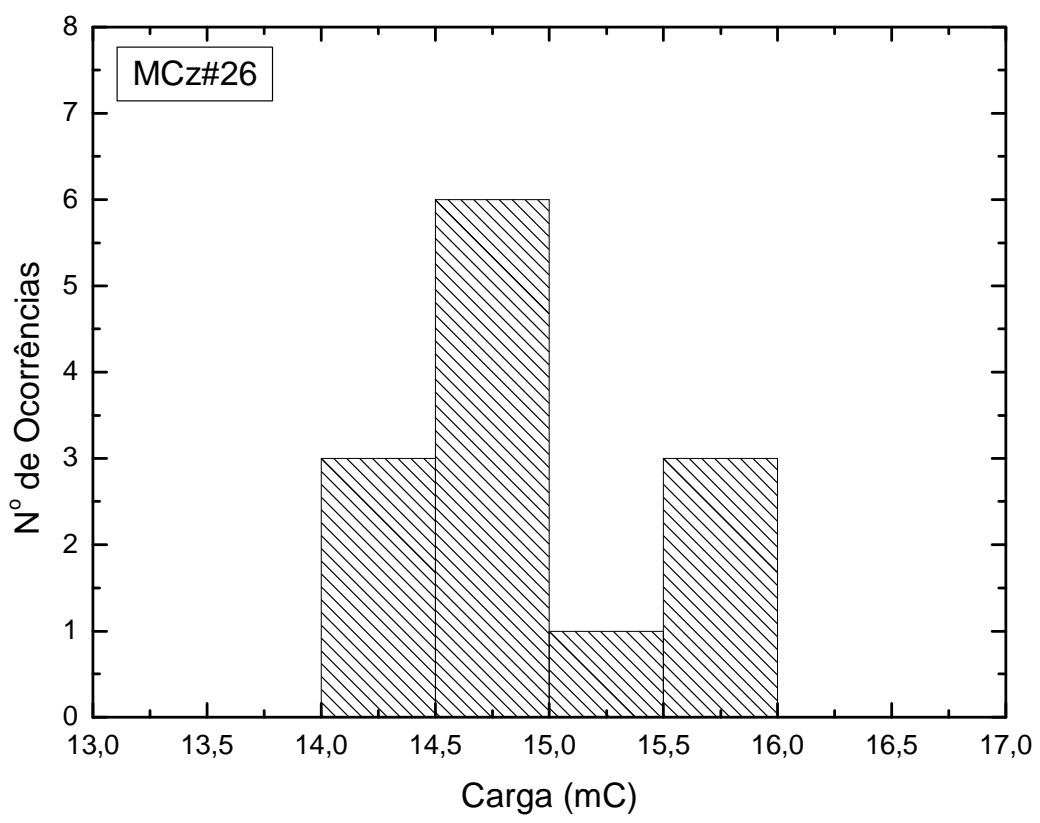

FIGURA 5.2.13 - Histograma das cargas obtidas nas etapas de irradiação do teste de repetitibilidade da amostra MCz\#26. 
A fim de avaliar a resposta das amostras em termos dosimétricos, calculou-se o coeficiente de variação (Eq.5.2.1 e 5.2.2) [32] dos dispositivos com relação as suas respostas em carga durante as treze etapas de irradiação.

$$
\begin{aligned}
C V \% & =\frac{S_{n-1}}{\bar{x}} \cdot 100 \\
S_{n-1}{ }^{2} & =\frac{\left(x_{i}-\bar{x}\right)^{2}}{n-1}
\end{aligned}
$$

O coeficiente de variação obtido foi de 1,03\% para a amostra Fz\#67, aproximadamente metade do valor sugerido [25] para os dosímetros de polimetilmetacrilato (PMMA), atualmente utilizados como dosímetros de rotina para processos de irradiação nas instalações em nosso centro de pesquisas (CTR - IPEN/CNEN - SP). Para a amostra MCz\#26 o coeficiente de variação obtido foi de 3,41\%, mostrandose superior ao valor recomendado para os dosímetros PMMA.

Com os resultados do estudo de repetitibilidade mostrando o bom desempenho das amostras utilizadas como dosímetros de radiação nas condições descritas neste trabalho, decidiu-se efetuar um último estudo comparativo, quanto à reprodutibilidade de resposta das amostras. Este estudo foi realizado irradiando-se as amostras com um total de dose de $195 \mathrm{kGy}$, equivalente ao total absorvido pelas amostras durante as etapas do estudo de repetitibilidade. As irradiações foram realizadas no mês de novembro, cuja taxa de dose era de 2,04 kGy/h para ambas as amostras. Os valores de fotocorrete em função do tempo de irradiação obtidos durante o processo são mostrados nas FIG.5.2.13 e 5.2.14 para as amostras Fz\#67 e MCz\#26, respectivamente. 


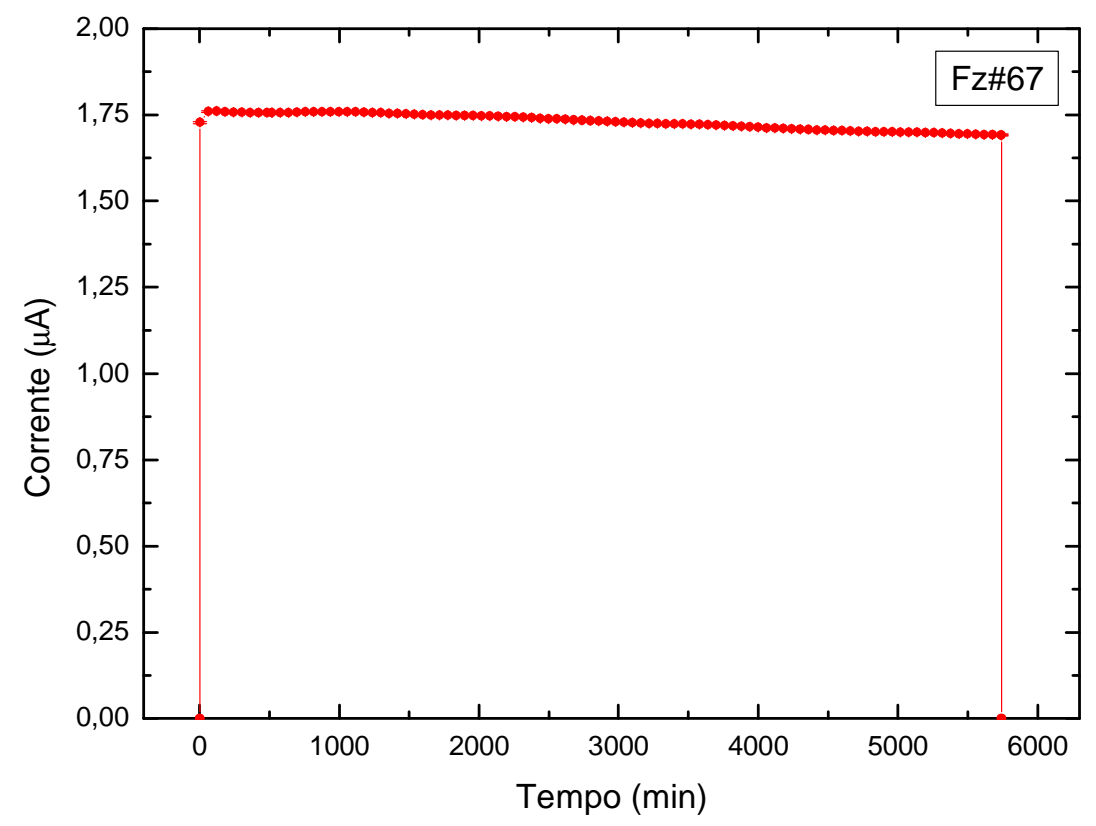

FIGURA 5.2.13 - Corrente em função do tempo obtida durante o estudo de reprodutibilidade da amostra Fz\#67.

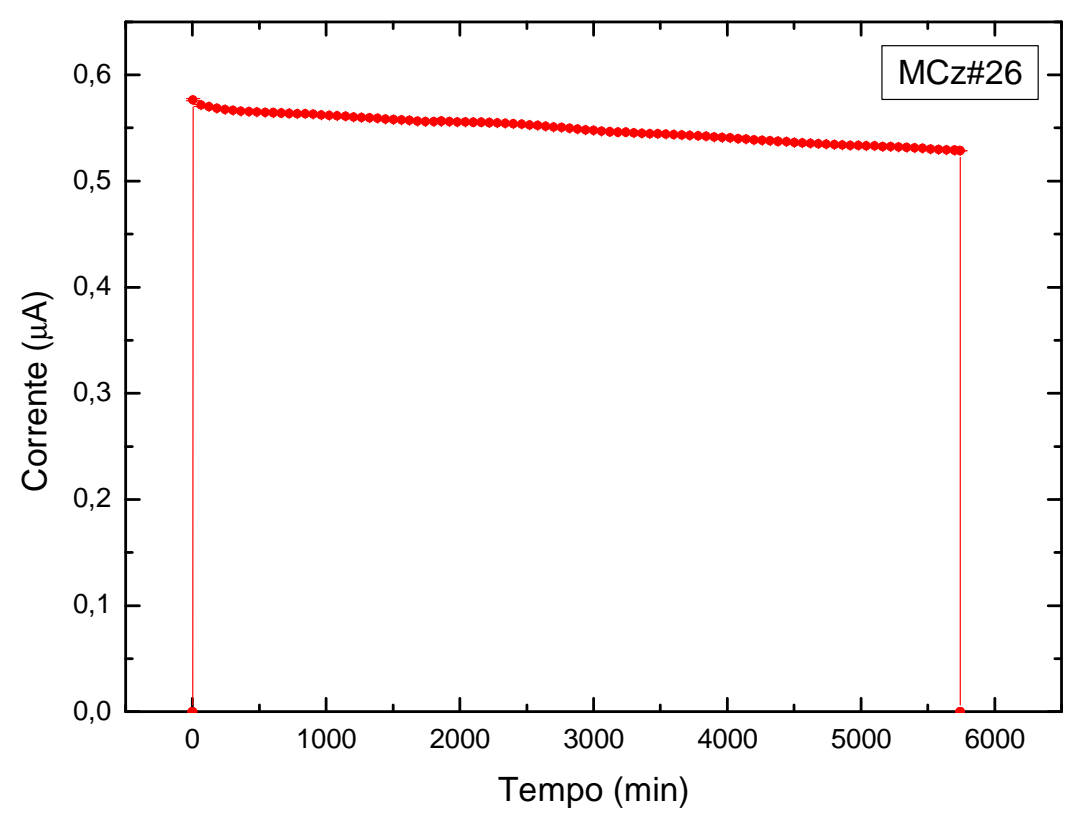

FIGURA 5.2.14 - Corrente em função do tempo obtida durante o estudo de reprodutibilidade da amostra MCz\#26.

A variação percentual dos valores de fotocorrente obtidos durante todo o processo de irradiação foi de 3,92\% e 8,29\% para as amostras Fz\#67 e MCz\#26 
respectivamente. Para a amostra Fz\#67 a carga obtida durante o processo de irradiação representado na FIG.5.2.13 foi de 595,49 mC enquanto que o mesmo parâmetro obtido ao longo das etapas de irradiação realizadas durante o estudo de repetitibilidade foi de 608,99 mC. O erro percentual entre estes valores foi de aproximadamente 2,21\%. Para a amostra MCz\#26 a carga obtida durante o processo de irradiação representado na FIG.5.2.14 foi de 188,93 mC enquanto que o mesmo parâmetro obtido ao longo das etapas de irradiação realizadas durante o estudo de repetitibilidade foi de 194,66 mC. O erro percentual entre estes valores foi de aproximadamente $2,94 \%$. Os valores dos erros percentuais obtidos para as duas amostras utilizadas mostram boa reprodutibilidade de suas respostas uma vez que as mesmas mostraram-se independentes do processo de irradiadiação e somente dependentes do valor da dose, $195 \mathrm{kGy}$. 


\section{CONCLUSÕES}

A análise dos dados obtidos, no tocante a monitoração da fotocorrente em função do tempo de irradiação, mostra uma queda de sensibilidade mais acentuada para o diodo $\mathrm{MCz}$ do que para o diodo Fz em intervalos iguais de dose absorvida.

A redução da fotocorrente com a irradiação evidencia a necessidade de uma pré-dose nestes dispositivos para que possam ser utilizados em dosimetria das radiações, reproduzindo respostas com variação dentro de limites aceitáveis.

Todavia, o estudo da tensão total de depleção das amostras como função da dose acumulada não revelou qualquer indício do fenômeno de inversão de tipo, sugerindo que, no tocante a esta alteração, o limite de utilização destes dispositivos sem que os danos induzidos pela radiação alterem sua resposta não foi atingido.

Com relação ao comportamento da corrente de fuga em função da tensão de polarização reversa para cada intervalo de dose estudado, os resultados mostram boa concordância com os dados bibliográficos existentes.

No tocante ao estudo de repetitibilidade das amostras, pode-se concluir que o diodo Fz\#67 apresenta uma resposta em carga bastante estável quando comparado aos dosímetros atualmente utilizados para a mesma finalidade. O coeficiente de variação obtido para a resposta em carga da amostra foi de 1,03\%. Entretanto, o mesmo estudo revelou um coeficiente de variação de $3,41 \%$, superior ao limite recomendado para os dosímetros PMMA, para a amostra MCz\#26, evidenciando novamente uma menor estabilidade de resposta quando comparada a amostra Fz\#67.

Quanto ao estudo de reprodutibilidade, pode-se concluir que ambas as amostras estudadas apresentam respostas em carga reprodutíveis, ou seja, dependentes somente da dose de radiação e independentes do método de irradiação. A variação percentual obtida quanto às respostas em carga devido a dois processos distintos onde as amostras absorveram um total de $195 \mathrm{kGy}$ de dose foi de 2,21\% e 2,94\% para as amostras Fz\#67 e MCz\#26, respectivamente. Os resultados revelam que a resposta em carga da amostra Fz\#67 é ligeiramente mais reprodutível que a resposta da amostra MCz\#26.

Este trabalho, aliado a todas as colaborações envolvidas, representa um avanço no campo da dosimetria de altas doses, pois, tem mostrado que os dispositivos semicondutores de Si podem ser aplicados a dosimetria de processos de irradiação em 
escala industrial com excelente reprodutibilidade e repetitibilidade de resposta permitindo ainda um monitoramento on-line dos processos, sendo tal aplicação, para o irradiador multipropósito do CTR (IPEN-CNEN/SP), inédita. 


\section{REFERÊNCIAS BIBLIOGRÁFICAS}

[1] LUTZ, G. Semiconductor Radiation Detectors. Springer, 1999.

[2] MOLL, M. Development of radiation hard sensors for very high luminosity colliders CERN-RD50 project. Nucl Instrum Meth A., v.511, p.97-105, 2003.

[3] MACEVOY, B.C.; HALL, G. Defect kinetics in novel detector materials. Mat Sci Semicon Proc., v.3, p.243-249, 2000.

[4] LI, Z.; DEZILLIE, B.; BRUZZI, M.; CHEN, W.; EREMIN, V.; VERBITSKAYA, E.; WEILHAMMER, P. HTLT oxygenated silicon detectors: radiation hardness and long-term stability. Nucl Instrum Meth A., v.461, p.126-132, 2001.

[5] DEZILLIE, B.; EREMIN, V.; Li, Z. Defect analysis of silicon detectors made of different materials for radiation hardness. Nucl Instrum Meth A., v.426, p.114-119, 1999.

[6] PINTILIE, I.; FRETWURST, E.; LINDSTRÖM, G.; STAHL, J. Results on defects induced by ${ }^{60} \mathrm{Co}$ gamma irradiation in standard and oxygen-enriched silicon. Nucl Instrum Meth A., v.514, p.18-24, 2003.

[7] FRETWURST, E.; LINDSTRÖM, G.; STAHL, J.; PINTILIE, I.; LI, Z.; KIERSTEAD, J.; VERBITSKAYA, E.; RÖDER, R. Bulk damage effects in standard and oxygenenriched silicon detectors induced by ${ }^{60} \mathrm{Co}$-gamma radiation. Nucl Instrum Meth A., v.514, p.1-8, 2003.

[8] BATES, A.; MOLL, M. A comparison between irradiated magnetic Czochralski and float zone silicon detectors using the transient current technique. Nucl Instrum Meth A., v.555, p.113-124, 2005.

[9] MOLL, M.; FRETWURST, E.; LINDSTRÖM, G. Investigation on the improved radiation hardness of silicon detectors with high oxygen concentration - CERN Project RD48 (The ROSE Collaboration). Nucl Instrum Meth A., v.439, p.282-292, 2000.

[10] XIE, X. B.; CHO, H. S.; LIANG, G. W.; HUANG, W.; LI, Z.; CHIEN, C. Y. Electrical characterization of a radiation-hardened silicon pixel design for CMS. $\mathbf{N u c l}$ Instrum Meth A., v.476, p.665-669, 2002.

[11] SWART, J.W. Materiais Elétricos. (apostila).

[12] MOLL, M. Radiation Damage in Silicon Particle Detectors. 1999. Tese (Doutorado) - Universität Hamburg, Hamburg.

[13] HURLE, D.T.J.; COCKAYNE, B. Czochralski growth. In: Handbook of Crystal Growth 2 - Part A: Basic Techniques. North-Holland, 1994. p. 99-212.

[14] BOHM, J.; LÜDGE, A.; SCHRÖDER, W. Crystal growth by floating zone melting. In: Handbook of Crystal Growth 2 - Part A: Basic Techniques. North-Holland, 1994. p. 99-212.

[15] SZE, S.M. Semiconductor Devices Physics and Tecnology. New York, N.Y.:John Willey \& Sons, 1985.

[16] STREETMAN, B.G. Solid State Eletronic Devices. 4.ed. New Jersey: Pretince Hall, 1995.

[17] REZENDE, Sérgio M. Materiais e Dispositivos Eletrônicos. 2a ed. São Paulo, SP: Editora Livraria da Física, 2004.

[18] COLInGE, J.P.; COLINGE, C.A. Physics of Semiconductor Devices. Kluwer Academic Publishers, 2002.

[19] DIXON, R.; EXTRAND, K. Silicon Diode Dosimetry. Int J Appl Radiat Isot., v.33, p. 1171-1176, 1982. 
[20] BARTHE, J. Electronic dosimeters based on solid state detectors. Nucl Instrum Meth B., v.184, p.158-189, 2001.

[21] RIKNER, G.; GRUSELL, E. General specifications for silicon semiconductors for use in radiation dosimetry. Phys $\mathbf{M e d}$ Biol., v.32, n.9, p.1109-1117, 1987.

[22] LINDSTRÖM, G. Radiation damage in silicon detectors. Nucl Instrum Meth A., v.4512, p.30-43, 2003.

[23] PINTILIE, I.; LINDSTROEM, G.; JUNKES, A.; FRETWURST, E. Radiationinduced point- and cluster-related defects with strong impact on damage properties pf silicon detectors. Nucl Instrum Meth A., v.611, p.52-68, 2009.

[24] CAMARgO, F. Desenvolvimento de Dosímetros com Diodos de Si Resistentes à Radiaçõa para Dosimetria de Altas Doses. 2009. Tese (Doutorado) - Universidade de São Paulo, São Paulo.

[25] ISO/ASTM 51276. Standard practice for use of a polymethylmethacrylate dosimetry system., 2002.

[26] NASCIMENTO, J. S. Development of a semiconductor parameter analyser. Private Communication.

[27] RD50 Technical Note 2003/03 - Version 5/15.10.04.

[28] PELlEGRINI, G.; Ullán, M.; RAFÍ, J. M.; FleTA, C.; CAMPABADAL, F.; LOZANO, M. Annealing studies of magnetic Czochralski silicon radiation detectors. Nucl Instrum Meth A., v.552, p.27-33, 2005.

[29] TAYLOR, G.N.; FARES, F.; BATES, S.J.; FURETTA, C.; GLASER, M.; LEIMEILLEUR, F.; LEON-FLORIAN, E.; GÖBLING, C.; KAISER, B.; ROLF, A.; WUNSTORF, R.; FEICK, H.; FRETWURST, E.; LINDSTRÖM, G.; MOLL, M.; CHILINGAROV, A. Radiation induced bulk damage in silicon detectors RD2 Collaboration. Nucl Instrum Meth A., v.383, p.144-154, 1996.

[30] LI, Z.; HARKONEN, J.; CHEN, W.; KIERSTEAD, J.; LUUKKA, P.; TUOMINEN, E.; TUOVINEN, E.; VERBITSKAYA, E.; EREMIN, V. Radiation Hardness of High Resistivity Magnetic Czochralski Silicon Detectors After Gamma, Neutron and Proton Radiations. IEEE T Nucl Sci., v.51, n.4, p.1901-1908, 2004.

[31] BRUZZI, M.; BUCCIOLINI, M.; NAVA, F.; PINI, S.; RUSSO, S. Advanced materials in radiation dosimetry. Nucl Instrum Meth A., v.485, p.172-177, 2002.

[32] ISO/ASTM 51707. Standard guide for estimating uncertainties in dosimetry for radiation processing., 2002. 